\title{
Human Factors Engineering Guidance for the Review of Advanced Alarm Systems
}

Manuscript Completed: August 1994

Date Published: September 1994

Prepared by

J. M. O’Hara, W. S. Brown, J. C. Higgins, W. F. Stubler

Brookhaven National Laboratory

Upton, NY 11973-5000

Prepared for

Division of Systems Research

Office of Nuclear Regulatory Research

U.S. Nuclear Regulatory Commission

Washington, DC 20555-0001

NRC FIN A3967 


\section{DISCLAIMER}

This report was prepared as an account of work sponsored by an agency of the United States Government. Neither the United States Government nor any agency thereof, nor any of their employees, make any warranty, express or implied, or assumes any legal liability or responsibility for the accuracy, completeness, or usefulness of any information, apparatus, product, or process disclosed, or represents that its use would not infringe privately owned rights. Reference herein to any specific commercial product, process, or service by trade name, trademark, manufacturer, or otherwise does not necessarily constitute or imply its endorsement, recommendation, or favoring by the United States Government or any agency thereof. The views and opinions of authors expressed herein do not necessarily state or reflect those of the United States Government or any agency thereof. 


\section{DISCLAIMER}

Portions of this document may be illegible in electronic image products. Images are produced from the best available original document. 


\begin{abstract}
This report provides guidance to support the review of the human factors aspects of advanced alarm system designs in nuclear power plants. The report is organized into three major sections. The first section describes the methodology and criteria that were used to develop the design review guidelines. Also included is a description of the scope, organization, and format of the guidelines. The second section provides a systematic review procedure in which important characteristics of the alarm system are identified, described, and evaluated. The third section provides the detailed review guidelines. The review guidelines are organized according to important characteristics of the alarm system including: alarm definition; alarm processing and reduction; alarm prioritization and availability; display; control; automated, dynamic, and modifiable characteristics; reliability, test, maintenance, and failure indication; alarm response procedures; and control-display integration and layout.
\end{abstract}





\section{CONTENTS}

$\underline{\text { Page }}$

ABSTRACT $\quad \ldots \ldots \ldots \ldots \ldots \ldots \ldots \ldots \ldots \ldots \ldots \ldots \ldots \ldots$ ii

LIST OF TABLES $\ldots \ldots \ldots \ldots \ldots \ldots \ldots \ldots \ldots \ldots \ldots \ldots \ldots \ldots \ldots$ viii

EXECUTIVE SUMMARY $\ldots \ldots \ldots \ldots \ldots \ldots \ldots \ldots \ldots \ldots \ldots$ ix

PREFACE $\quad \ldots \ldots \ldots \ldots \ldots \ldots \ldots \ldots \ldots \ldots \ldots \ldots \ldots \ldots \ldots \ldots \ldots \ldots \ldots \ldots$

ACRONYMS $\ldots \ldots \ldots \ldots \ldots \ldots \ldots \ldots \ldots \ldots \ldots \ldots \ldots \ldots \ldots \ldots \ldots$

GLOSSARY $\ldots \ldots \ldots \ldots \ldots \ldots \ldots \ldots \ldots \ldots \ldots \ldots \ldots \ldots \ldots \ldots \ldots \ldots$

1. INTRODUCTION $\ldots \ldots \ldots \ldots \ldots \ldots \ldots \ldots \ldots \ldots \ldots \ldots \ldots \ldots$

2. GUIDELINE DEVELOPMENT AND DESCRIPTION $\ldots \ldots \ldots \ldots$

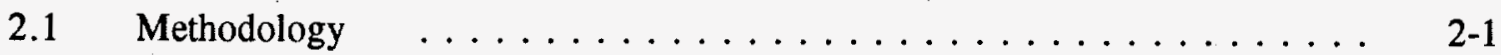

2.1.1 General Approach .................. 2-1

2.1 .2 Guideline Compilation $\ldots \ldots \ldots \ldots \ldots \ldots$

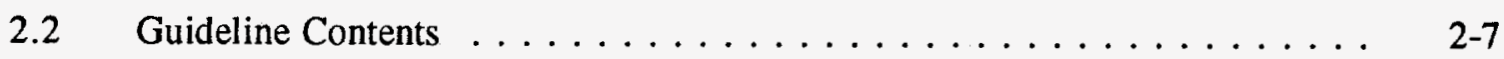

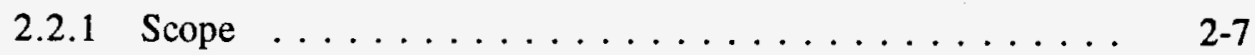

2.2.2 Description of Guideline Sections . . . . . . . . 2-7

2.2.3 Format of Individual Guidelines . . . . . . . . . 2-8

2.3 Intended Usage and Limitations $\ldots \ldots \ldots \ldots \ldots \ldots$

3. ALARM REVIEW PROCEDURE $\ldots \ldots \ldots \ldots \ldots \ldots \ldots \ldots \ldots \ldots \ldots$. . . . . . .

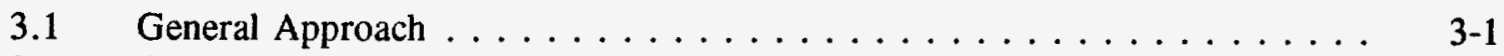

3.2 Characterizing the Alarm System $\ldots \ldots \ldots \ldots$ 3-1

3.2.1 General Alarm System Characteristics ............. 3- 3

3.2.2 Alarm Definition . . . . . . . . . . . . . . . . 3-2

3.2.3 Alarm Processing . . . . . . . . . . . . . . . . . 3-4

3.2.4 Alarm Condition Priority and Message Availability ......... 3 3-5

3.2.5 Alarm Display . . . . . . . . . . . . . . . . . . . 3-8

3.2.6 Alarm Controls . . . . . . . . . . . . . . . . . . . . 3-9

3.2.7 Automated, Dynamic, and Modifiable Characteristics . . . . . . . . 3-11

3.2.8 Reliability, Test, Maintenance, and Failure Indication . . . . . . . . . 3-12

3.2.9 Alarm Response Procedures (ARPs) . . . . . . . . . . . . . 3 3-13

3.2.10 Control-Display Integration and Layout $\ldots \ldots \ldots$ 3-13

3.3 Guideline Selection and Application . . . . . . . . . . . . $3-14$ 
CONTENTS (Cont'd.)

$\underline{\text { Page }}$

4. ALARM REVIEW GUIDELINES $\ldots \ldots \ldots \ldots \ldots \ldots \ldots \ldots$ 4-1

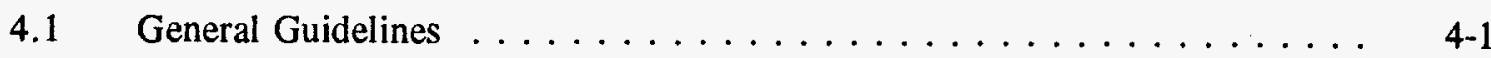

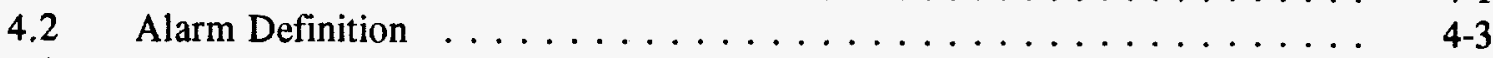

4.3 Alarm Processing and Reduction .................. 4 . 4

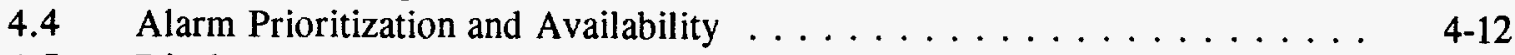

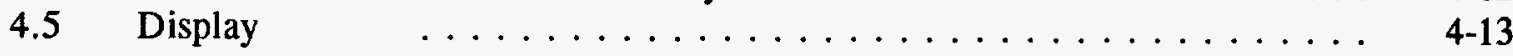

4.5.1 General Alarm Display Guidelines . . . . . . . . . . . . . . 4 4 . . . . . . .

4.5.2 Display of High-Priority Alarms . . . . . . . . . . . . . 4-16

4.5.3 Display of Alarm Status ................. 4-17

4.5.4 Display of Shared Alarms . . . . . . . . . . . . . . . 4-18

4.5 .5 Alarm Messages . . . . . . . . . . . . . . 4-20

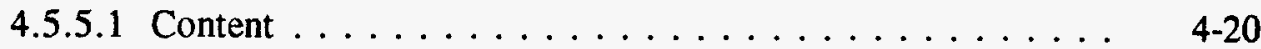

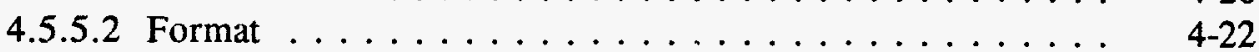

4.5 .6 Coding Methods . . . . . . . . . . . . . . . . . 4-23

4.5 .6 .1 General $\ldots \ldots \ldots \ldots \ldots \ldots \ldots \ldots \ldots \ldots \ldots \ldots \ldots$ 4-23

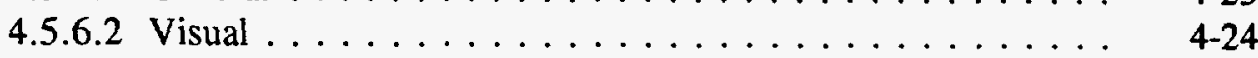

4.5.6.3 Audible Codes . . . . . . . . . . . . . 4 4-26

4.5.7 Organization of Alarms $\ldots \ldots \ldots \ldots \ldots \ldots \ldots \ldots \ldots \ldots$ 4-33

4.5.7.1 Spatially Dedicated, Continuously Visible Alarm Displays . 4-33

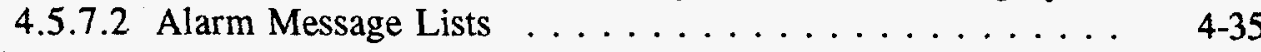

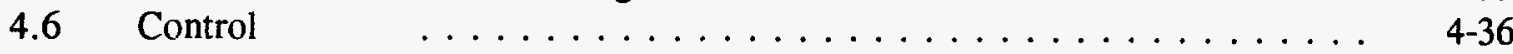

4.6.1 General Alarm Control Guidelines . . . . . . . . . . . . . . 4 4 46 . . . . . .

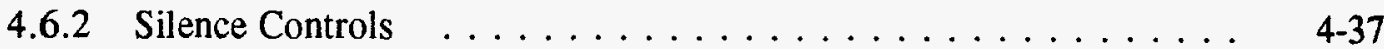

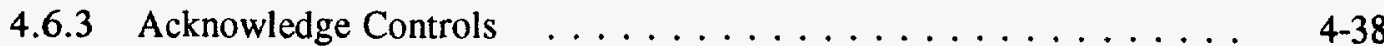

4.6.4 Reset Controls .................... 4-38

4.7 Automated, Dynamic, and Modifiable Characteristics . . . . . . . . . 4 4-39

4.8 Reliability, Test, Maintenance, and Failure Indication . . . . . . . . . . 4-42

4.8.1 Reliability . . . . . . . . . . . . . . . . . . 4 4-42

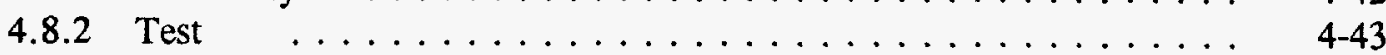

4.8 .3 Maintenance ....................... $4 . \ldots \ldots$

4.8 .4 Failure Indication $\ldots \ldots \ldots \ldots \ldots \ldots \ldots \ldots \ldots \ldots \ldots$ 
CONTENTS (Cont'd.)

$\underline{\text { Page }}$

$4.9 \quad$ Alarm Response Procedures (ARPs) $\ldots \ldots \ldots \ldots \ldots \ldots \ldots \ldots .4 .45$

4.10 Control-Display Integration and Layout $\ldots \ldots \ldots \ldots \ldots \ldots \ldots .4-47$

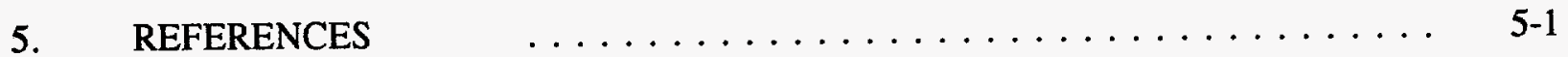

APPENDIX A: High-Level Design Review Principles $\ldots \ldots \ldots \ldots \ldots \ldots \ldots$ A-1

APPENDIX B: Alarm System Characterization Checklist $\ldots \ldots \ldots \ldots \ldots$ B-1

APPENDIX C: Index of Alarm System Design Review Guidelines $\ldots \ldots \ldots \ldots$ C-1 


\section{LIST OF TABLES}

No.

Page

$2.1 \quad$ High-level Design Review Principles $\ldots \ldots \ldots \ldots \ldots \ldots \ldots$

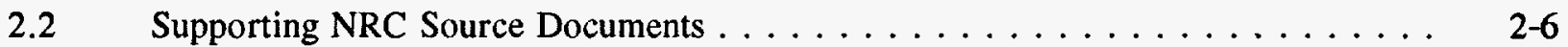

2.3 Supporting Non-NRC Nuclear Industry Guidance Documents $\ldots \ldots \ldots$. . . . . . .

3.1 Alarm Processing Approaches $\ldots \ldots \ldots \ldots \ldots \ldots \ldots$

4.5.4-1 Shared Alarm Considerations* .................... 4-19

* This table is contained in Guideline 4.5.4-1. 


\section{EXECUTIVE SUMMARY}

The human engineering deficiencies associated with conventional alarm systems in nuclear power plants (NPPs) are well documented (Malone et al., 1980; Banks and Boone, 1981; Rankin et al., 1983; Seminara et al., 1979; Pine et al., 1982; Fink, 1984; Kinkade and Anderson, 1984; MPR, 1985). The need to improve the human factors engineering (HFE) of alarm systems has led to the development of advanced alarm systems in which alarm data are processed beyond the one sensor - one alarm framework. The processing can be simple, such as the filtering nuisance alarm messages, or complex, such as dynamically prioritizing alarm messages based upon unfolding events. The defining feature of an advanced system is the capacity to assist the operator by processing alarm data prior to its presentation. This technology promises to provide a means of correcting many known alarm system deficiencies and may be used in new plants as well as in upgrades to existing plants.

In order to assure public health and safety, the U.S. Nuclear Regulatory Commission (NRC) reviews NPP human-system interfaces (HSIs) to ensure that they are designed to good human factors engineering principles and that operator performance and reliability are appropriately supported. The principal guidance available to the NRC, NUREG-0700 (NRC, 1981), however, was developed in 1981, well before these technological changes. Since there is general agreement in the literature that there is an "international lack of guidance and requirements for alarm systems" (Kennedy, 1989), guidance for the review of advanced alarm system designs is needed. The development of guidance to support the NRC staff review of advanced alarm systems was the main purpose of this project. The alarm review guidelines contained herein will eventually be integrated with the Human-System Interface Design Review Guideline presented in NUREG-0700, Revision 1.

The guideline development methodology reported in Volume 1 of NUREG/CR-5908 (O'Hara, 1994) served as the model for this effort. Guidance is based upon multiple sources of information including: NRC and other nuclear industry guidance documents, technical reports, journal articles, and similar documents. These included research reports of the Halden Reactor Project (HRP) and nuclear power plant (NPP) designers such as Atomic Energy of Canada Limited (AECL) and Mitsubishi. Non-nuclear guidelines documents and research reports were used as well.

Using the guideline development methodology, a draft set of alarm review guidelines was developed. The guidelines were developed into a standardized format including the specific acceptance criteria to be used by an NRC reviewer and the technical basis upon which the guidelines were formulated.

The guidelines are intended to apply to all types of alarm systems, i.e., conventional tile-type systems as well as more advanced computer-based systems, and are organized into the following sections:

General Guidelines - The guidelines in this section address the functional criteria for the alarm system and the general principles to which it should conform, such as consistency with the main control room HSI. Alarm system validation is also addressed.

Alarm Definition - This section provides guidance for the review of the selection of plant parameters for inclusion in the alarm system and specification of the setpoints for each alarm condition.

Alarm Processing and Reduction - This section provides guidance for the review of the processing techniques applied to alarm system input, from simple processing such as signal validation to more complex alarm reduction processing strategies. 
Alarm Prioritization and Availability - In this section, review guidance for alarm prioritization criteria and implementation is presented. In addition, review guidance is provided for alarm availability, i.e., the method by which the results of alarm display processing are made available to the operating crew through filtering, suppression, and coded prioritization.

Display - This section is broken into seven main subsections which address general alarm display guidelines, display of importance/urgency, display of alarm status, display of shared alarms, alarm message content and format, coding methods, and alarm organization. Several of these subsections are further subdivided.

Control - This section is broken into four main subsections which address general control guidelines and guidelines for alarm silence, acknowledge, and reset controls.

Automated, Dynamic, and Modifiable Characteristics - This section addresses the implementation of operator defined alarms and setpoints as well as other features of the alarm system that may be modified by the operating crew.

Reliability, Test, Maintenance, and Failure Indication - This section provides guidelines for the review of various aspects of alarm system reliability to assure that (a) the alarm system provides alarm information to the operators in a reliable manner, (b) the crew can periodically test alarm functions and components, (c) the alarm system can be maintained with minimum interference with the operators' ability to receive and understand alarm messages, and (d) the alarm system provides adequate indication of alarm system failures.

Alarm Response Procedures - This section includes guidelines on the scope, content, and format of alarm response procedures (ARPs). In addition, operator access to ARPs and their location is addressed.

Control-Display Integration and Layout - This section addresses the layout of alarm system control and display components, their physical relationship to associated controls and displays, and their integration in the control room.

In addition to the review guidelines presented in this document, general HFE guidelines for display, control, and user-interface design will be provided in NUREG-0700, Revision 1.

A procedure for the review of an alarm system is described. Since the alarm review guidelines will be used in conjunction with the guidelines in NUREG-0700, Revision 1, the review procedure developed for NUREG-0700, Revision 1 served as the basis. The steps for a full review are listed below:

1. Assemble NRC Review Team

2. Assemble Supporting Information

3. Identify Human Functions and Tasks

4. Sample Human Tasks to Guide the HFE Review

5. Characterize Tasks Used in the Evaluation

6. Characterize the HSI

7. Select the Guidelines to be Used in the Evaluation

8. Conduct Evaluation

9. Interpret the Findings. 
With the exception of step 6 , the details of these steps are not repeated in this report. Since the review of a NPP alarm system has special information requirements and consideration, Step 6 is described in more detail. 



\section{PREFACE}

This draft report has been prepared for the Human Factors Branch of the Nuclear Regulatory Commission's Office of Nuclear Regulatory Research. This document is submitted as part of the work performed for the "Annunciator" project (FIN A-3967). The U.S. Nuclear Regulatory Commission (NRC) Project Manager for this effort is Jerry Wachtel. The BNL Principal Investigator is John O'Hara. 



\section{ACRONYMS}

ACR

AECL

ALWR

ARP

CFR

CR

CRT

DPAS

EOP

EPRI

HALO

HFE

HRP

HSI

IEC

FSAR

NPP

NRC

P\&ID

SAR

SART

SDCV

URD

VDU
Advanced Control Room

Atomic Energy of Canada, Limited

Advanced Light Water Reactor

Alarm Response Procedures

Code of Federal Regulations (of the United States)

Control Room

Cathode Ray Tube

Dynamic Priorities Alarm System

Emergency Operating Procedure

Electric Power Research Institute

Handling Alarms with Logic

Human Factors Engineering

Halden Reactor Project

Human-System Interface

International Electrotechnical Commission

Final Safety Analysis Report

Nuclear Power Plant

U.S. Nuclear Regulatory Commission

Piping and Instrumentation Diagram

Safety Analysis Report

Silence, Acknowledge, Reset, and Test (controls)

Spatially-Dedicated, Continuously Visible Alarm Display

Utility Requirements Document

Video Display Unit 



\section{GLOSSARY}

Acknowledged alarm - An alarm is considered to be in the acknowledged state when the operator has provided some type of input to the alarm system (such as pressing a button) to indicate receipt of the alert or message provided by the alarm system. The act of acknowledging an alarm typically causes the attentiongetting characteristics of the alarm display to cease or decrease (e.g., the auditory tone stops and the flashing display changes to a steady illumination).

Activated alarm - The condition in which a monitored parameter exceeds a specified limit (setpoint), the deviation is evaluated by the processing portion of the alarm system, and a message is conveyed to the operator via the display portion of the alarm system (e.g., annunciators).

Advanced alarm system - A primarily digital alarm system employing alarm processing logic and advanced control (e.g., on-screen controls) and display (e.g., VDU) technology. (This is in contrast to conventional alarm systems, which are largely based on analog instrument and control technologies.)

Alarm - The term alarm is used in the broad sense, i.e., a plant parameter, component, system, or function that is in a state requiring the attention of plant personnel. The alarm may be the result of exceeding a setpoint or value or may result from the alarm processing system as in the case of alarm generation. As used here alarms contrast with annunciators in that they require operator attention. In a narrow sense, the term alarm is used to mean an attention eliciting message given to plant personnel regarding an unspecified or potentially adverse deviation of a plant parameter, component, system, or function from its expected value or performance.

Alarm availability - The display processing method by which the results of alarm processing are made available to the operating crew. This relates to which alarms are made available to the operator rather than how they are presented (which is referred to as alarm display). Three techniques are identified: filtering, suppression, prioritization.

Alarm display - The method(s) by which alarm coding and messages are presented to plant personnel.

Alarm generation processing - A class of alarm processing which includes techniques that analyze the existing alarms and, then based upon the evaluation, generate alarm messages which (1) give the operator higher level or combined information, (2) notify the operator when "unexpected" alarms occur, or (3) notify the operator when "expected" alarms do not occur.

Alarm message - Information presented to the operator by the auditory, visual, and other display devices of the alarm system in response to an alarm condition.

Alarm processing techniques - The rules or algorithms that are used to analyze plant sensor data to determine their importance, validity and relevance and determine whether an alarm message should be presented to the operator.

Alarm signal processing - The process by which signals from plant sensors are automatically evaluated. This process, which include signal validation and other techniques, determines whether an alarm condition exists. 
Alarm system - An automated system consisting of processing and display hardware and software, which processes or analyzes signals from plant sensors and alerts the operator via visual and/or auditory displays when monitored plant parameters deviate from specified limits (setpoints).

Annunciator - An indicator of the status of a plant parameter, component, system, or function that does not necessarily require the attention of plant personnel. When such attention is required, an alarm condition exists. In conventional plants, the term annunciator is used to refer to the spatially-dedicated display portion of an alarm system.

Blackboard (also called darkboard) - An alarm display approach in which the display medium is dark (not illuminated) if all monitored plant parameters are in the normal range. Thus, an illuminated alarm display device indicates a deviation from normal plant conditions. This is in contrast to many conventional alarm systems which employ display devices to indicate both normal and abnormal changes in plant condition.

Cleared alarm - An alarmed parameter that has returned from an alarmed state to its normal range. Some alarm systems generate alarm messages when the parameter enters the normal range. The operator may be required to acknowledge the alarm in order to "clear" it.

Component - An individual piece of equipment such as a pump, valve, or vessel; usually part of a plant system.

Conventional alarm system - A primarily analog-based alarm system employing little or no alarm display processing logic and using conventional control (e.g., pushbutton) and display (e.g., annunciator tiles) technology. (This is in contrast to advanced alarm systems).

Darkboard (also called blackboard) - An alarm display approach in which the display medium is dark (not illuminated) if all monitored plant parameters are in the normal range. Thus, an illuminated alarm display device indicates a deviation from normal plant conditions. This is in contrast to many conventional alarm systems which employ display devices to indicate both normal and abnormal changes in plant condition.

Decibel (dBA) - Sound level in decibels, measured using A-weighting. The use of A-weighting causes the frequency response of the sound level meter to mimic that of the human ear, i.e., response is maximum at about $2 \mathrm{kHz}$, less at very low or very high frequencies. A-weighted measurements correlate well with measures of speech interference and judgements of loudness (Beranek, 1988).

Existing alarm (also called steadied) - An acknowledged alarm which has not yet cleared.

Extinguished alarm (also called reset alarm) - An alarm that has returned to an inactive state (e.g., the plant parameter has returned to the normal range and all associated alarm messages have been acknowledged by the operator).

Filtering - An alarm display processing technique which may cause alarm messages that are irrelevant, less important, or otherwise unnecessary to be eliminated. These alarm messages are not available to the operators. (This is in contrast to suppressing which does not make the alarm messages immediately available but does allow the operator to retrieve them.)

First-out alarm - An alarm message which indicates the initial parameter change responsible for reactor and/or turbine trips. 
Frequency modulation - Sinusoidal variation of the frequency of a tone around a center frequency.

Grouping - Locating alarm messages that are related to a common function or system in one area of a display.

Legend - The textual content of a continuously present, spatially dedicated alarm display.

Message - Alarm information displayed in text.

New alarm - An unacknowledged (unsilenced) alarm.

Nuisance alarm processing - A class of alarm display processing which includes techniques that essentially eliminate alarm messages which have no operational significance to current plant conditions. For example, mode dependent processing eliminates alarms that are irrelevant to the current mode of the plant, e.g., a low temperature or pressure signal which is an alarm condition in normal operation mode but is expected and normal during startup or cold shutdown.

Parameter - A power conversion process variable or quantity that can assume any of a given set of physically feasible values. Plant parameters are typically measures of the performance of systems and processes of the plant, e.g., the parameter $T_{\text {hot }}$ is a measure of the temperature of reactor coolant that has passed through the reactor core.

Plant - The operating unit of a nuclear power station including the nuclear steam supply system, the turbine, electrical generator, and all associated systems and components. In the case of a multi-unit plant, the term plant refers to all systems and processes associated with the unit's ability to produce electrical power, even though some systems or portions of systems may be shared with the other units.

Prioritization - A class of alarm display processing that presents alarm messages to the operator according to an evaluation of importance, often using 2 to 4 categories of priority. The intent of this approach is to help the operators focus attention on the most important alarm conditions when multiple alarm conditions exist.

Redundant alarm processing - A class of alarm display processing which includes techniques that evaluate active alarm conditions to identify those that are true/valid but are redundant with other active alarm conditions. This processing filters, suppresses, or reduces the priority of alarm messages that have been determined to be of less importance because they provide information that is redundant with other existing alarm conditions and theoretically provide no new/unique information to the operator. For example, in causal relationship processing alarm messages associated with "causes" are displayed prominently, while alarm messages associated with "consequences" are eliminated or lowered in priority.

Reflash - An alarm presentation method that can be implemented any time an alarm condition is based on input from more than one plant parameter. Reflash causes an alarm display to re-enter the new alarm state when an associated plant parameter reaches its setpoint. The alarm display cannot return to normal until all related parameters return to their normal ranges.

Ringhack - An alarm display feature that provides a distinct cue such as a slow flash or audible tone to indicate that an alarm condition has cleared, i.e., the monitored parameter(s) has returned to its normal range. 
Safety function - A process or activity that must occur to achieve a safety goal such as preventing the release of radioactive material into the environment. Safety functions are often defined in terms of a boundary or entity that is important to plant safety, such as "reactivity control". The safety function is often described without reference to specific plant systems and components or the level of human and machine intervention that is required to carry out the function such as "provide core cooling".

Safety goal - A high-level objective such as, "Preventing the release of radioactive material to the environment" which designers strive to achieve through the design of the plant, and which plant operators strive to achieve through safe operation of the plant.

Safety related - A term applied to those NPP structures, systems, and components that prevent or mitigate the consequences of postulated accidents that could cause undue risk to the health and safety of the public (reference 10 CFR 50, Appendix B).

Setpoint - The value of a monitored parameter which defines the boundary between the parameter's normal range and an alarm condition. An alarm condition exists when the parameter exceeds the normal range that is defined by the upper and/or lower limit setpoints. Graded alarms may have multiple setpoints outside of the normal range that produce alarms that indicate increasing levels of severity of the abnormal condition such as Low Level, Low-Low Level, etc.

Shared alarm - An alarm condition that is defined by the activation of one or more of a set of different process deviation conditions. An example of a shared alarm is a "reactor coolant system trouble" message which may be displayed when any one of the reactor coolant pumps malfunctions. An individual alarm message associated with the particular malfunctioning reactor coolant pump may also be displayed in addition to the reactor coolant system trouble message.

Signal validation - A set of alarm processing techniques by which signals from redundant or functionally related sensors are compared and analyzed to determine whether a true alarm condition exists. The purpose of these techniques is to prevent the presentation of false alarms to the operator due to malfunctioning plant instrumentation such as a failed sensor.

Significance processing - A class of alarm display processing which includes techniques that evaluate active alarm conditions to identify those that are true/valid but are of less operational significance than other active alarm conditions. This processing filters, suppresses, or reduces the priority of alarm messages that have been determined to be of less importance. For example, in an anticipated transient without scram event, alarms associated with minor disturbances on the secondary side of the plant are eliminated or lowered in priority.

Spatially-dedicated, continuously visible (SDCV) alarm display - An alarm display which is in a spatially dedicated position and is always visible whether in an alarmed or cleared state. Conventional alarm tiles are an example of a SDCV alarm display.

Spatially focused, variable location, serial display - A display where alarms are presented in no fixed location and according to some logic such as time or priority. Usually the same display device can be used to present many different alarms (in contrast with SDCV display where a given location presents only one alarm. A scrolling message list is an example of this type of display.

Steadied - An alarm which has been acknowledged. 
Suppression - A class of alarm display processing by which alarms determined by processing techniques to be less important, irrelevant, or otherwise unnecessary are not presented to the operators, but can be accessed by operators upon request. The intent of this approach is to help the operators focus attention on the most important alarm conditions when multiple alarm conditions exist.

System - An integrated collection of plant components and control elements that operate together and possibly in conjunction with other systems to perform a function.

Task -A group of operator actions that have a common purpose, often occurring in temporal proximity, and which utilize the same displays and controls

Tile - A type of spatially dedicated, continuously visible alarm display consisting of an element of a conventional NPP alarm panel.

Transilluminated Display - A display having light passed through, rather than reflected off, an element to be viewed, e.g., illumination used on traditional annunciator tile panels or indicators utilizing edge or back lighting techniques on clear, translucent, fluorescent, or sandwich type plastic materials. (in contrast to video display units). 


\section{INTRODUCTION}

Advanced control room (ACR) concepts are being developed in the commercial nuclear industry as part of future reactor designs. The ACRs will use advanced human-system interface (HSI) technologies that may have significant implications for plant safety in that they will affect the operator's overall role (function) in the system, the method of information presentation, the ways in which the operator interacts with the system, and the requirements on the operator to understand and supervise an increasingly complex system. In order to assure public health and safety, the U.S. Nuclear Regulatory Commission (NRC) reviews nuclear power plant (NPP) human-system interfaces (HSIs) to ensure that they are designed to good human factors engineering principles and that operator performance and reliability are appropriately supported. The principal guidance available to the NRC, NUREG-0700 (NRC, 1981), however, was developed in 1981, well before these technological changes. Accordingly, the human factors guidance needs to be updated to serve as the basis for NRC review of these advanced designs. This effort resulted in the development of NUREG/CR-5908 (O'Hara et al., 1994). As part of the guidance development effort, topics in need of further research were identified. Advanced alarm systems was identified as one of these topics.

The advanced HSI guidance provided in NUREG/CR-5908 will be integrated with those for conventional HSI design in NUREG-0700 to produce NUREG-0700, Revision 1. The research reported in this document is intended to provide guidelines for the review of advanced alarm systems and will be integrated with the guidelines in NUREG-0700, Revision 1.

The human engineering deficiencies associated with conventional alarm systems in NPPs are well documented (Malone et al., 1980; Banks and Boone, 1981; Rankin et al., 1983; Seminara et al., 1979; Pine et al., 1982; Fink, 1984; Kinkade and Anderson, 1984; MPR, 1985), and recommendations for improvements have been offered (Crouch et al; 1989; Fink, 1984; Kinkade and Anderson, 1984; MPR, 1985; Pine, 1982; U.S. NRC, 1981). However, the presentation of alarm information to operators continues to present problems for operators (Seminara, 1988). One reason appears to be that not all of the human factors issues (for example, the large number of alarms during major plant disturbances) can be effectively resolved through upgrades to conventional systems (Woods et al., 1987; Beltracchi, 1988).

The need to improve the human factors engineering (HFE) of alarm systems has led to the development of advanced systems in which alarm data are processed beyond the one sensor - one alarm framework to provide information about plant upsets in a more integrated form rather than as a series of apparently unrelated individual deviations from normal conditions. In addition to generating more integrated alarm messages, advanced alarm systems also perform additional processing of alarm information so that the most important information is made the most apparent and accessible to the operators. This alarm display processing can be simple, such as the filtering of plant mode-dependent alarms, or complex, such as dynamically prioritizing alarms based upon unfolding events. The defining feature of an advanced system is the capacity to assist the operator by processing alarm data prior to its presentation. This technology promises to provide a means of correcting many known alarm system deficiencies and may be used in new plants as well as in upgrades to existing plants. Therefore, guidance for the review of advanced alarm system design is needed and there is general agreement in the literature that there is an "international lack of guidance and requirements for alarm systems" (Kennedy, 1989). 
In support of alarm guidance development, a review of the literature on alarm system design features and their effects on operator performance was conducted (O'Hara and Brown'). The results indicated that there are many HFE issues associated with advanced alarm systems. Once the issues were identified, the availability of HFE design review guidance for addressing the issues was assessed. The available guidance was then evaluated for technical basis, internal consistency, and comprehensiveness (O'Hara and Brown, 1991). It was found that while guidance on several aspects of alarm system design is available, the guidance did not adequately address all the issues identified in the human performance literature. Thus, the development of more comprehensive guidance based upon additional sources of information was undertaken and resulted in this report.

The guidance development methodology and a description of the guidelines is presented in Section 2 of this document. Section 3 provides the procedures for use of the guidelines. The alarm system review guidelines are presented in Section 4.

"BNL Technical Report entitled "Advanced Alarm Systems in Nuclear Power Plants" still in preparation currently; not publicly available. 


\subsection{Methodology}

\subsubsection{General Approach}

The methodology developed in NUREG/CR-5908 (O'Hara, 1994), specifically the methodology for new guidance development, served as the model for guideline development. The basic methodology is illustrated in Figure 2.1.

In the selection of primary source documents to serve as the technical basis for NUREG/CR-5908, a high priority was given to assuring the validity of the guidelines, i.e., assuring that they were based upon empirical research and/or accepted human engineering practice. Validity was defined in terms of two aspects of document development. "Internal" validity was evaluated by the degree to which the individual guidelines within a document were based upon empirical research and an audit trail to the research maintained. "External" validity was evaluated as a function of the degree to which the guidelines were subjected to independent peer review. The peer review process was considered a good method of screening guidelines for conformance to accepted human engineering practices. In general, documents which had strong validity were considered primary source documents to serve as a basis for NUREG/CR5908. However, while a similar approach should be followed for the development of additional guidance, the process is more complicated since there is little "primary" material (see Figure 2.1) on which to rely. Thus, while the definitions of validity are the same, they are applied in a slightly different manner since the internal validity and external validity must be established as part of the guidance development effort and not "inherited" as when the principal sources are primary guideline documents.

Guidance development proceeded as shown in the flow chart. Primary source documents are existing guidance documents with internal and external validity. Secondary source documents are existing guidelines documents which possess either internal or external validity. Tertiary documents are typical HFE handbooks and texts, rather than guideline documents, and do not possess internal or external validity. Handbooks and texts, however, represent human factors knowledge for specific topics. Guidelines can be derived from these tertiary documents with relatively little effort in comparison to the final three sources shown in Figure 2.1 (basic literature, industry experience, and original research).

Basic literature and industry experience were used where guidelines could not be obtained from primary, secondary, and tertiary sources. Results were evaluated from basic literature including articles from refereed technical journals, reports from research organizations, and papers from technical conferences. Industry experience information was obtained from published surveys/interviews. It is a valuable source for identifying human performance issues and tested design solutions that are of particular interest to a specific domain (e.g., nuclear power plant operation). Although information from industry experience may lack a rigorous experimental basis it does have the benefits of high relevance to the practical application of alarm systems.

In addition to alarm literature, guidance was also developed based upon the application of the high-level design review principles (O'Hara, 1994) to alarm system characteristics. These principles were developed based upon an assessment of the human-performance issues associated with advanced technology systems and on HSI design guidance and evaluation literature. Human performance is enhanced and the potential for human error minimized if the HSI is designed to support the operators' primary task of monitoring and controlling the process, without imposing an excessive secondary 


\section{Completed}

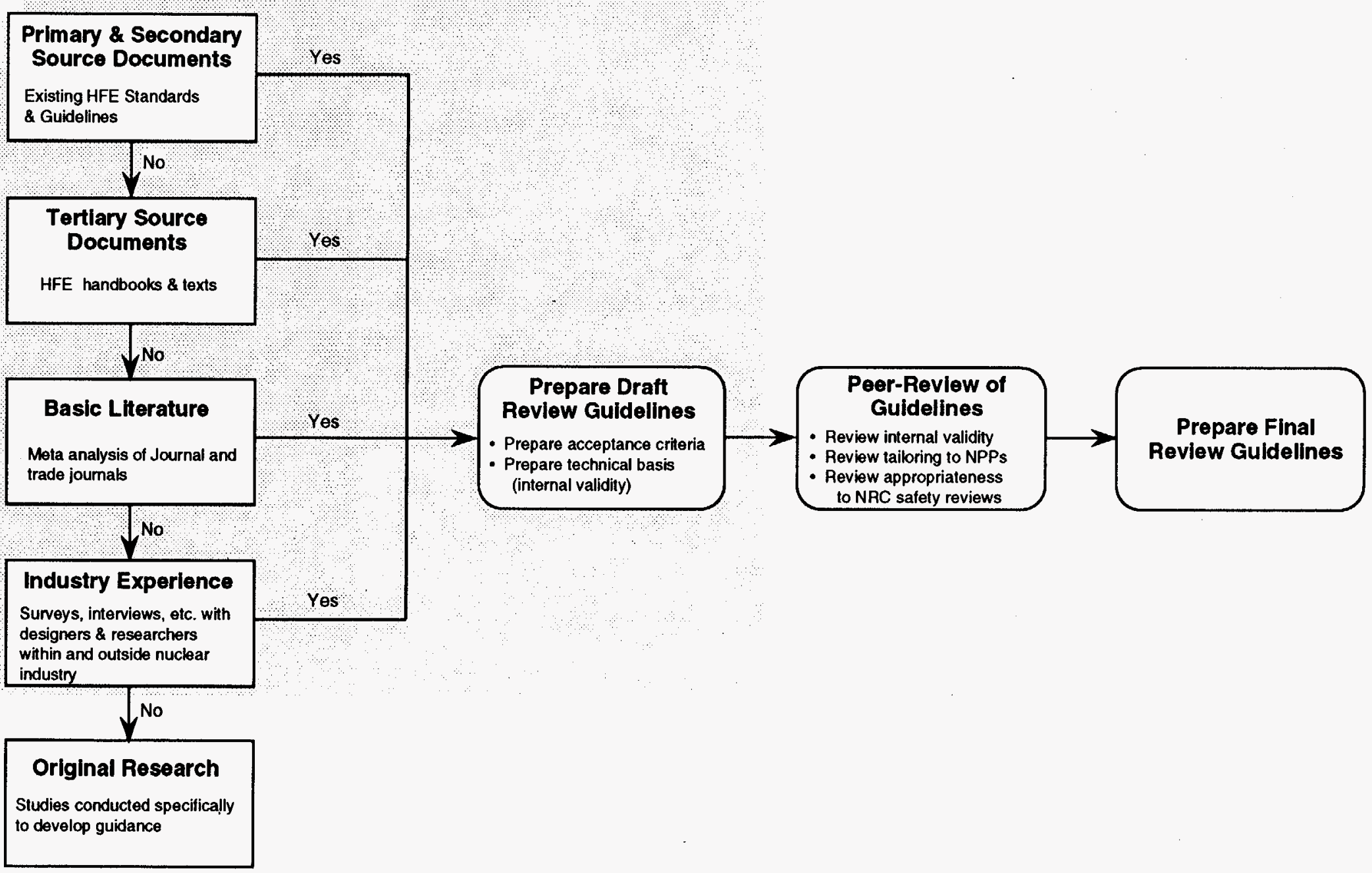

Figure 2.1. Alarm system guidelines development methodology

(The shaded area represents completed work covered in this report) 
workload for interfacing with the HSI (window manipulation, display selection, and navigation, for example). The HSI also should support recognition, tolerance, and recovery from human errors when they occur. As an intermediary step between research on human performance issues and detailed design review guidelines, a set of "high-level" design-review principles was developed. The principles are intended to be used to support (1) the identification of significant HSI issues, (2) the interpretation of the significance of individual discrepancies in the guidelines, and (3) the development of more detailed guidance for specific review applications. It is principally the latter application that is applicable to this report.

The principles are divided into four categories (see Table 2.1):

- General Principles - These principles ensure the HSI is generally safe and compatible with general cognitive and physiological capabilities.

- $\quad$ Primary Task Design - These principles support the operator's primary task of process monitoring, decision-making, and control.

- Secondary Task Control - These principles minimize secondary tasks, i.e., tasks the operator must perform when interfacing with the system but that are not directed to the primary task. Examples include efforts the crew must expend managing the interface, such as navigation through displays, managing windows, and accessing data. Although necessary, performance of secondary tasks detracts from the crew's performance of primary tasks, so their effects must be controlled.

- $\quad$ Task Support - These principles support the operator's use of the HSI, such as providing (1) HSI flexibility so tasks can be accomplished in more than one way, (2) user guidance, and (3) error mitigation.

The individual principles within each category are presented in Appendix A.

Since the principles are stated in general terms, they must be made more application-specific through detailed design-review guidance. That is, the general principles must be translated into terms that can be applied to specific reviews of HSI technology, e.g., graphic displays, touch screens, expert systems, or alarm systems. Some of the guidelines presented in Section 4 were derived from the tailoring of these high-level principles to alarm system characteristics. Two examples of this approach follow.

First, the human performance literature has demonstrated that the configurable aspects of the computerbased systems can give rise to operator error due to confusion over changing modes of operation. A common human error in such a system is called "mode error" which is the failure to recognize the current operating mode of the system. This leads to errors resulting from the improper interpretation and use of system information (e.g., Cook, Woods, and Howie, 1990; Sarter and Woods, 1992). This type of research gave rise to general principle related to design considerations of Situation Awareness (i.e., ....the information presented to the users by the HSI should be correct, rapidly recognized, and easily understood and support higher-level goals of user awareness of the status of the system) and Feedback (i.e., ...the system should provide information on system status). These general principles led to the development of the following alarm system review guideline: 


\section{7-1 Automated Alarm System Configuration}

If the alarm system automatically changes operational configurations under some alarm situations, then these configuration changes should be coupled with an alert to the operator and an indication that the configuration has changed.

Second, research literature has demonstrated the difficulties operators have with complex software design when they are required to monitor, supervise, and use the information it provides. For example, the use of information from an expert system is greatly enhanced when the user understands the processing strategies used by the system (e.g., Madni, 1988; Maylin et al, 1991). This type of research led to the high-level design review principles of User Model Compatibility [i.e., .... all aspects of the system should be consistent with the users' mental models (understanding and expectations about how the system behaves developed through training, use of procedures, and experience)]; Logical/Explicit Structure (i.e., ....all aspects of the system should reflect an obvious logic and the way the system works. Its structure should be clear to the user); and Simplicity of Design (i.e., the HSI should represent the simplest design consistent with functional and task requirements). These general principles led to the development of the following alarm system review guideline:

\section{3-12 Processing Complexity}

Processing methods should not be so complex that operators have difficulty evaluating the meaning or validity of the resulting alarm messages.

Table 2.1. High-level Design Review Principles

\begin{tabular}{|l|l|}
\hline \multicolumn{1}{|c|}{ CATEGORY } & \multicolumn{1}{c|}{ PRINCIPLE } \\
\hline General & $\begin{array}{l}\text { Personnel Safety } \\
\text { Cognitive Compatibility } \\
\text { Physiological Compatibility } \\
\text { Simplicity of Design } \\
\text { Consistency }\end{array}$ \\
\hline Primary Task Design & Situation Awareness \\
& Task Compatibility \\
& User Model Compatibility \\
& Organization of HSI Elements \\
& Logical/Explicit Structure \\
& Timeliness \\
& Controls/Displays Compatibility \\
& Feedback \\
\hline Secondary Task Control & Cognitive Workload \\
& Response Workload \\
\hline Task Support & Flexibility \\
& User Guidance and Support \\
& Error Tolerance and Control \\
\hline
\end{tabular}


In sum, the guidance developed was based upon:

- the compilation of available primary and secondary guideline documents,

- the analysis and integration of engineering and research literature from tertiary and basic literature sources,

- review of survey and other information from industrial experience sources, and

- $\quad$ application of high-level design review principles to alarm systems.

Original research is appropriate when sufficient guidance or technical bases do not exist in the available literature or practice, or when additional experimentation is needed to provide supporting evidence. Original research has the advantage of being focused on specific issues of interest. In addition, interpretation of results for a NPP context is more straightforward than it is for more general research. Independent research, therefore, has both high relevance and an experimental basis. The complexity of alarm system issues will require research in the areas of alarm processing and display. A research program in these areas is under development, and the current guidance will be expanded when this information is available.

Once the source methodology was executed, the draft set of guidelines was developed. The guidelines contain the specific acceptance criteria to be used by the NRC reviewer and indicates the information source(s) upon which the technical basis of the guidelines were established. The latter provides a basis for evaluating the internal validity of the guidelines that were developed. It should be noted that the technical bases vary for each guideline. Some guidelines are based on technical conclusions from a preponderance of empirical evidence, while others are based upon a consensus of existing standards. Some guidelines are based on the judgement of the indicated information sources that the guideline represents good practices. An independent evaluation should be conducted by reviewers who evaluate: (1) the internal validity of the guidance, (2) the tailoring of the guideline to NPPs, and (3) the appropriateness of the guideline for NRC safety reviews. Independent review constitutes the external validation of the guidelines.

\subsubsection{Guideline Compilation}

The identification of potential sources of advanced alarm system guidelines included review of human factors guidance from both within and outside the nuclear industry. However, in the compilation effort, primary consideration was given to only those documents representing nuclear applications because of the unique issues associated with NPP alarms and because alarm system guidance for the nuclear industry has been subject to more research and investigation than in the other sources considered.

Advanced alarm systems are likely to use a variety of display and control technologies, e.g., information presented on alarm tiles and/or video display units (VDU). In addition to using advanced display technologies, advanced alarm systems may retain many features of conventional annunciator warning systems such as first out and alarm combination logic. To the extent that this is the case, some of the guidance available on the design of conventional alarm systems (such as NUREG-0700 and EPRI NP3448 ) is relevant to advanced alarm systems and was, therefore, included in the compilation.

Table 2.2 identifies the NRC documents which were used as part of the guidance development process (full references are provided in Section 5). Several non-NRC nuclear industry HFE guideline documents also contributed significantly to the guidelines and are identified in Table 2.3. 
Table 2.2. Supporting NRC Source Documents

\begin{tabular}{|l|l|l|}
\hline \multicolumn{1}{|c|}{ SOURCE } & \multicolumn{1}{|c|}{ DOC. NO. } & \multicolumn{1}{c|}{ TITLE } \\
\hline USNRC (USNRC, 1981) & NUREG-0700 & Guidelines for Control Room Design Reviews \\
\hline USNRC (Rankin, 1983) & NUREG/CR-3217 & $\begin{array}{l}\text { Near-Term Improvements for NPP CR Annun- } \\
\text { ciator Systems }\end{array}$ \\
\hline USNRC (Rankin, 1985) & NUREG/CR-3987 & Computerized Annunciator Systems \\
\hline USNRC (Kennedy, 1989) & NUREG-1361 & $\begin{array}{l}\text { Lessons learned in process control from the } \\
\text { Halden Reactor Project }\end{array}$ \\
\hline USNRC (USNRC, 1993) & $\begin{array}{l}\text { Info. Notice 93- } \\
47\end{array}$ & Unrecognized loss of control room annunciators \\
\hline USNRC (USNRC, 1978) & Reg. Guide 1.33 & $\begin{array}{l}\text { Quality assurance program requirements - Opera- } \\
\text { tion (Rev. 2) }\end{array}$ \\
\hline USNRC (USNRC, 1989) & Reg. Guide 1.114 & $\begin{array}{l}\text { Guidance on being operator at the controls of a } \\
\text { NPP (Rev. 2) }\end{array}$ \\
\hline USNRC (USNRC, 1983) & Reg. Guide 1.97 & $\begin{array}{l}\text { Instrumentation for light-water-cooled NPPs to } \\
\text { assess plant and environmental conditions during } \\
\text { and following an accident }\end{array}$ \\
\hline
\end{tabular}

Table 2.3. Supporting Non-NRC Nuclear Industry Guideline Documents

\begin{tabular}{|l|l|l|}
\hline \multicolumn{1}{|c|}{ SOURCE } & \multicolumn{1}{c|}{ DOC. NO. } & \multicolumn{1}{c|}{ TITLE } \\
\hline IEC (IEC, 1989) & IEC 964 & $\begin{array}{l}\text { Design for Control Rooms of Nuclear Power } \\
\text { Plants }\end{array}$ \\
\hline EPRI (EPRI, 1992) & ALWR/URD & $\begin{array}{l}\text { Advanced Light Water Reactor Utility Require- } \\
\text { ments Document }\end{array}$ \\
\hline EPRI (Fink, 1984) & EPRI NP-3448 & $\begin{array}{l}\text { A Procedure for Improving Power Plant Alarm } \\
\text { Systems }\end{array}$ \\
\hline EPRI (Kinkade, 1984) & EPRI NP-3659 & Human Factors Guide for NPP CR Development \\
\hline EPRI (Pine, 1982) & EPRI NP-2411 & $\begin{array}{l}\text { Human engineering guide for enhancing nuclear } \\
\text { control rooms }\end{array}$ \\
\hline
\end{tabular}

In addition, documents providing guidelines, a large number of technical reports, journal articles, and similar documents were used to support alarm review guidance development. These included research reports of the Halden reactor project and NPP designers such as Atomic Energy of Canada Limited (AECL) and Mitsubishi. Non-nuclear guidelines documents and research reports were used as well. These sources are cited and discussed within the context of the individual guidelines, and are fully referenced in Section 5. 
The documents identified above were assessed for (1) actual design and review guidelines, (2) recommendations, and (3) definitive statements about the characteristics which alarm systems should possess. There was considerable overlap in guideline content across the source documents. Thus, the guidelines were edited to combine similar guidelines into a single guideline. Information as to the primary source document from which each guideline was derived was recorded to maintain an audit trail.

\subsection{Guideline Contents}

\subsubsection{Scope}

The scope of the guidelines presented in Section 4 includes alarm system functional characteristics, processing, display, control, test, maintenance, alarm response procedures, and integration of the alarm system into the control room. The technical scope is briefly described in the description of the guideline sections contained in Section 2.2.2 below.

It is intended that the guidelines apply to all types of alarm systems, i.e., conventional tile-type systems as well as more advanced computer-based systems. It should be noted, however, that the guidance is necessarily general (i.e., does not apply solely to any one alarm system). Therefore, some tailoring of individual guidelines to the review of individual alarm systems will be necessary.

The scope of the guidelines presented in this report is limited to those aspects of the HSI that are unique to alarm systems. Many alarm systems, especially advanced systems, will have alarm system features that are not unique to alarms, e.g., the use of symbols and icons or the use of keyboards and touch screens. The HFE review guidance that applies to these general HSI features is not contained in this document. NUREG-CR 5908 contains guidance for the review of these general HSI features. Since the guidelines provided here will be incorporated into that document, those general guidelines were not duplicated here unless alarm system considerations necessitated a modification to the more general guidance.

\subsubsection{Description of Guideline Sections}

Section 4.1, General Guidelines - The guidelines in this section address the functional criteria for the alarm system and the general principles to which it should conform, such as consistency with the main control room HSI. Alarm system validation is also addressed.

Section 4.2, Alarm Definition - This section provides guidance for the review of the selection of plant parameters for inclusion in the alarm system and specification of the setpoints for each alarm.

Section 4.3, Alarm Processing and Reduction - This section provides guidance for the review of the processing of alarm data, from simple processes such as signal validation to more complex alarm reduction processing strategies.

Section 4.4, Alarm Prioritization and Availability - In this section, review guidance for alarm prioritization criteria and implementation is presented. In addition, review guidance is provided for alarm availability, i.e., the method by which the results of alarm processing are made available to the operating crew through filtering, suppression, and/or coded prioritization. 
Section 4.5, Display - This section is broken into seven main subsections which address general alarm display guidelines, display of importance/urgency, display of alarm status, display of shared alarms, alarm message content and format, coding methods, and alarm organization. Several of these subsections are further subdivided.

Section 4.6, Control - This section is broken into four main subsections which address general control guidelines, silence controls, acknowledge controls, and reset controls.

Section 4.7, Automated, Dynamic, and Modifiable Characteristics - This section addresses the implementation of operator defined alarms and setpoints as well as other features of the alarm system that may be modified by the operating crew.

Section 4.8, Reliability, Test, Maintenance, and Failure Indication - This section provides guidelines for the review of various aspects of alarm system reliability to assure that (a) the alarm system provides alarm information to the operators in a reliable manner, (b) the crew can periodically test alarm functions and components, (c) the alarm system can be maintained with minimum interference to the operators' ability to receive and understand alarm messages, and (d) the alarm system provides adequate indication of alarm system failures.

Section 4.9, Alarm Response Procedures - This section includes guidelines on the scope, content, and format of alarm response procedures (ARPs). In addition, operator access to ARPs is addressed.

Section 4.10, Control-Display Integration and Layout - This section addresses the layout of alarm system control and display components, their relationship to related controls and displays, and their integration in the control room.

\subsubsection{Format of Individual Guidelines}

The guidelines were developed into the standardized format shown below.

\section{3-9 Logical Consequences Processing}

If a single event systematically leads to subsequent faults that are the direct consequence of this event, only the alarm message associated with the main event should be presented and the other alarm messages suppressed, so long as this does not interfere with the operators' use of alarm information.

ADDITIONAL INFORMATION: For example, the logical sequences processing may be used to suppress alarms that follow as a logical consequence of trip or isolation conditions. When implementing logical sequences processing the designer should ensure that messages associated with the "consequence" alarm conditions are not needed by the operators for other operational tasks and that operators are aware that the associated "consequence" alarm conditions were generated but not presented. This guideline only suggests suppression of these alarms not their complete elimination (i.e., filtering).

Discussion: The suppression of alarms, such as the typical alarms associated with reactor and turbine trip, has been shown to reduce the number of "maverick" alarms (those not typically occurring during a plant trip) missed by the operators by 50 percent (Fink et al., 1992). However, it should be noted that some operators may object to such suppression since the timing of some of the normal trip-related alarms facilitates the crew's understanding of transients.

SOURCE: IEC 964, NUREG/CR-3987, Authors. 
The components of the standard guideline format are as follows:

- $\quad$ Guideline Number - Within sections/subsections individual guidelines are numbered consecutively beginning with 1 . Each guideline has a unique number which reflects its section/subsection location followed by a dash and then its unique number.

- $\quad$ Guideline Title - Each guideline has a brief unique title.

- $\quad$ Guideline Statement - Each guideline has a statement of the aspect of the HSI to review and the criteria/characteristic the HSI should embody. An effort was made to keep guideline statements succinct. Supplemental information was located in the "additional information" section of the guideline described below.

- $\quad$ Additional Information - For many guidelines additional information is provided which may address clarifications, examples, technical basis, etc. This information is intended to support the reviewer's interpretation or application of the guideline. The additional information field may also contain a "discussion" regarding the technical basis and/or relevant research contributing to the guideline development. In such cases specific studies are cited that provide the supporting research. The discussion is presented in smaller font size than the rest of the material and is preceded by the heading "Discussion:" (see the example above). It is intended that the discussion will be removed from the additional information field when the alarm guidelines are incorporated into NUREG0700 , Revision 1.

- $\quad$ Source - This designates the primary materials from which the guideline was developed. For some guidelines, "Authors" is listed as one of the sources. Such an indication means that (1) the authors developed the new guideline by modifying an existing guideline from a source document, or (2) the guideline is based significantly on research discussed in the technical basis discussion included in the Additional Information field (rather than a guidance document such as those listed in Tables 2.1 and 2.2) At present, the Source field does not list the specific individual studies indicated in the technical basis discussion. It is intended that when the alarm guidelines are integrated with the guidelines in NUREG-0700, Rev. 1, the citation "Authors" will be replaced by a reference to this document ("NUREG/CR-6105").

\subsection{Intended Usage and Limitations}

As indicated above, the purpose of the guidelines presented in this document is to support the performance of HFE reviews to assure that the alarm system is appropriate to the crew tasks and designed according to accepted HFE guidelines, standards, and principles. In addition to the review of an actual alarm system implementation, the guidance can support the review of a designer's design-specific alarm system guidelines and specifications.

There are many important reasons for conducting reviews using HFE guidelines as presented here:

1. HFE guidelines help assure that the design accommodates general human physiological and cognitive capabilities. 
2. HFE guidelines generally represent the collective inheritance of knowledge from a vast array of systems developed over many years. HFE guidelines capture years of lessons learned from system design and research in terms of HSI characteristics that support operating and maintenance crew tasks.

3. Guidelines help ensure standardization and consistency in the application of human factors principles throughout the design.

4. HFE guidelines highlight design characteristics that can detract from human performance.

5. HFE guideline reviews provide an evaluation which is generalizable to all uses of an HSI.

While HFE guideline reviews provide valuable data to support safety determinations, this type of evaluation has its limitations as well. It is essential that the reviewer recognize both the strengths and weaknesses of HFE guideline reviews. Some of these limitations are discussed below:

1. An HFE guideline review is a necessary, but not fully sufficient basis to determine if the operating crew can monitor and operate the HSI to adequately control system functions.

2. HFE guidelines are not sensitive to time dependency of task performance requirements.

3. Since the establishment of a validated set of guidelines requires professional consensus from research and industry experience, HFE guidelines will always be somewhat incomplete in scope and coverage of advanced technology (where research and lessons learned from practical applications are too limited to fully address all technology applications).

4. HFE guidelines are generally insensitive to interactive effects between multiple guidelines or their tradeoffs, e.g., between requirements for consistency and flexibility.

As a result of these limitations it is important to recognize two issues when conducting HFE guideline evaluations. First, design-specific discrepancies from generic review guidelines are not necessarily problematic. The importance of discrepancies from individual guidelines has to be considered within the context of the individual review. Second, other methods of evaluation (such as dynamic performance evaluation) should be considered in conjunction with guideline reviews to provide a robust foundation upon which to base safety evaluations. While this is generally true, it is especially applicable to alarm system evaluation for several reasons. First, alarm systems have historically been problematic and alarm system problems, such as operator information overload, are not yet so well understood that they are completely addressed by guidelines. Second, alarm systems are still the subject of considerable research in the nuclear power industry because many issues have not been fully resolved. Therefore, the technical basis for guidance development is weak in many important areas, such as alarm processing. Third, advanced alarm systems may use new technology for which operational experience is limited. In recognition of these factors, the need to perform operational tests of alarm system performance has been included as a general alarm system guideline (see Guideline 4.1-5, Alarm System Validation). 


\section{ALARM REVIEW PROCEDURE}

\subsection{General Approach}

The objective of the alarm system review is to assure that the alarm system functionality and its associated controls, displays, and data processing support are appropriate to the crew tasks and designed according to accepted HFE guidelines, standards, and principles.

The alarm system review guidance contained in this document should be used in conjunction with the guidelines and procedures described in NUREG-0700, Revision 1. Briefly, the conduct of an HFE guideline review is a multi-step process. The activities performed at each step may differ depending on the unique requirements of each individual review (e.g., availability of supporting documentation). The steps for a full review are listed below:

1. Assemble NRC Review Team,

2. Assemble Supporting Information,

3. Identify Human Functions and Tasks,

4. Sample Human Tasks to Guide the HFE Review,

5. Characterize Tasks Used in the Evaluation,

6. Characterize the HSI,

7. Select the Guidelines to be Used in the Evaluation,

8. Conduct Evaluation, and

9. Interpret the findings.

With the exception of step 6, the details of these steps are not repeated here but may be found in the discussion of HFE Design Verification process in NUREG-0700, Revision 1. Since the review of a NPP alarm system has special information requirements and considerations, Step 6 is described in more detail in Section 3.2 below. Section 3.2 provides an outline as to how these special considerations are addressed in the alarm review guidelines in Section 4.

The alarm review guidelines in Section 4 provide guidance for design characteristics that are largely unique to alarm systems. More generic characteristics such as coded symbols are addressed by the general guidance provided by NUREG-0700, Revision 1. Thus, in addition to conforming to the review guidelines of Section 4, the alarm system should conform to general HFE guidelines for display, control, and user-interface design, which are provided in NUREG-0700, Revision 1. This requirement is identified as a general guideline in the alarm system review guidance in the next section (see Guideline 4.1-4, Conformance to HSI Design Review Guidelines).

\subsection{Characterizing the Alarm System}

Step 6 above involves describing the characteristics of the HSI, using information provided by the designer/applicant and/or onsite observations. For an alarm system review, this can be done using the structure provided in this section. For each sub-section below, three types of information are provided: an introduction to the information topic, an identification of the information that should be compiled about the alarm system, and a reference to the appropriate section in Section 4 which contains the guidelines for the review of the topic. A summary listing of the alarm system review information requirements discussed below is contained in Appendix B. 
An overview of the major components of an alarm system, as reflected in the guidelines in this report, is presented in Figure 3.1. A discussion of important characteristics and concerns associated with the major components is provided below. Not depicted are considerations of system reliability, test, maintenance, failure indication (described in Section 3.2.8) and, control-display integration and layout (described in Section 3.2.10).

\subsubsection{General Alarm System Characteristics}

General characteristics include the basic functions associated with alarm systems (e.g., to alert the operator, to guide operator actions, to assist monitoring of plant events, and to facilitate the operator's interaction with the plant) and the relationship between the alarm system and the rest of the HSI. Therefore, the reviewer should obtain information on the following general alarm system characteristics:

- Functional characteristics (e.g., alert, inform, guide, feedback) of the alarm system.

- The methods by which consistency was established between the alarm system and (1) non-alarm HSI standards and conventions, and (2) general HFE principles, standards, and guidelines. A design guideline or system specification may be available from the designer/utility to support this information requirement.

- Development tests, evaluations, and validation tests performed on the system.

Guidelines for the review of general alarm system characteristics are provided in Section 4.1. In addition, the need for general validation of the alarm system is identified.

\subsubsection{Alarm Definition}

Alarm definition is the specification of the types of process parameters selected to be monitored and displayed by the alarm system and the setpoints to be used to represent those parameters. The reviewer should obtain information on the following:

- $\quad$ Alarm categories (the events, states, etc. from which alarms are selected)

- The criteria used to select alarm parameters to represent the categories

- The criteria for determination of setpoints

- The verification process (for task appropriateness)

- $\quad$ process by which alarm inclusion was checked

- $\quad$ process for assuring that non-alarms are not presented in the alarm system

- Alarm states (new, acknowledged, cleared, and reset)

The basis for the alarm definition specification should be reviewed to ensure that it is appropriate from a safety standpoint. The alarm system should assist the operators in maintaining the plant within the safety envelope as defined by the Safety Analysis Report (SAR) and technical specifications.

The complete inventory of alarms should be subject to a verification to confirm that all parameters that are defined as alarms are monitored by the alarm system. The inventory should also be checked to ensure that the alarm system is not monitoring and displaying parameters that do not meet the alarm selection criteria (unless sufficient justification is provided by the designer/utility). 


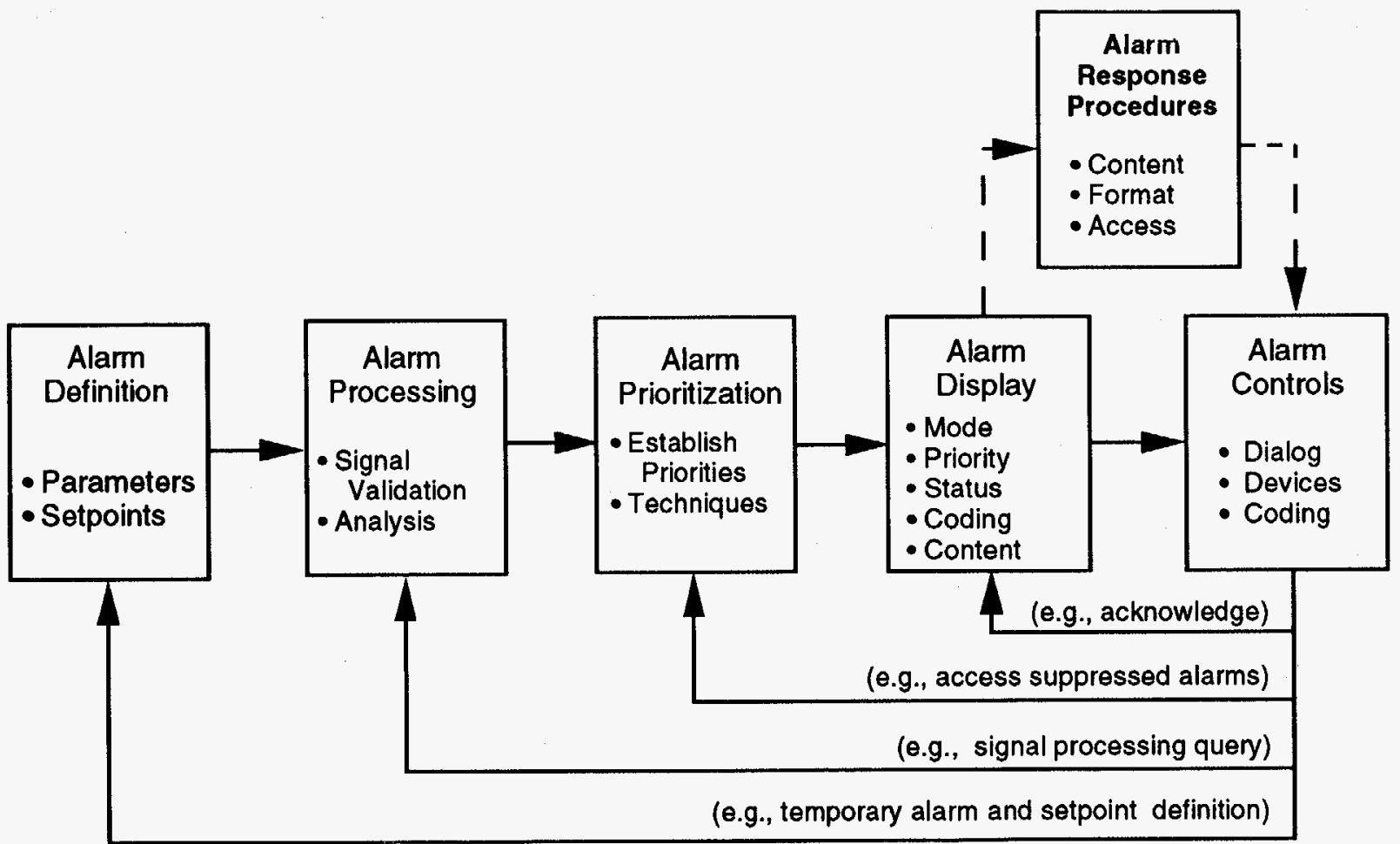

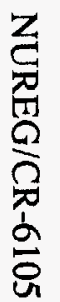

Figure 3.1. Alarm system elements 
Guidelines for the review of alarm definition are provided in Section 4.2.

\subsubsection{Alarm Processing}

Alarms in conventional plants tend to be stand-alone systems that alert operators to off-normal conditions and to the status of systems and components, and, by inference, the functions they support. After being alerted, the operators would consult other indicators for specific information (e.g., they may determine the actual value of a parameter for which an alarm for low level had just activated). Such systems tended to overwhelm operators during transients because of a large number of nearly simultaneous annunciator activations with varying degrees of relevance to operator tasks. Thus, alarm processing techniques were developed to support operators in coping with the volume of alarms, to identify which alarms are significant, and to reduce the need for operators to infer plant conditions. Alarm processing addresses a fundamental aspect of system design, namely, which alarms are presented to the operating crew.

Alarm signal processing refers to the process by which signals from plant sensors are automatically evaluated to determine whether any of monitored plant parameters that have exceeded their setpoints and to determine whether any of these deviations represent true alarm conditions. Alarm signal processing includes techniques for analyzing normal signal drift and noise signals and signal validation. Techniques for analyzing normal signal drift and noise signals are used to eliminate signals from parameters that momentarily exceed the setpoint limits but are not indicative of a true alarm condition. Signal validation is a group of techniques by which signals from redundant or functionally related sensors are compared and analyzed to identify and eliminate false signals that may result from malfunctioning plant instrumentation such as a failed sensor. Alarm conditions that are not eliminated by the alarm signal processing may be evaluated further by alarm condition processing and other analyses before they result in the presentation of alarm messages to the operator.

Alarm condition processing refers to the rules or algorithms that are used to determine the operational importance and relevance of alarm conditions. This is done to determine whether the alarm messages that are associated with these alarm conditions should be presented to the operator. A wide variety of processing techniques have been developed (see Table 3.1 for examples). It should be noted that advanced alarm processing systems often employ combinations of these techniques. Each processing technique changes the resulting information provided to operators. For the purposes of this discussion, four classes of processing techniques will be defined: Nuisance Alarm Processing, Redundant Alarm Processing, Significance Processing, and Alarm Generation Processing.

1. Nuisance Alarm Processing - This class of processing includes techniques which seek to eliminate alarms which have no operational safety importance. For example, mode dependent processing eliminates alarms that are irrelevant to the current mode of the plant, e.g., the signal for a low pressure condition may be eliminated during modes when this condition is expected such as startup and cold shutdown but be maintained during modes when this condition is not expected such as normal operation.

2. Redundant Alarm Processing - This class of processing includes techniques which analyze for alarm conditions that are true/valid but are considered to be less important because they provide information that is redundant with other alarms and theoretically provide no new/unique information. For example, in causal relationship processing only causes are alarmed and consequence alarms are eliminated or lowered in priority. Such techniques may, however, minimize information that is used by the operator for confirmation that the situation represented 
by the "true" alarm has occurred, for situation assessment, and for decision-making. Thus, in addition to quantitatively reducing alarms, processing methods may qualitatively affect the information presented to the operating crew.

3. Significance Processing - This class of processing includes techniques that analyze for alarm conditions that are true/valid but are considered to have less importance due to their significance in comparison to other alarm conditions. For example, in an anticipated transient without scram event, alarms associated with minor disturbances on the secondary side of the plant could be eliminated or lowered in priority.

4. Alarm Generation Processing - This class of processing includes techniques that analyze the existing alarm conditions and, based upon the evaluation, generate alarm messages which (1) give the operator higher level or aggregate information, (2) notify the operator when "unexpected" alarm conditions occur, and (3) notify the operator when "expected" alarm conditions do not occur. These processing techniques in effect generate new (e.g., higher -level) alarm conditions. The generation of alarm conditions and their resulting alarm messages presents an interesting paradox. Alarm systems should facilitate the reduction of heuristics-initiated errors which often reflect the overloaded operator's incomplete processing of information (Norman, 1988; Reason, 1987, 1988, 1990). Alarm generation features may help mitigate these problems by calling the operator's attention to plant conditions that are likely to be missed. However, the single most significant problem with alarms systems, as reported in the literature, is the high number of alarm messages presented to the operator at one time. Since alarm generation creates additional alarm messages, it may potentially exacerbate the problem.

The reviewer should obtain information on the following:

- Alarm signal validation

- $\quad$ Processing of nuisance alarms

- Processing of alarm redundancy

- Processing to determine relative alarm importance

- $\quad$ Processing to identify patterns/events/states

- $\quad$ Processing to generate alarms

- $\quad$ expected alarms that are not in

- $\quad$ alarms that are in but are not expected based upon plant condition

Guidelines for the review of alarm processing and reduction are provided in Section 4.3.

\subsubsection{Alarm Condition Priority and Message Availability}

Alarm condition priority refers to the determination of the relative importance to the operating crew of all present alarm conditions, following the application of alarm condition processing. Evaluation dimensions for alarm condition priority should include the required immediacy of operator action and the significance of the alarm condition to plant safety. 
Table 3.1. Alarm Processing Approaches

\begin{tabular}{|c|c|c|}
\hline CATEGORY & APPROACH & FUNCTIONAL DESCRIPTION ${ }^{1,2}$ \\
\hline Nuisance & Status-alarm Separation & $\begin{array}{l}\text { Separating status annunciators from alarms that require } \\
\text { operator action. }\end{array}$ \\
\hline Nuisance & Plant Mode Relationship & $\begin{array}{l}\text { Alarms which are irrelevant to the current operational } \\
\text { mode, such as start-up, are suppressed. }\end{array}$ \\
\hline Nuisance & Time Dependency & $\begin{array}{l}\text { Time dependency is used to delay the actuation of an } \\
\text { alarm by some predefined period of time to ensure the } \\
\text { alarmed condition is stable to prevent presentation of false } \\
\text { alarms due to momentary fluctuations. }\end{array}$ \\
\hline Redundant & Multi-setpoint Relationship & $\begin{array}{l}\text { The relationship between multi-setpoints of a process vari- } \\
\text { able is used to suppress lower priority alarms, e.g., when } \\
\text { the level in the steam generator exceeds the high-high } \\
\text { level setpoint, the high-level alarm is suppressed. }\end{array}$ \\
\hline Redundant & State Relationship & $\begin{array}{l}\text { Alarms associated with a well-defined situation, e.g., } \\
\text { pump trip, are suppressed. }\end{array}$ \\
\hline Redundant & Causal Relationship & $\begin{array}{l}\text { The cause-effect relationship is used to identify alarms } \\
\text { associated with causes while suppressing alarms associated } \\
\text { with affects. }\end{array}$ \\
\hline Significance & Relative Significance & $\begin{array}{l}\text { Alarms associated with relatively minor disturbances } \\
\text { during more significant events are suppressed. }\end{array}$ \\
\hline Generation & Hierarchical Relationship & $\begin{array}{l}\text { Using an alarms relationship with components, trains, } \\
\text { systems, and functions, hierarchical alarms can be gener- } \\
\text { ated to provide operators with higher-level information. }\end{array}$ \\
\hline Generation & Event Relationship & $\begin{array}{l}\text { The unique pattern of alarms typically activated following } \\
\text { the occurrence of an event is recognized and the potential } \\
\text { initiating event is identified. }\end{array}$ \\
\hline Generation & Alarm Generation & $\begin{array}{l}\text { Alarms are generated when (1) conditions or events are } \\
\text { expected to occur but do not occur (for example, when all } \\
\text { control rods do not reach their fully inserted limits within } \\
\text { a prescribed time after a scram) or (2) an alarm is expect- } \\
\text { ed but does not occur. }\end{array}$ \\
\hline
\end{tabular}

1 For illustration purposes, the descriptions refer to alarm suppression, but filtering and prioritization can be used as well.

2 Functional descriptions are not intended to imply how the processing is accomplished in software. 
Alarm message availability refers to the process by which alarm messages are selected for presentation to the operators based on the priority of their alarm conditions. Thus, while two alarm messages may be valid for current plant conditions, one may be very important to the operator's role and should be emphasized, while the other message may be of little importance and should be de-emphasized. Alarm message availability techniques emphasize important alarm messages and de-emphasize less important alarm messages. This supports the operator in focussing attention on the alarm messages that have the greatest operational significance.

Three alarm availability techniques have been identified - filtering, suppression, and priority coding. (Note that the definitions of these terms are the authors'; the terms filtering and suppression were sometimes used interchangeably by other authors due to varying or imprecise definitions.) The definitions of these techniques are given below:

1. Alarm filtering - alarms determined by processing to be less important, irrelevant, or otherwise unnecessary are eliminated and are not available to the operators.

2. Alarm suppression - alarms determined by processing to be less important, irrelevant, or otherwise unnecessary are not presented to the operators, but can be accessed upon request.

3. Alarm priority coding - the results of alarm processing are provided via prioritization (alarms are not filtered or suppressed).

A specific alarm system may employ a combination of these approaches. There are trade-offs between these approaches, and thus an issue remains as to which method should be used or in what contexts the various options should be exercised. Filtering completely eliminates the possibility of less important alarms distracting the operators. However, the designer may be removing information useful for other purposes. In addition, the designer must be certain that the processing method is adequately validated and will function appropriately in all plant conditions. Suppression provides the potential benefits of filtering by removing distracting alarms. However, since such alarms are still accessible on auxiliary displays, they potentially impose additional secondary task workload to retrieve them. Alarm priority coding does not conceal any information from operators. However, the method requires operators to perceptually "filter" alarms, using the priority codes, to identify the higher priority alarm messages. This creates the potential for distraction because it presents alarm messages of all levels of importance. The effects of these alternatives on operator performance need to be considered.

The reviewer should obtain information on the following:

- Dimensions used to prioritize alarms, e.g.,

- $\quad$ Need for operator action

- $\quad$ Safety system challenge

- Threat to critical safety function

- Other

- Alarm priority dimensions

- $\quad$ Number of levels for each dimension

- $\quad$ Method for assigning priority (for static prioritization) or computing priority (for dynamic prioritization) 
- The treatment of alarms that have been removed through filtering (complete removal) or suppression (available to operators upon request).

For selected scenarios, listings of the following should be obtained to support the review:

- $\quad$ Priorities assigned to alarms

- Alarms suppressed

- Alarms filtered

Guidelines for the review of alarm prioritization and availability are provided in Section 4.4.

\subsubsection{Alarm Display}

Alarm display addresses the ways in which information is presented to the operating crew. The general trends in visual display design are toward increased integration of information into displays. This trend has extended to alarm information as well. There are two principal reasons for this: one related to design trends and the other to information processing.

First, computer-based information systems, such as those in digital control rooms, can access and present a very large quantity of data in integrated and hierarchical form, typically more than conventional control rooms which present information in simultaneous/parallel form with hardwired displays. Thus, information can be presented in a more compact work space providing significantly less display surface area (contrast the display area available in a conventional NPP with that provided by advanced control room designs). The net effect of these two characteristics of advanced control room design is that more information may be presented in less space. There is a need to understand appropriate methods to integrate, layer, and present information at higher levels (aggregates of lower level information).

Second, it is thought that the cognitive processing of information is supported by integration of information into a single object (Kahneman and Triesman, 1984) or display (Bennett and Flach, 1992). Such displays are thought to enhance parallel processing (lowering cognitive workload), enable operators to better understand the relationships between display elements, and develop a more rapid and accurate awareness of the situation. Woods (1991) has indicated that merely making information available.does not necessarily support decision making and problem solving. Techniques for integrating information into a single object tend to maintain rather than reduce the amount of information presented while making that information more understandable to the operator.

The roles of alarm systems in NPPs have typically been quite complex, i.e., providing a first alert to anomaly or status and providing a source of information to operators to aid decision making. The importance of the multiple roles of alarm systems has been noted by many researchers (e.g., Fink et al., 1992; Kragt et al., 1983; MPR Associates, 1985; Sheehy et al., 1993). To support the different functions of the alarm system, multiple display formats may be required, e.g. a combination of separate (such as alarm tiles) and integrated displays (such as alarms integrated into process displays). Thus, the display format of alarm information in advanced systems and the degree to which that information is presented in separate or integrated fashion, with other process information, are important safety considerations.

To facilitate the review, it may be helpful to first characterize the presentation of alarm information into the following three display "types": 
1. Spatially-dedicated continuously-visible (SDCV) alarm displays (e.g., tiles).

2. Alarm message lists (e.g., temporary alarm displays).

3. Alarms integrated into process displays.

Other display types, which combine features of more than one type, are certainly possible. The reviewer may choose to create additional type categories or review the characteristics of these display types as special cases of the three types presented above. The goal is to insure that all unique alarm display characteristics are reviewed.

For each of the alarm display types, the reviewer should obtain information pertaining to the following characteristics and then compare this information to the detailed guidelines for the review of alarm displays provided in Section 4.5.

- General characteristics

- Display functions (e.g., operator monitoring and decision-making capabilities to be supported)

- Degree of independence of alerting and informing functions

- $\quad$ Degree of independence of priority and detailed information

- $\quad$ Principles and criteria for allocation of alarms to major display types

- $\quad$ Alarm graphics

- $\quad$ Consistency of alarm coding

- Display of high-priority alarms

- Display of alarm status

- Display of shared alarm

- $\quad$ Alarm messages

- Coding methods

- Detailed arrangement of alarm information

- $\quad$ SDCV alarm displays

- $\quad$ Alarm message lists

For the case where alarms are integrated into process displays, the reviewer should obtain information about display characteristics that are addressed by NUREG-0700, Revision 1 . The detailed arrangement of alarm information in these displays should be consistent with the guidelines for the design of process displays of the HSI (as per Guideline 4.1-4, Conformance to HSI Design Review Guidelines).

For all types of alarm displays, an inventory of alarm display elements (symbols, acronyms, labels, measurement units, and coding) should be developed so it can be compared with the same display elements in the rest of the HSI and procedures (as per Guideline 4.1-3, Consistency with the Main HSI).

\subsubsection{Alarm Controls}

The control aspects of the interface should be considered along three dimensions: functional requirements (what control functions are needed by operators), operator-system dialog format, and implementation of controls. 
Functional requirements refers to the specification of control functions that the system provides for operator interaction with the alarm system. The typical alarm system control functions used in the nuclear industry are silence, acknowledge, reset, and test (SART) controls. In conventional plants these functions are supported by dedicated controls such as pushbuttons. The SART philosophy also applies to advanced alarm systems, where control functions with respect to operator interaction may be more sophisticated and require greater flexibility than conventional alarm systems. For example, the operator may have the capability to define temporary alarms, adjust setpoints, and control filtering options. Some of these capabilities may require more sophisticated methods of communication with the system than is possible with traditional dedicated switches, or pushbuttons.

The general method of communication between the operator and the alarm system, also called the dialog format, can include methods such as menu selection, command language, and special function keys (see NUREG-0700, Revision 1 for a discussion of dialog design options). In advanced control rooms, this aspect of operator communication with the system is likely to be integrated with other control room interfaces. Therefore, the alarm system may use the same input/control interfaces as the other HSIs, such as, for example, entry of temporary setpoints through a general purpose keyboard. The reviewer should consider the most appropriate method of dialog and whether the alarm system can use common control room input devices (see NUREG-0700, Revision 1 for a discussion of general input/control interface options and their appropriate use).

A variety of alarm control switch options are possible such as:

Dedicated Hard Switches - Dedicated hard switches are the type of control device typically used in conventional control rooms (such as conventional SART controls). They have only one defined function, and are always physically present.

Software-Defined Hard Switches - Software-defined hard switches are hardware switches like those described above, but their function is programmed to be different for various situations. Thus they are spatially (physically) dedicated, but variable/multiple function switches. The pushbuttons along side a multifunction display are an example of this type of control device.

Soft Switches - Soft switches are not traditional switches but rather computer-generated graphic objects that are displayed on a CRT, flat panel, or other display device. The switch may have either a dedicated or variable location on the display. It may be activated by touch, if a touch screen is used, or by cursor action.

The controls provided by the alarm system may be used by the operator to perform the following alarm control functions:

$\begin{array}{ll}- & \text { Silence } \\ - & \text { Acknowledge } \\ - & \text { Reset } \\ - & \text { Test } \\ \text { - } & \text { other }\end{array}$

For each type of alarm control or alarm control function, the reviewer should obtain the following information: 
- Control availability

- $\quad$ Modes of User Interaction

- $\quad$ Dialog types (e.g., menus, command language)

- Verification indications

- Navigation and access of additional information

- $\quad$ Additional parameter information and process displays

- Devices (design implementation)

- $\quad$ Types (push buttons, switches, and touch screen)

- $\quad$ Coding

- Dialog/protocol

- Organization/layout (of control devices)

- $\quad$ Location (with respect to alarm displays and panels)

This information should be used to support the review of the following topics addressed by the review guidelines found in Section 4.6 - Control:

- General characteristics

- $\quad$ Provision of control functions

- $\quad$ Coding of control functions

- Layout of control group(s)

- Controls for tile and VDU alarms

- Defeating controls

- $\quad$ Access to new undisplayed alarms

- Guidelines for specific control types

- $\quad$ Effect of control action

- $\quad$ Means of performing control action

- $\quad$ Appropriate use of control

- $\quad$ Location of control

In addition to these guidelines, the controls of the alarm system should conform to the general HSI guidelines of NUREG-0700, Revision 1.

\subsubsection{Automated, Dynamic, and Modifiable Characteristics}

In certain situations, such as during major process disturbances, it may be desirable to reduce workload by automating some alarm system functions, such as the silencing of lower priority alarms or by temporary cessation of unacknowledged alarm flashing. Similarly, automated controls may be implemented to trigger appropriate displays such as alarm graphics, data windows, or display pages. Other dynamic aspects of the alarm system may allow operators to introduce operator-defined characteristics such as alarm parameters and setpoints. These dynamic aspects of the interface should be reviewed to ensure that excessive workload demands are avoided, while the overall functional characteristics of the 
alarm system are preserved. These dynamic aspects of the alarm system should not be disruptive or confusing to operators, especially when the alarm system changes modes of operation.

The reviewer should obtain information on the following:

- An inventory of system features and characteristics which automatically change in response to plant conditions

- An inventory of operator-definable features and characteristics, e.g., alarms and setpoints

- HSI characteristics of automatic and operator-defined dynamic features and characteristics

- Methods of input/control

- $\quad$ Methods of verifying modifications/feedback

- Methods of display

- Administrative controls for operator-defined dynamic features

Guidelines for the review of general alarm system characteristics are provided in Section 4.7.

\subsubsection{Reliability, Test, Maintenance, and Failure Indication}

The alarm system must provide alarm information to the operator in a reliable manner. Important considerations include the reliability of alarm system hardware and software, the manner in which the alarm system conveys information to the operator regarding alarm system failures or malfunctions, and the ease with which test and maintenance activities may be performed upon the alarm system with minimal interruption to the operators. Each of these points is discussed below.

First, the hardware and software components of the alarm system should have sufficient reliability that single component failures do not cause significant loss of functions or information. For example, the redundancy and diversity of the alarm system design should protect against alarm indications being lost or spurious alarm messages being generated as the result of sensor or signal processing malfunctions. In addition the alarm system should allow the operators to obtain alarm information from an alternate display device if the primary display device fails.

Second, when alarm system malfunctions do occur, the alarm system should make them apparent to the operators. Recent events at NPPs (see Information Notice 93-47, U.S. NRC, 1993) have emphasized the importance of providing operators with an active method of verifying the status of the alarm system itself. Test controls provided in conventional control rooms have traditionally provided the operators with the capability to check the operation of the alarm display (e.g., detect burnt-out annunciator lamps), but not other portions of the alarm system, such as signal processing components. In addition, these test controls only tested the alarm system upon demand; they did not provide continuous monitoring for alarm system anomalies. Since operators rely on the alarm system as the first indication of a process disturbance, it is important that advanced systems notify the operator of any loss of functioning when it occurs. The capability of the alarm system to provide the operators with prompt indications of malfunctions of the alarm system is an important review consideration.

Third, test and maintenance features of the alarm system should be designed so that these activities can be performed with minimal interference with the activities of the operators. Desirable design features may include built-in test capabilities, modular components that can be rapidly removed and replaced, and 
rear access panels which prevent maintenance activities from obstructing the operator's view of controls and displays.

The reviewer should obtain information on the following:

- Design features addressing alarm system reliability

- Design features addressing alarm system test by operators

- Design features addressing alarm system maintenance

- Method of indicating loss of entire alarm system or its components such as sensors, processors, displays, and controls.

Guidelines for the review of these characteristics are provided in Section 4.8.

\subsubsection{Alarm Response Procedures (ARPs)}

ARPs provide more detailed information concerning the nature of the alarm condition than is typically provided in the alarm message. Typically information provided is alarm source (sensor), setpoint, causes, automatic actions, and operator actions. They are especially important to operators when an unfamiliar alarm activates or when an alarm seems inconsistent with the operator's understanding of the plant state. ARPs may be hard-copy or computer-based.

The reviewer should obtain information on the following:

- $\quad$ ARP information content

- $\quad$ ARP format

- APR location

- $\quad$ Methods of user access to, and interaction with ARPs (especially computer-based ARPs)

Guidelines for the review of ARPs are provided in Section 4.9.

\subsubsection{Control-Display Integration and Layout}

Control display relationships and general layout significantly impact operator performance with alarm systems, as it does for other aspects of the HSI.

The reviewer should obtain information on the following:

- Control console layout of alarm display devices and controls

- Alarm display layouts for VDUs

- $\quad$ Relationship between alarm controls and displays and the associated process indicators and controls

- Physical relationship between the operators and the alarm controls and displays and associated process indicators and controls

Guidelines for the review of control-display integration are provided in Section 4.10. 


\subsection{Guideline Selection and Application}

When evaluating an alarm system the reviewer should select appropriate guidance to serve as the basis for the review. In so doing, two considerations need to be addressed: alarm guidelines in Section 4 and general HSI guidelines in NUREG-0700, Revision 1.

First, based on the alarm system characterization, the individual guidelines (from Section 4) appropriate to the review should be identified. Not all of the guidelines in Section 4 will be applicable to every review. The subset of guidelines that are appropriate to a specific design should be identified by the reviewer through the process of characterizing the alarm system as established in Section 3.2 and then comparing the review guidance to the characteristics of the alarm system. Guidelines that do not correspond to characteristics of the alarm system under consideration may be excluded from the review.

Second, the general display and control guidelines contained in NUREG-0700, Revision 1 should be considered because the alarm system is a part of the overall control room HSI. For example, if the alarm system uses a touch screen interface for operator input and query of the system, the review guidance for touchscreens in NUREG-0700, Revision 1 should be used to evaluate that aspect of the interface. As another example, if the alarm displays are integrated into piping and instrumentation diagram-type (P\&ID) VDU displays, the P\&ID or mimic aspect to the display, such as icons and symbols, should be evaluated using those sections of NUREG-0700, Revision 1. However, it should be noted that the guidance provided in Section 4 is directed to unique concerns of alarm systems. In the event of overlap in guidance between this document and NUREG-0700, Revision 1, the guidance of this document should take precedence.

In addition, if there are aspects of the alarm system that are not addressed by current guidelines, the reviewer may (1) seek supplemental guidance from alternative sources; and/or (2) identify and review the guidance used by the designer/applicant in designing the system. If no guidance exists to support the review, then that aspect of the HSI should be evaluated by other methodologies, such as operator interviews and dynamic performance evaluations.

The review can be conceptualized as being directed towards two aspects of HSI features:

1. Standardized Features Review - A standardized features review addresses those alarm system features that are governed by the designer/applicant's design standards and conventions (as defined by the designer/applicant's standards and guidelines documents) and used across individual controls and displays. Examples may include display screen organization, format conventions, and coding conventions.

Because the use of these standardized features should be fairly consistent across the HSI, human factors concerns should be more predictable than for those design features that are not addressed by the designer/applicant's standards and guidelines. Thus, if a standard has been considered acceptable by the NRC, then it may not be necessary to review this design feature in detail for each control or display device in which it occurs. For example, if display labeling is controlled by an acceptable designer/applicant standard convention, then the display labels may be checked on a sampling basis for conformance to the standard rather than conducting an exhaustive check of each display label. 
Where possible, a desktop review of the designer's alarm system guidance document or design specification should be performed prior to the onsite review. This can greatly enhance the effectiveness of the onsite review; HFE concerns identified during the desktop review can receive increased attention during the onsite review. Features found acceptable in the desk-top review can be checked on a sampling basis for conformance to the designer's guidance during the onsite review.

2. Detailed Features Review - A detailed features review addresses individual displays and controls in their task-support context. The majority of this effort would be directed towards the taskappropriateness of HSI features and aspects of the HSI which are not governed/controlled by the designer/applicant's standards and guidelines. These aspects of the HSI can be expected to be more variable than the standardized design features. For each HSI element, the reviewer should use the guidelines as the basis of the evaluation only after the following have been identified:

- The task(s) for which the HSI is being used by the crew.

- The role of the HSI in support of the task; e.g., identifying the task information that is intended to be provided to the operating crew by a particular display.

Depending on the availability of documentation and supporting information, the reviewer may have to access several potential data sources while conducting the review, including:

- Design documentation linking task analysis to interface design

- Reviewer observations

- Interviews with plant staff

- Alarm system walk-downs

All available information should be used to support the HSI review. Inconsistencies between different sources of information available to the reviewer should be noted because these inconsistencies may be indicative of broader issues.

The HFE guidelines for the review of the alarm system are presented in Section 4. An index of all guidelines by number and title is presented in Appendix C. These guidelines are expressed in two forms:

- $\quad$ "Should" - Expected characteristics of the design under review whose absence must be justified and evaluated for acceptability.

- $\quad$ "May" - Features that are considered acceptable, but whose absence does not require justification.

The reviewer should indicate whether the aspect of the HSI under review is:

- $\quad$ "Acceptable," conforms to the guideline

- $\quad$ "Discrepant" from the guideline (therefore, potentially unacceptable), or

- $\quad$ "Not Applicable."

The interpretation of findings and evaluation of discrepancies is addressed in NUREG-0700, Revision 1. However, as noted earlier, HFE guideline reviews have limitations. The designer's tradeoffs and evaluations may result in design-specific deviations from the guidelines presented in Section 4 
which may be perfectly acceptable within the context of the integrated design. Such discrepancies may be judged acceptable by the reviewer if they can be justified by a documented rationale, such as:

- Analysis of recent literature or operating experience,

- Trade-off studies, and

- $\quad$ Results of tests and evaluations.

See NUREG-0700, Revision 1 for a further discussion of this topic.

Special considerations should be given to the following issues when evaluating a modification to an existing alarm system or the installation of a new alarm system into an existing control room:

- "Crew-identified" functionality should be addressed, in addition to that specified by system designers. That is, when a new system is introduced to replace an existing system, it is important to make sure that all functional uses of the old system by the operators have been addressed, even though such uses may not have been part of the initial (or original) intended use of the system by the designer/applicant. The design of the replacement system should consider the actual usage of the old system by its users.

- Integration with the existing HSIs,

- Integration with procedures and training, and

- Impact on operator tasks and workload. 


\section{ALARM REVIEW GUIDELINES}

\subsection{General Guidelines}

\section{1-1 Alarm System Functional Criteria}

The alarm system should:

- Alert the operator to the fact that a system or process deviation exists;

- Inform the operator about the priority and the nature of the deviation;

- Guide the operator's initial response to the deviation; and

- Confirm, in a timely manner, whether the operator's response corrected the deviation.

ADDITIONAL INFORMATION: This information will support plant personnel in detecting state changes for plant systems or functions, avoid information overload, and avoid startling the operator.

SOURCE: NUREG/CR-3987, IEC 964, EPRI ALWR.

\section{1-2 Alarm System Upgrade Functionality}

A new alarm system that is installed into an existing control room should support all of the operator functions that the old system supported, in addition to satisfying the functional requirements of the SAR and various other functional criteria (such as those listed in Section 4.2).

ADDITIONAL INFORMATION: Operators use alarm systems in ways not always envisioned by the designers. When an alarm system is replaced, an analysis of the functional use of the old system should be conducted in conjunction with operations personnel to assure that safe operation is not compromised by removing an information source and not replacing it in the new alarm system. For example, operators frequently use alarm systems to determine overall plant status. It should be noted that the specific roles that an alarm system plays in a plant depend on the overall design of the HSI of which the alarm system is only a part. Thus, for example, the use of alarm systems to determine overall plant and system status may not be necessary in advanced plants where large plant and system overview displays are available to the operating staff.

Discussion: The importance of the multiple purposes for which operators use alarm systems has been noted by many researchers (e.g., Fink et al., 1992; Kragt et al., 1983; MPR Associates, 1985; Sheehy et al., 1993). For example, MPR Associates (1985) evaluated the role of alarm systems in the operator's decision making during off-normal conditions. Several specific uses were identified:

- Support for the determination of the status of various systems or components (an aspect of the alarm system that may be lost when a conventional system is replaced with a advanced system).

- $\quad$ Alert to a simple malfunction where simple "rule-based" action is used. 
- Facilitate the operator's recognition of the need to branch to alternate sections of the procedures during use of emergency operating procedures (EOPs).

- Provide both high-level and system/component level information to the operator to support more abstract, knowledge-based responses to plant upsets in situations where appropriate immediate actions/strategies are not clear.

- $\quad$ Provide feedback functions such as the return to normal status.

- Indicate the need for Site Emergency Plan activation.

Thus, the alarm system supports the operator's goal-directed information processing which has been found to play a role at all levels of abstraction. In addition, this guideline is consistent with the high-level design review principles of Task Compatibility and User Model Compatibility (see Appendix A).

SOURCE: Authors.

\section{1-3 Consistency with the Main HSI}

The alarm system HSI should be consistent with the standards and conventions used for the HSIs for other displays and controls in the control room.

ADDITIONAL INFORMATION: The alarm system should use the same conventions such as symbols, icons, acronyms, coding, and measurement units that are used in the main HSI displays and procedures. While some minor differences may exist, the alarm system should never use a display feature, such as coding, in a way that is different from or conflicts with other HSIs. For example, if color is used to code priority, it should have the same meaning in the alarm system as in the process displays.

Discussion: This guideline is consistent with the high-level design review principle of Consistency (see Appendix A).

SOURCE: Authors.

\section{1-4 Conformance to HSI Design Review Guidelines}

Alarm system elements (e.g., displays and controls) should conform to general HSI guidance as well as alarm system guidelines.

ADDITIONAL INFORMATION: While alarm system guidance takes precedence over other more general HFE guidance, it should be kept in mind that alarm system is a part of the overall HSI. As such, should conform to the same guidelines for general display and control design. For example, if the alarm system uses a touch screen interface for operator input and query of the system, the review guidance for touchscreens in NUREG-0700, Revision 1 should be used to evaluate that aspect of the interface. As another example, if the alarm displays are integrated into P\&ID VDU displays, the P\&ID aspect to the display, such as icons and symbols, should be evaluated using those sections of NUREG-0700, Revision 1 . In the event of overlap in guidance, the guidance for alarm systems takes precedence when reviewing the alarm system.

SOURCE: Authors. 


\section{1-5 Alarm System Validation}

The effectiveness of the alarm system should be validated through real-time, dynamic simulation.

ADDITIONAL INFORMATION: Alarm system design has been an historical problem in complex process control systems in general and NPPs in particular. While HFE guidance addresses many design issues, there remain aspects of alarm system design review that are not adequately addressed by HFE guidelines. Thus, the functionality of the system should be assessed through dynamic performance evaluation that addresses both (1) the HSIs associated with operation of the alarm system and (2) the quality, accuracy, timing, and usefulness of the information provided by the alarm system to plant personnel.

SOURCE: EPRI ALWR, Authors.

\subsection{Alarm Definition}

\section{2-1 Alarm Selection}

The following criteria should be included in the basis for selecting alarm conditions:

- Monitoring critical safety functions and key parameters

- $\quad$ Preventing personnel hazards

- $\quad$ Avoiding significant damage to equipment having a safety function

- $\quad$ Assuring that technical specifications are met

- $\quad$ Monitoring emergency procedure decision points

ADDITIONAL INFORMATION: One of the key aspects of an alarm system is to support operators in ensuring that the plant remains within the safety operating envelop as defined by the Safety Analysis Report (SAR) and technical specifications. This includes ensuring that automatic systems can still perform their intended functions to protect the plant and personnel. This assurance can be provided in a number of ways by the alarm system with the monitoring of critical safety functions and key parameters being a typical choice. After a scheme for selecting alarm conditions has been developed and applied, the selected alarm conditions should be reviewed to verify that important aspects of all of the above categories are addressed within the main control room alarm system.

SOURCE: NUREG-0700, EPRI ALWR, EPRI NP-3659, Authors.

\section{2-2 Setpoint Determination}

Alarm set points should be determined to ensure that the operating crew can monitor and take appropriate action for each category of alarms, e.g., respond to out-of-tolerance conditions, in a timely manner.

ADDITIONAL INFORMATION: Alarms are established to help ensure that the plant remains within SAR and technical specification limits. In order to achieve this, the setpoints may be specified at conservative levels that are well before the actual limits to allow sufficient response time for operators and plant systems. Thus, where practical, alarm setpoints should be 
determined such that the operator is alerted before a major system or component problem results in a condition which causes a loss of availability (e.g., plant trip), equipment damage, violation of SAR and technical specification requirements, or other serious consequences. Other criteria are acceptable if they do not compromise these factors.

Discussion: This guideline is consistent with the high-level design review principle of Timeliness (see Appendix A).

\section{SOURCE: EPRI NP-3659, EPRI ALWR, NUREG-0700, Authors.}

\section{2-3 Setpoint Determination and Nuisance Alarm Avoidance}

The determination of alarm setpoints should consider the trade-off between the timely alerting of an operator to off-normal conditions and the creation of nuisance alarms caused by establishing setpoints that are within the "normal" parameter value drift.

ADDITIONAL INFORMATION: When determining setpoints, consideration should be given to the performance of the overall human-machine system (i.e., operator and alarm system acting together to detect process disturbances).

Discussion: Process control operators are in a monitoring environment that has been described in signal detection terms as an "alerted-monitor system" (Sorkin et al., 1985 and 1988). This is a two-stage monitoring system with an automated monitor and a human monitor. The automated monitor in a NPP is the alarm system which monitors the system to detect off-normal conditions. When a plant parameter exceeds the alarm criterion, the human monitor is alerted and must then detect, analyze, and interpret the signal as a false alarm or a true indication of a plant disturbance. Both the human and automated monitors have their own specific signal detection parameter values for sensitivity and response criterion. For the human monitor, both parameters are strongly affected by alarm system characteristics including set points, the presence of nuisance and false alarms, and alarm density. A significant issue associated with alerted-monitor systems is that optimal overall performance of the alerted-monitor system is a function of the interaction of both components. Optimizing the signal detection parameters for one component of the system may not optimize performance of the entire two-stage system. An alarm setpoint philosophy frequently employed is to attempt to optimize the detection of signals by the automated monitor subsystem. The response criterion is set to minimize missed signals. This, however, increases the false alarm rate, thus increasing the noise and lowering the operators' confidence in the alarm system. In addition, this guideline is consistent with the high-level design review principles of Cognitive Compatibility and Timeliness (see Appendix A).

SOURCE: Authors, NUREG-0700.

\section{2-4 Darkboard Configuration}

Candidate alarms and setpoints should be chosen so that no alarms are active for the normal operating conditions of the plant.

ADDITIONAL INFORMATION: This has traditionally been referred to as the dark board (or blackboard) concept. Typically, this condition will be full power operation, with all systems lined up in their most typical configuration for full power operation. This concept has implications for the plant's operating philosophy as well, including issues such as (1) repairing 
failed equipment expeditiously, (2) taking corrective actions for instrument drifts that cause alarms, and (3) correcting conditions that frequently lead to repeat alarms.

SOURCE: EPRI NP-3448.

\subsection{Alarm Processing and Reduction}

\section{3-1 Assured Functionality Under High Alarm Conditions}

The alarm processing system should ensure that alarms which require immediate operator action or which indicate a threat to plant critical safety functions are presented in a manner that supports rapid detection and understanding by the operator under all alarm loading conditions.

ADDITIONAL INFORMATION: Alarm processing should be provided to ensure that alarm functional criteria (see 4.1-1, Alarm System Functional Criteria) are not lost under any operational or accident conditions. The alarm system should provide the capability to reduce the number of concurrent alarm messages so that during off-normal conditions the alarm system does not overload of the operator's cognitive processes. Special attention should be given to the problem of "secondary disturbance detection," i.e., detection of a second malfunction following the presentation of alarms related to an initial disturbance.

Discussion: While guidance documents generally agree that alarm processing and reduction are features necessary to achieve an effective alarm system, especially under high alarm conditions, there is conflicting evidence regarding how these objectives can be met and what the specific effects are on human performance. The major conclusion from key research in this area (summarized below) is that alarm processing effects are complex and need to be carefully reviewed for each specific application. However, comprehensive HFE guidance is not yet available.

The HALO (Handling Alarms with Logic) alarm system was developed by the Halden Reactor Project in Norway and tested to determine its effects on operator performance. In an initial study, inexperienced students were trained with the system and were asked to identify disturbances in a simulated pressurized water reactor (Marshall, 1982). Alarm information was presented as (1) unfiltered message lists, (2) filtered message lists, or (3) filtered message lists with an overview display. Alarm information was presented in static displays rather than dynamic simulation. Diagnosis time and accuracy were the primary dependent variables. The results indicated that accuracy was improved with filtering, but the benefit was specific with respect to the plant transient. No significant difference was found for operator response times. Also no differences were observed between the filtered message list used alone and the filtered list used with the overview display.

More recent studies evaluated the alarm processing and display characteristics of HALO (Baker et al., 1985a and 1985b; Marshall and Owre, 1986). Three alarm systems were compared: (1) an unfiltered text-based version of conventional alarms presented on a CRT, (2) a filtered text-based version of alarms presented on a CRT, and (3) a filtered text/symbolic-based version of alarms presented on a CRT. In the latter condition, top-level alarm schematic overview displays of the plant were presented on a CRT. When an alarm activated, symbols representing the appropriate subsystems would blink (red if high priority and yellow if not). The operator could then move to a second-level display which was an enlarged schematic presented on a separate CRT. Flashing symbols indicated the problem system. Text-based alarm messages were provided. An alarm keyboard was used to interface with the alarm system. The filtering system reduced the alarms by approximately fifty percent; the filtered alarms were not available to the operator. The principal dependent variables were detection time and percentage, diagnosis time and percentage, 
percentage of checks, and percentage action. Process variables and subjective evaluations were also measured. Seven crews of two operators each used the three systems in 12 simulated scenarios. Filtering of alarms had little effect on observed performance. It was observed that the detection of events decreased from 81 percent to 51 percent when the event occurred late in a scenario rather than early in a scenario. This statistically significant result demonstrated the failure of the alarm system to achieve its primary function of alerting the operator to off-normal conditions when high alarm conditions exist. None of the systems tested helped to mitigate the problem. One potential problem with interpreting the results of this study is that the display type and use of alarm filtering were experimentally confounded. Thus, no conclusions with respect to the independent effects of display mode or filtering can be made.

These results conflict with previous findings (reported above) that alarm filtering improves diagnostic accuracy (Marshall, 1982). In part, the difference may be explained by the fact that the earlier tests were performed using inexperienced subjects viewing static displays rather than dynamic simulations.

Fujita and Sanquist (1988) used a simulator to investigate the effects of alarm filtering on the operator's information processing. Verbal protocol analysis was used to measure the operator's cognitive processes. The protocols were taken in real time from three operators during simulated malfunctions. The investigators found the method to be weak and not very successful for revealing decision-making strategies. None the less, they found that although the operators expressed support for the alarm filtering system, no evidence was found that it had a positive effect on their performance.

As part of research conducted by Mitsubishi in support of development of the Dynamic Priorities Alarm System (DPAS), Fujita and Kawanago (1987) found that operators preferred to have status alarm information presented to them rather than to have status information filtered out. Color was used to support the operators in distinguishing between status and alarm information.

In another more rigorous test (Fujita, 1988 and 1989), DPAS reduced the number of high-priority alarms through mode, multi-setpoint, and cause-consequence alarm processing. Alarms were displayed on a combination of tiles and CRTs. The tiles were the primary display mode. Each tile was capable of being lit in three colors. The CRT displays used the same color coding conventions. Performance with and without the new system was compared. Nine crews of three experienced operators used the systems during simulated scenarios involving single and multiple failure events. Operator performance measures included time to identify initiating event, time to identify second malfunction, time to take control action, and alarm utilization frequency. No difference between the two systems was found for initiating event identification; however, detection time for second malfunctions was significantly reduced in three of the four scenarios when the alarm handling system was available. Thus, it was concluded that the alarm handling system helped reduce the operator's "mental fixation" on the initiating event. Scenario effects were again observed. DPAS significantly reduced the time required to take a control action in two of the four test scenarios. The finding that second malfunction detection time was reduced with the alarm handling system is not consistent with the findings from the HALO research reported earlier where secondary event detection was not enhanced. There are several possible reasons for the discrepancy, i.e., scenario differences, the implementation of the alarm handling logic, and the alarm system's integration with the control room controls and displays.

Finally, in a study conducted for comparing conventional and CRT-based alarm presentations (Fink et al., 1992), one of the experimental conditions included a CRT presentation of alarms where the typical alarms associated with reactor and turbine trip were suppressed. This presentation reduced the number of "maverick" alarms (those not typically occurring during a plant trip) that were missed by the operators by approximately 50 percent in comparison to a typical tile display. However, it was noted that one operator objected to such suppression because he believed that the timing of some of the normal trip-related alarms facilitated the crew's understanding of transients. 
In summary, the results of the research discussed above on the effects of alarm processing on operator performance do not provide a technical basis on which to develop more definitive review guidance. While no negative performance effects were observed, two studies (Baker, 1985a and 1985b, and Fujita and Sanquist, 1988) found little effect due to alarm filtering. One study (Fujita, 1988 and 1989) found no effect for the detection of initial disturbances, but found improved performance in the detection of secondary malfunctions (which is a significant problem). Another study (Fink et al., 1992) found a positive effect on detection of unusual alarms, but raised a question regarding possible trade-offs with the loss of information making the operator's understanding of events more difficult. Finally, interaction effects with scenarios seems to be an important consideration.

In addition, this guideline is consistent with the high-level design review principles of Cognitive Compatibility, Situation Awareness, Task Compatibility, and Timeliness (see Appendix A).

SOURCE: Authors, IEC 964.

\section{3-2 Alarm Reduction}

The number of alarm messages presented to the crew during off-normal conditions should be reduced by alarm processing techniques (from a no processing baseline) to support the crew's ability to detect, understand, and act upon all alarms that are important to the plant condition within the necessary time.

ADDITIONAL INFORMATION: Since there is no specific guidance on the degree of alarm reduction required to support operator performance, the designer should evaluate the system with operators to assess the effectiveness of the alarm reduction process. This assessment should include evaluations that simulate the operation of the alarm system under situations that activate multiple alarm conditions and/or generate increased operator workload. The use of dynamic mockups and prototypes of the alarm system and dynamic control room simulators should be considered when developing these assessments.

Discussion: While it is clear that the number of unprocessed alarms is overwhelming to operators and that processing techniques can reduce the number of alarms (Cory et al., 1993; Gertman et al., 1986), little research exists that provides more specific guidance on what number of alarms is an appropriate target. Hollywell and Marshall (1994) found that operators preferred CRT alarm message rates of not more than 15 messages per minute and that when the rate increased the number of missed alarms increased. This of course depends on the alarm display and types of message design implemented. It has also been found that reducing the number of alarms by $50 \%$ has little effect on operator performance (Baker, 1985a). In terms of operator processing of alarm information, it is probably inappropriate to specify alarm reduction in terms of absolute numbers of alarms (a metric often used to assess alarm reduction schemes). Demands on operator information processing depends not specifically on the absolute number of alarms, but on their rate, their recognizability as familiar patterns, their predictability, and the complexity of the operator's ongoing task. In addition, this guideline is consistent with the high-level design review principles of Cognitive Compatibility, Situation Awareness, Task Compatibility, and Timeliness (see Appendix A).

SOURCE: Authors. 


\section{3-3 Alarm Signal Validation}

Processing of sensor signals should be applied to ensure that spurious alarms are not presented to plant personnel, due to sensor or processing system failure.

ADDITIONAL INFORMATION: Instrumentation failure is not a common problem in nuclear power plants. However, when such failures occur such as a failed sensor, biased or false signals are generated. The use of these signals by the alarm system may result in the presentation of either false or nuisance alarm messages. Such alarm messages are misleading and may interfere with the crew's situation assessment or reduce the crew's confidence in future alarm messages. Signal validation is a set of alarm processing techniques by which signals from redundant or functionally related sensors are compared and analyzed to determine whether a true alarm condition exists. The purpose of these techniques is to prevent the presentation of false alarms to the operator due to malfunctioning plant instrumentation. Hence, signal validation should be included in an advanced alarm system.

Discussion: This guideline is consistent with the high-level design review principles of Cognitive Compatibility, Situation Awareness, and Task Compatibility (see Appendix A).

SOURCE: Authors.

\section{3-4 Time Delay Processing}

The alarm system should incorporate the capability to apply time filtering and/or time delay to the alarm inputs to allow filtering of noise signals and to eliminate unneeded momentary alarms.

ADDITIONAL INFORMATION: Noise from plant instrumentation may result in signals that momentarily exceed the limit for alarm message activation for a plant parameter. Time delay processing prevents this signal from generating a spurious alarm message to the crew.

\section{SOURCE: EPRI ALWR.}

\section{3-5 Alarm-Status Separation}

Status indications, messages that indicate the status of plant systems but are not intended to alert the operator to the need to take action, generally should not be presented via the alarm system display because they increase the demands on the operators for reading and evaluating alarm system messages.

ADDITIONAL INFORMATION: While status information is important to operators, status indications which do not meet the functional definition of an alarm condition should be presented to operators via a non-alarm display, e.g. on process displays. If the presentation in the alarm display of status indications is justified on the basis of the unique aspects of the a design, such status messages should be designed so that operators may readily distinguish them from true alarm messages.

Discussion: Many studies have found that operators use the alarm system to obtain status information and that under some conditions they prefer to have status alarm information presented to them rather than to 
have status information eliminated (Kragt and Bonton, 1983, Fujita and Kawanago, 1987, MPR Associates, 1985, Sheehy et al., 1993). The issue as to whether to include status indications in an alarm system is mainly a question of how the criteria for alarm selection are defined and what capabilities are provided by other portions of the HSI for displaying plant status indications in a manner that rapidly informs the operator but does not interfere with the operator's ability to handle alarm messages. In addition, this guideline is consistent with the high-level design review principles of Cognitive Compatibility, Situation Awareness, and Task Compatibility (see Appendix A).

SOURCE: Authors.

\section{3-6 First-Out Processing}

As an aid to diagnostic procedures and root cause analysis, provision should be made for identifying the initiating event associated with automatic plant trips through the use of first-out alarms.

ADDITIONAL INFORMATION: In conventional alarm systems first-out alarms, which identified the parameter within an interrelated group which first exceeded its setpoint, were provided to support operators in determining the initiating cause of a reactor or turbine trip. Advanced alarm systems should include this first-out capability along with the results of any additional processing that could improve the identification of initiating event.

SOURCE: NUREG-0700, EPRI NP-3659.

\section{3-7 Mode Dependence Processing}

If a parameter value represents a fault in some plant modes and not others, it should be alarmed only in the appropriate modes.

ADDITIONAL INFORMATION: The following is an example of mode dependent processing. The fact that a particular pump has shutdown may only have operational significance to the crew when the plant is operating in the power range. Mode dependent processing would allow this alarm message to be presented when the plant is in the power range but not when it is in other modes (e.g., hot standby).

SOURCE: IEC 964, NUREG/CR-3987, Authors.

\section{3-8 System Configuration Processing}

If a parameter value represents a fault in some system configurations and not others, it should be alarmed only in the appropriate configurations.

ADDITIONAL INFORMATION: The following is an example of system configuration processing. The fact that a particular pump has a low discharge pressure may only indicate a fault when the associated fluid system is configured to perform a particular function. Other discharge pressures may be appropriate when the fluid system is configured to perform a different function. In addition, a low pump discharge pressure may not be relevant when the fluid system is taken out of service. System configuration processing would allow the alarm message for pump 
discharge pressure to be presented when the fluid system is in the proper configuration and prevent its presentation when the system is in an alternate configuration.

SOURCE: IEC 964, NUREG/CR-3987, Authors.

\section{3-9 Logical Consequences Processing}

If a single event systematically leads to subsequent faults that are the direct consequence of this event, only the alarm message associated with the main event may be presented and the other alarm messages suppressed, so long as this does not interfere with the operators' use of alarm information.

ADDITIONAL INFORMATION: For example, the logical sequences processing may be used to suppress alarms that follow as a logical consequence of trip or isolation conditions. When implementing logical consequences processing the designer should ensure that messages associated with the "consequence" alarm conditions are not needed by the operators for other operational tasks and that operators are aware that the associated "consequence" alarm conditions were generated but not presented. This guideline only suggests suppression of these alarms not their complete elimination (i.e., filtering).

Discussion: The suppression of alarms, such as the typical alarms associated with reactor and turbine trip, has been shown to reduce the number of "maverick" alarms (those not typically occurring during a plant trip) missed by the operators by 50 percent (Fink et al., 1992). However, it should be noted that some operators may object to such suppression since the timing of some of the normal trip-related alarms facilitates the crew's understanding of transients.

SOURCE: IEC 964, NUREG/CR-3987, Authors.

\section{3-10 Exceptions to Known Alarm Patterns}

The system should notify the operator when "unexpected" alarms occur, if the alarm processing logic can support such an analysis.

ADDITIONAL INFORMATION: Such an analysis may apply, for example, during certain transients (e.g., reactor scram) where the expected alarm pattern is well known.

Discussion: EPRI research (Fink et al., 1992) has found that CRT presentations were superior to tiles for highlighting alarms that were "unusual" for a given transient. In addition, this guideline is consistent with the high-level design review principle of Situation Awareness (see Appendix A).

SOURCE: Authors, NUREG/CR-3987.

\section{3-11 Exceptions to Expected Alarm Patterns}

The system should notify the operator when "expected" alarms do not occur, if the alarm processing logic can support such an analysis. 
ADDITIONAL INFORMATION: Such an analysis may apply, for example, during certain transients (e.g., reactor scram) where the expected alarm pattern is well known.

Discussion: Processing techniques which generate new alarms present a paradox. Alarm systems should facilitate the reduction of heuristics-initiated errors which often reflect the overloaded operator's incomplete processing of information (Norman, 1988; Reason, 1987, 1988, 1990). Alarm generation features may help mitigate these problems by calling the operator's attention to plant conditions that are likely to be missed due to the operator's bias toward "capture" errors. However, this type of alarm processing should be used judiciously because the generation of new alarms has the potential of increasing demands on operators, thus potentially exacerbating the original problem. In addition, this guideline is consistent with the high-level design review principle of Situation Awareness (see Appendix A).

SOURCE: Authors, NUREG/CR-3987.

\section{3-12 Processing Complexity}

Processing methods should not be so complex that operators have difficulty evaluating the meaning or validity of the resulting alarm messages.

ADDITIONAL INFORMATION: Complexity of the processing impacts the operator's ability, as the system supervisor, to understand the results of alarm processing and to understand its constraints and limitations. Since the alarm system is the operator's first indication of process disturbances and operators will confirm the validity of alarm signals prior to taking action, it is essential that operators easily comprehend the meaning of alarm data, how they are processed and the bounds and limitations of the system. An alarm system that combines multiple processing methods should not be so complex that it cannot be readily understood and interpreted by the operators who must rely on the system's information.

Discussion: The concept of information "decomposition" used in the expert-system domain is particularly relevant here. This concept states that users should be able to access progressively greater levels of detail, including processing rules, and sensor values in order to understand the basis upon which the system is providing recommendations. (See NUREG-0700, Revision 1 for guidelines related to expert system interface design review). In addition, this guideline is consistent with the high-level design review principles of Logical/Explicit Structure and Simplicity of Design (see Appendix A).

SOURCE: Authors.

\section{3-13 Processing Override}

Operators should have the capability of viewing inputs to the alarm processing system (e.g., sensor data).

ADDITIONAL INFORMATION: Operators may need to view sensor data and values that result from alarm system processing under certain circumstances such as if the pattern of alarm messages appears to be contradictory or if operators suspect that there is a problem with the processing system such that the results of alarm processing are incorrect.

Discussion: This guideline is consistent with the high-level design review principles of Logical/Explicit Structure User Guidance and Support, and Flexibility (see Appendix A). 
SOURCE: Authors.

\subsection{Alarm Prioritization and Availability}

\section{4-1 Prioritization Criteria}

Alarm messages should be presented to the operators in prioritized form based on one or more prioritization dimensions to indicate immediacy of required operator action and challenges to plant safety.

ADDITIONAL INFORMATION: Alarm priority dimensions and classifications, other than immediacy of required operator action and challenges to plant safety, may also be implemented. The selected prioritization scheme should be logical such that those alarms of the highest safety significance receive the highest priority and such that the prioritization appears reasonable to operators.

Discussion: Alarm prioritization has been determined to be required in order for an alarm system to meet alarm system functional criteria as described in NUREG/CR-3217. In addition, this guideline is consistent with the high-level design review principles of Situation Awareness and Task Compatibility (see Appendix A).

SOURCE: NUREG-0700, NUREG/CR-3217, EPRI NP-3659, IEC 964, Authors.

\section{4-2 Number of Priority Levels}

The number of priority levels within a dimension should be no greater than four.

ADDITIONAL INFORMATION: Prioritization schemes with many levels may require operators to devote excessive attention to the priority level and thus reduce the benefits of prioritization.

SOURCE: NUREG-0700, EPRI NP-3448.

\section{4-3 Suppressed Alarms}

When alarm suppression is used, the operator should be able to access the alarm information that is not displayed.

ADDITIONAL INFORMATION: Suppressed alarms are not presented to the operators, but they can be accessed by operators upon request. The method for accessing suppressed alarms and the scheme for their presentation to the operators should not be excessively complex.

Discussion: This guideline is consistent with the high-level design review principles of Logical/Explicit Structure User Guidance and Support, and Flexibility (see Appendix A).

SOURCE: Authors, EPRI ALWR, IEC 964. 


\section{4-4 Filtered Alarms}

Alarm filtering should only be employed where alarm messages have no operational significance to the crew's monitoring, diagnosis, decision making, procedure execution, and alarm response activities.

ADDITIONAL INFORMATION: As the term is used here filtered (as contrasted with suppressed) alarm messages are eliminated and are not available to the operators. Research has indicated that operators prefer to have information available to them to support verification and decision-making activities. Thus only alarms that can be demonstrated to have no operational significance to operators should be filtered. This includes, alarm messages that are irrelevant within the context of the current plant mode or the configuration of the associated plant system. For example, alarm messages that indicate that a pump discharge pressure is low after the fluid system has been removed from service should be filtered. Alarms that are considered redundant or lower priority should be suppressed (where operators can retrieve them) rather than filtered.

Discussion: This guideline is consistent with the high-level design review principle of Task Compatibility (see Appendix A).

SOURCE: Authors.

\subsection{Display}

\subsubsection{General Alarm Display Guidelines}

\subsection{1-1 Display Functions}

The alarm display should support the operator's ability to rapidly discern:

- The priority (e.g., urgency for operator action and importance to plant safety)

- $\quad$ Distinct alarm states: new, acknowledged, and cleared

- The first-out alarms for reactor trip.

- $\quad$ The need to access other displays to verify or clarify the alarm state

- The difference between alarms which can be cancelled through ongoing corrective actions (i.e., by operations personnel) and alarms that require significant maintenance intervention.

SOURCE: NUREG-0700, IEC 964, EPRI NP-3659.

\subsection{1-2 Independence of Alarm Alerting and Informing Functions}

When alarm alerts are displayed separately from detailed alarm information, the design should support the operator in making rapid transitions between alerts and detailed information.

ADDITIONAL INFORMATION: In conventional annunciator tile-based alarm systems the annunciator tile performs both the alerting function (i.e., providing a salient indication of the presence of an alarm condition) and the informing function (i.e., providing information that describes the nature of the alarm condition). In advanced alarm systems the alerting and informing functions may be separated. For example, an alarm tile display may alert the operator 
to the presence of an alarm condition while an alarm message list display may provide detailed information such as the alarm parameter name and setpoint value. The presentation of the alerting and informing information should be coordinated so the operator can rapidly access detailed alarm information associated with the alarm condition alerts.

Discussion: This guideline is consistent with the high-level design review principles of Task Compatibility and Response Workload (see Appendix A).

SOURCE: Authors.

\subsection{1-3 Presentation of Alarm Priority with Detailed Alarm Information}

When alarm alerts are displayed separately from detailed alarm information, the detailed alarm information display should provide an indication of the priority and status of the alarm condition.

ADDITIONAL INFORMATION: The operational significance of the detailed alarm information, such as the parameter name and the exceeded setpoint value, may be more readily apparent to the operator when accompanied by an indication of alarm condition priority and status (e.g., new, acknowledged).

Discussion: This guideline is consistent with the high-level design review principles of Task Compatibility and Response Workload (see Appendix A).

SOURCE: Authors.

\subsection{1-4 Use of Spatially-Dedicated, Continuously-Visible Displays}

Spatially-dedicated, continuously-visible (SDCV) alarm displays should be considered for:

- $\quad$ Regulatory Guide 1.97 Category 1 parameters

- $\quad$ alarms that require short-term response by the operators

- main alarms used by operators in diagnosing and responding to plant upsets

- main alarms used by operators to maintain an overview of plant and system status.

ADDITIONAL INFORMATION: Spatial dedication means that the alarm messages always appear in the same position. Continuously visible means a parallel presentation method is used, i.e., the alarm information is always available to the operator, as opposed to serial presentation methods in which the operator must select the information to be seen. A SDCV alarm display (such as is provided by conventional tiles) has generally been found during high-density alarm conditions to be superior to a spatially focused, variable location, serial display (as has been typical of some computer-based presentations, such as on CRT or flat panel displays). SDCV displays provide perceptual advantages of rapid detection and enhanced pattern recognition. Note that VDU displays can be used as SDCV alarm displays, but the space required for this type of alarm display can make their use impractical when a large number of alarms is to be presented.

Discussion: Direct comparisons of operator performance under spatially distributed but fixed alarm display (conventional boards) versus focussed but variable alarm display (computer-based system) are of significant 
interest. EPRI performed a series of tests examining the role of conventional and CRT-based alarm presentations (Fink et al., 1992). The study investigated alternative systems for alarm presentation including (1) alarm tile display alone, (2) CRT display alone, and (3) combined tile and CRT alarms (additional display conditions were also evaluated). Fifteen licensed operators participated in the tests using an alarm system (not a full-mission) simulator. Performance measures included the speed and accuracy with which operators could extract information from the alarm system and operators' opinions on ease of use and other subjective parameters. The results indicated that the grouping of alarms by system and function improves performance. This was consistent with the finding of an earlier EPRI study (Fink,1984). Interestingly, the conventional alarm system allowed the operators to obtain information more quickly and easily than did the CRT presentation.

Matsushita (1988) requested experienced operators to evaluate an advanced control room design after using the design in simulated scenarios. The alarm display system was CRT-based. The operators indicated that the CRT displays were sufficient when few alarms were presented. However, during accident or transient conditions, the CRT system made problem identification harder than it was when using the conventional alarm system. The advanced control room design was modified to include both a conventional alarm system and the CRT-based system.

Kragt (1984) compared three types of alarm systems in terms of their effects on human performance. The main objective of the comparison was to evaluate the parallel versus sequential presentation of alarms. The three systems were (1) the conventional lighted window arrangement, (2) a CRT-based model similar to the conventional system, and (3) a CRT-based sequential textual alarm presentation. A laboratory simulation was set up to make the comparison, and 24 chemical plant trainees served as test subjects. Operator errors and difficulty ratings were the main dependent variables. The results indicated that the sequential presentation of alarms was inferior both in terms of operator performance and subjective ratings. The differences between presentation modes was even greater during high alarm density conditions. The lack of operator ability to recognize a pattern of alarms was offered as an explanation for the advantages of parallel alarm presentation.

Operator preference for conventional systems has been found in other studies as well (e.g., Kragt, 1982; Rankin, 1985; and Wickens, 1987). Wickens (1987) found increased memory load for computer-based display presented information and a loss of spatial organization of information which facilitates information processing.

Data obtained via survey and/or anecdote provide similar results. MPR (1985) surveyed utilities in North America to identify potential alarm improvements. In plants having both conventional and VDU alarm displays, operators reported a preference for the VDU alarms during normal power operations when the number of alarms is small but a preference for the conventional systems during plant upsets when the number of alarms was large. In the Canadian plants surveyed, while VDU-based displays are the primary method of alarm presentation, an increasing trend toward conventional alarm presentations had been observed. One of the major problematic issues was the method of alarm presentation. When alarm data are presented as message lists on a CRT, the display becomes difficult to manage during plant upsets. In fact, the authors state that "there is clear evidence that CRT message lists are a poorer method of presenting alarms that the conventional alarms that they 'supplement'." More recently, CRT alarm message flooding has been identified as a significant problem in some Canadian plants (Sheehy et al., 1993; Moore et al., 1993). Operator problems with VDU-based message displays in high density situations have been noted in other field observations (Corsberg, 1988).

The EPRI ALWR document requires the use of spatially dedicated, continuous, and parallel display (such as a tile-based system) for (1) main process alarms used by operators in diagnosing and responding to plant disturbances, (2) alarms used to maintain an overview of plant and system status, and (3) alarms that 
require short-term response by operators. NUREG/CR-3987 recommends such a display for "most critical warning information." EPRI NP-3659 recommends the use of tile displays for indicating deviant plant conditions that require immediate access to displays to verify alarms. NUREG/CR-3987 indicates that alarm systems should include both variable (e.g., VDU-displayed) warnings and permanent, spatially dedicated (e.g., tile-displayed) alarms.

In addition, this guideline is consistent with the high-level design review principles of Situation Awareness and Cognitive Workload (see Appendix A).

SOURCE: Authors, EPRI ALWR.

\subsection{1-5 Alarm Graphics}

The graphics related to alarm presentation should be designed such that the display is fully contained in one VDU screen.

ADDITIONAL INFORMATION: For example, the operators should not have to scroll the graphic of the overall reactor system, a major subsystem such as the primary system, or a portion of the subsystems such as the pressurizer to access a complete set of related alarm messages.

SOURCE: NUREG/CR-3987.

\subsection{1-6 Alarm Coding Consistency}

Coding (e.g., flash-rate, intensity, and color coding) conventions should be consistently applied throughout alarm displays (e.g., on tiles and VDU).

SOURCE: EPRI NP-3659.

\subsubsection{Display of High-Priority Alarms}

\subsection{2-1 Importance/Significance}

The display of important alarms should override the display of alarms of lower importance.

SOURCE: IEC 964.

\subsection{2-2 Simultaneous Display of High-Priority Alarms}

For non-spatially dedicated alarm presentations such as VDU message lists, sufficient display area should be provided for the simultaneous viewing of all high priority alarms.

ADDITIONAL INFORMATION: Non-spatially dedicated alarm displays, such as message lists, should generally not be used as the primary method of presenting high-priority alarm messages. If non-spatially dedicated alarm displays are used, they should have sufficient display space available for simultaneous presentation of all high priority alarms under worst credible conditions. Operators should never have to page or scroll a display to view high-priority alarms. 
Discussion: This guideline is consistent with the high-level design review principle of Response Workload (see Appendix A).

SOURCE: Authors, IEC 964, EPRI NP-3659, EPRI ALWR.

\subsection{2-3 Coding of Alarm Priority}

A method of coding the visual signals for the various priority levels should be employed.

ADDITIONAL INFORMATION: Acceptable methods for priority coding include color, position, shape, and symbolic coding. Color and position (top to bottom) are especially effective visual coding methods [NUREG/CR-3217]. However, coding priority by alarm element position can disrupt the functional grouping of elements and should not be used when the loss of functional grouping may affect the operator's ability to effectively use alarm information. In this case other dimension, such as color, should be used for priority coding.

SOURCE: EPRI NP-2411.

\subsubsection{Display of Alarm Status}

\subsection{3-1 Indication of Alarm Status}

New, acknowledged, and cleared alarm states should have unique presentations to support the operators ability to rapidly distinguish them.

SOURCE: EPRI NP-3448.

\subsection{3-2 New Alarms}

New alarms should be indicated both by visual (e.g., flashing) and audible means.

SOURCE: NUREG/CR-3987, EPRI NP-3448.

\subsection{3-3 Notice of Undisplayed New Alarms}

If the operator is not currently using the VDU display where new, unacknowledged alarm messages appear, the alarm system should notify the operator that a new alarm message is available, the priority of the alarm message, and the location where the alarm message can be found.

SOURCE: NUREG/CR-3987. 


\subsection{3-4 Acknowledged Alarms}

After the operator has acknowledged an alarm (e.g., pressed the acknowledge button) the alarm display should change to a visually distinct acknowledged state and the alerting function (e.g., audible tone) should cease.

SOURCE: EPRI NP-3448, Author.

\subsection{3-5 Clearing Alarms/Ringback}

If the operator is required to take action when an alarm clears (i.e., the parameter returns to the normal range from an abnormal range), the return to normal conditions should be indicated by visual and audible means.

ADDITIONAL INFORMATION: Ringback, alerting the operator when a parameter returns to normal, should not be required for all alarms but should be required when it is important that the operator know immediately when the deviation has cleared, or when the deviation is not expected to clear for some time. Such cleared alarms should provide a positive indication by initiating audible and visual signals. Techniques that may be employed include: a special flash rate (twice or one-half the normal flash rate is preferred, to allow discrimination); reduced brightness; or a special color that is consistent with the overall control room color coding scheme. Cleared alarms should have a dedicated, distinctive audible signal which should be of finite and relatively short duration.

SOURCE: EPRI NP-3448, NUREG/CR-3217, NUREG-0700.

\subsubsection{Display of Shared Alarms}

\subsection{4-1 Minimize Shared Alarms}

Alarms with inputs from more than one plant parameter (shared alarms) should be minimized.

ADDITIONAL INFORMATION: Shared alarms are those formed from the combination of different process deviation conditions through "or" logic. For example, a "trouble" message may combine several potential problems associated with a single plant system or component, or it may address the same problem for a group of similar components (e.g., a bearing temperature alarm may address bearings from more than one component). When shared alarms are used, an inquiry capability should be provided to allow the operator to obtain specific information about which of the ganged parameters exceeded its setpoint. Criteria for the use/avoidance of shared alarms are given in Table 4.5.4-1. In traditional (i.e., tile-based annunciator) alarm systems, shared alarms imposed additional workload on the operator compared to single alarms because the operator had to identify the deviant parameter(s). This type of shared alarm should be minimized in advanced alarm systems. Some advanced alarm systems automatically present information related to the deviant parameter when the shared alarm is initiated. This reduces the operator workload associated with retrieving alarm information and minimizes the negative effects of shared alarms. 
Table 4.5.4-1. Shared Alarm Considerations

\section{TYPES OF ALARMS THAT MAY BE CONSIDERED FOR COMBINATION (SUBJECT TO THE RESTRICTIONS LISTED BELOW)}

- Alarms for the same condition on redundant components, or logic trains, when each has a separate indicator and the indicators are placed in close proximity on the console (e.g., pump A or B trip, logic train A or B actuation) [EPRI NP-3448]

- $\quad$ Alarms for several conditions relating to one component or several redundant components, which require the operator to obtain further diagnostic information either by sending an auxiliary operator out to the component(s) or checking the computer (e.g., pump A or B trouble) [EPRI NP-3448]

- Alarms for several conditions that call for the same corrective action [EPRI NP3659]

- Alarms that summarize single-input alarms elsewhere in the control room [NUREG-0700]

\section{CONDITIONS UNDER WHICH ALARMS SHOULD NOT BE COMBINED}

- Different actions are to be taken depending on which alarm condition exists and information is not readily available to the operator to identify which constituent is alarming [EPRI NP-3448]

- The required response must be initiated immediately, so that taking time to consult the control panel or the computer to determine which constituent is alarming would risk an inadequate operator response [EPRI NP-3448]

- Information or protection for other alarm constituents is not available to the operator after any one alarm constituent has activated the combined alarm (reflash can provide such protection as discussed above) [EPRI NP-3448]

- Operator understanding is improved by alarming the conditions separately because of similarity to the layout of associated controls [EPRI NP-3448]

The constituent conditions are not of a similar nature, or are not of the same order of importance, such that the action to be taken is very different depending on which condition is alarming [EPRI NP-3448]

SOURCE: NUREG-0700, EPRI NP-3659, EPRI NP-3448.

\subsection{4-2 Shared Alarm Identification}

Operators should have the capability to access the individual alarm information when a shared alarm activates.

ADDITIONAL INFORMATION: The information could be provided by means of alarm messages on a VDU, an alarm list on an alarm printer, or by other means. This information may be provided automatically or by operator action.

SOURCE: NUREG-0700. 


\subsection{4-3 Shared Alarm Reflash}

If a new parameter deviation has occurred before a preceding alarm has cleared, the shared alarm should return to the new alarm state (e.g., flashing).

ADDITIONAL INFORMATION: The alarm logic system should provide the capability to "reflash" (i.e., reactivate the visual and audible alert indications for the alarm) when subsequent alarm conditions occur after the initial alarm condition has been acknowledged.

SOURCE: EPRI NP-3659, EPRI ALWR, NUREG-0700.

\subsubsection{Alarm Messages}

\subsubsection{Content}

\subsubsection{1-1 Alarm Information Content}

The alarm should provide the following information:

- Alarm title or legend

- Alarm source, i.e., the particular sensor or group of sensors supplying the signal

- Alarm priority

- Setpoint values

- Parameter values

- Required immediate operator actions

- $\quad$ Reference to procedure for more detailed follow-up actions.

ADDITIONAL INFORMATION: This information should be presented whenever possible, so long as it does not result in a confusing display or overload the operator with information. It should be noted that conventional alarm systems generally cannot effectively supply most of this information, but advanced systems can by providing it on alarm display screens or on operatorselectable displays upon receipt of a given alarm. The system should not provide excessive information in a single display (e.g., by separately coding color, size, shape, flash rate, and sound). More detail on each of these individual information requirements is specified by subsequent guidance in this section.

SOURCE: NUREG-0700, NUREG/CR-3987, EPRI NP-3659, Authors.

\subsubsection{1-2 Alarm Tile/Legend}

Alarm legends should be clearly understandable, use standard terminology, and address conditions specifically.

ADDITIONAL INFORMATION: For example, specifically identify the parameter and state (e.g., HIGH PRESSURE) instead of using one legend for multiple parameters or multiple states (e.g., TEMPERATURE-PRESSURE or HIGH-LOW).

SOURCE: NUREG-0700. 


\subsubsection{1-3 Alarm Source}

The content of each message should provide information that identifies the alarm source.

ADDITIONAL INFORMATION: Information should be available as to which specific sensor (or group of sensors) supplied the alarm signal.

SOURCE: EPRI NP-3659.

\subsubsection{1-4 Alarm Priority}

Alarm messages should indicate its priority.

SOURCE: EPRI NP-3659, NUREG/CR-3987.

\subsubsection{1-5 Setpoint Values}

If an alarm condition requires verification before action is taken, the relevant setpoint limits should be included in the alarm message.

ADDITIONAL INFORMATION: NUREG/CR-3217 provides three reasons why setpoints should not be included in alarm displays. However, these reasons apply to conventional, not advanced alarm systems. First, the setpoint values may change and temporary labels will have to be used thus violating the human factors principle that states that labels should be as permanent as the equipment to which it is attached. While this may be a concern in conventional tile-like displays, computer-driven displays characteristic of advanced control rooms would not be subject to this limitation since the label is "soft." Second, the setpoint information only gives partial information (i.e., condition is above or below some set point), and the operator could assume that the condition is near the setpoint when in fact it is well above it or below it. However, parameter values should be given in alarm messages provided in VDU and printer displays (see Guideline 4.5.5.1-6) thus this objection is overcome. Third, adding this type of information goes against the principle that the alarm system should not encourage undue reliance. However, advanced control rooms should provide enhanced data integration and minimize the requirements for operators to integrate information from different sources, e.g., alarms and indicators. Thus, while the concerns expressed in NUREG/CR-3217 may apply to a conventional alarm system, setpoint values should be provided in an advanced system.

SOURCE: EPRI NP-3659, Authors.

\subsubsection{1-6 Parameter Values}

Where alarm information is presented on VDU or printer displays, deviant parameter values should be included in the alarm message.

SOURCE: EPRI NP-3659. 


\subsubsection{1-7 Required Immediate Operator Actions}

Where alarm information is presented on VDU or printer displays, the immediate operator actions should be presented or made available directly upon operator request.

ADDITIONAL INFORMATION: To meet the general alarm system principle of guiding the operator's response to an alarm (see Guideline 4.1-1, Alarm System Functional Criteria), the immediate actions should be provided to the operator. For conventional alarm systems, the immediate operator actions should be available in Alarm Response Procedures that are clearly and simply keyed to an alarm tile and located nearby for easy and quick reference. In this case, the procedure would contain those items noted in Guideline 4.5.5.1-1, Alarm Information that could not be incorporated into the alarm display itself (e.g., alarm source, setpoint value, immediate actions, and follow-up actions).

SOURCE: Authors.

\subsubsection{1-8 Reference to Procedures}

Where alarm information is presented on VDU or printer displays, references to alarm response procedures should be provided.

ADDITIONAL INFORMATION: The document title, major section, and page number should be included in such references.

Discussion: In NUREG/CR-3217, keying procedures to alarms was considered an alarm system requirement to meet alarm system functional criteria.

SOURCE: EPRI NP-3659.

\subsubsection{1-9 Reference to Other Panels}

Alarms which refer the operator to another, more detailed display located outside the primary operating area should be minimized.

ADDITIONAL INFORMATION: Advanced alarm systems should be designed such that required information is readily accessible from within the primary operating area.

SOURCE: NUREG-0700.

\subsubsection{Format}

\subsubsection{2-1 Format for Tile Displays}

The format of messages on alarm tiles or tile-like displays should be consistent for all alarms. 
ADDITIONAL INFORMATION: EPRI NP-3659 provides the following example: top line, name of alarmed parameter; middle line, alarm setpoint value; bottom line, indication of severity.

SOURCE: EPRI NP-3448.

\subsubsection{2-2 Format of VDU and Printer Messages}

The alarm message format should be consistent for VDU and printer message displays.

SOURCE: EPRI NP-3659.

\subsubsection{Coding Methods}

\subsubsection{General}

\subsubsection{1-1 Coding Effectiveness}

The coding scheme used by the alarm system should assure rapid detection and interpretation by the operators under all control room operating conditions.

SOURCE: NUREG-0700.

\subsubsection{1-2 Coding Dimension Discriminability}

Each level of a coding dimension should be easily and readily distinguishable from the other levels.

ADDITIONAL INFORMATION: For example, if color is used the different colors should be easily discriminated. Each color should have a single, precise meaning consistent with its use in the rest of the HSI. In addition, color should not be used in a manner that is counter to cultural stereotypes. A formal coding scheme that encompasses all coding dimensions (e.g., color, shape, brightness, textures/patterns, flashing) and specifies a hierarchical order of salience should be established and formally documented before any coding is applied to the displays. Alarm information should be organized into categories according to a scheme for priority. Coding dimensions should be systematically applied to these categories such that alarm information with the highest priority is also most salient.

SOURCE: EPRI NP-3448.

\subsubsection{1-3 Confounding Coding Techniques}

For coding techniques being used to support detection and recognition of status within an alarm dimension, each coding technique should represent one dimension of alarm classification. 
ADDITIONAL INFORMATION: If flashrate is being used to indicate alarm state (e.g., new, acknowledged, cleared), it should not also be used to indicate need for operator action (e.g., immediate action required, action required within 15 minutes, no near-term action needed).

SOURCE: EPRI NP-2411, Authors.

\subsubsection{1-4 Coding Complexity}

The number of different coding techniques should be kept to a minimum, so that the overall coding system does not become difficult to understand.

SOURCE: EPRI NP-2411, Authors.

\subsubsection{Visual}

\subsubsection{2-1 Visual Signal for Important Alarms}

A flashing visual signal should be included for all important alarms.

ADDITIONAL INFORMATION: An effective alarm system will capture and direct the operator's awareness under any and all conditions. Under high alarm volume conditions, the designer may consider suppressing or delaying the alerting indications (e.g., visual flashing) for those alarm conditions that (a) do not require immediate response, and (b) that do not indicate a challenge to plant safety and technical specifications. This will assist operators in detecting the more significant alarm messages and reduce distraction from less important ones.

Discussion: This guideline is consistent with the high-level design review principles of Situation Awareness and Cognitive Workload (see Appendix A).

SOURCE: Authors.

\subsubsection{2-2 Redundant Coding Dimensions}

Redundant codes (e.g., fast flashing, bright) should be used for alarms that require rapid operator action.

SOURCE: EPRI NP-3659.

\subsubsection{2-3 Flash Rate}

Flash rates should be from three to five flashes per second with approximately equal on and off times.

SOURCE: NUREG-0700. 


\subsubsection{2-4 Brightness Levels for Transilluminated Displays}

For transluminated display, such as lighted alarm tiles, the brightest state should be no more than $300 \%$ brighter than the inactivated state and the dim state should be at least $10 \%$ brighter than the inactivated state.

ADDITIONAL INFORMATION: Brightness of "on" alarms should not annoy or distract operators.

SOURCE: EPRI NP-3659, EPRI NP-3448.

\subsubsection{2-5 Brightness Levels for VDU Displays}

For VDU displays, the bright state should be at least $100 \%$ brighter than the inactivated state.

ADDITIONAL INFORMATION: While transilluminated alarms may display more than two levels of brightness, VDU displays should be limited to only two levels.

SOURCE: DoD-HDBK-761A.

\subsubsection{2-6 Color Detectability}

Where color coding is used, low-intensity or color (e.g., dark red) indications in the periphery of the visual field should be avoided, since they may not be readily detected.

ADDITIONAL INFORMATION: If the display system has an area that is a specific focus of attention, then displays located in adjacent areas may frequently be in the operator's periphery of the operator's field of vision.

SOURCE: EPRI NP-3659.

\subsubsection{2-7 Spatial Coding}

Spatial coding may be used to depict alarm importance.

ADDITIONAL INFORMATION: Spatial coding can be effective especially in VDU types of alarm presentation. In an otherwise variable alarm display, having a dedicated or consistent location for presentation of important alarms will enhance to operators ability to detect them. Spatial coding is related to alarm organization which is addressed in Section 4.5.7.

Discussion: This guideline is consistent with the high-level design review principle of Cognitive Workload (see Appendix A).

SOURCE: Authors. 


\subsubsection{2-8 Suppressed Visual Codes}

If the visual coding used to indicate alarm status is automatically suppressed or delayed during high alarm volume conditions or the presence of more important alarms, they should be automatically presented after the more important alarms have been addressed.

ADDITIONAL INFORMATION: Plant personnel should not be required to remember to request alarm automatically suppressed.

Discussion: This guideline is consistent with the high-level design review principles of Situation Awareness, Cognitive Workload, and Error Tolerance and Control (see Appendix A).

SOURCE: Authors.

\subsubsection{Audible Codes}

\subsubsection{3-1 Audio Signal for Important Alarms}

An auditory signal should be used to alert the operator to the existence of a new alarm, or any other condition of which the operator must be made immediately aware.

ADDITIONAL INFORMATION: Auditory cues should be provided for all new alarms under normal operating conditions. However, under off-normal conditions where high alarm density exists, the designer should consider suppressing the auditory signal for those alarmed conditions that (a) do not require immediate response and (b) do not indicate a challenge to plant safety and technical specifications. For example, audio signals associated with clearing alarms might be omitted under certain circumstances. This will prevent operators from being distracted by less important alarms while attending to more significant ones.

Discussion: This guideline is consistent with the high-level design review principles of Situation Awareness, Cognitive Workload, and Response Workload (see Appendix A).

SOURCE: Authors.

\subsubsection{3-2 Auditory Coding of Remote Alarms}

Auditory coding techniques should be used when the operator workstation associated with the alarm is not in the primary operating area.

ADDITIONAL INFORMATION: During off-normal conditions the designer should consider the suppression of the auditory code for those alarms that (a) do not require immediate response and (b) do not indicate a challenge to plant safety and technical specifications. This will prevent operators from being distracted by less important alarms while attending to more significant ones.

SOURCE: NUREG-0700. 


\subsubsection{3-3 Distinguishable Auditory Signals}

The auditory signal associated with a SDCV alarm should be easily distinguishable from the auditory signal associated with an alarm message displayed by other means (e.g., on a VDU message display).

SOURCE: NUREG/CR-3987.

\subsubsection{3-4 Audible Signals for Alarm States}

The tones used for incoming alarms should be separate and distinct from tones used to signify "clearing" alarms, which should be momentary or "self-silencing."

SOURCE: EPRI ALWR.

\subsubsection{3-5 Reminder Audible Signals}

If the tone to indicate an unacknowledged alarm automatically turns off after an interval of time, a reminder tone should be presented to alert the operator to the alarm's unacknowledged status.

ADDITIONAL INFORMATION: The same principle holds for alarms which may have had the auditory code suppressed because of high alarm conditions or the presence of more important alarms. When the more important alarms have been addressed, the alarm system should remind the operator of the presence of the unacknowledged alarms.

Discussion: This guideline is consistent with the high-level design review principles of Situation Awareness, Cognitive Workload, and Error Tolerance and Control (see Appendix A).

SOURCE: Authors.

\subsubsection{3-6 Reset of Auditory Alert}

The auditory alert mechanism should automatically reset when it has been silenced.

SOURCE: NUREG-0700.

\subsubsection{3-7 Interference Among Signals}

Audio alarm signals should not conflict with other auditory codes or signals.

ADDITIONAL INFORMATION: If continuous, relatively loud signals are used, they may render other codes and signals less audible. Thus it may be necessary to consider the audibility of a signal not just in the presence of ambient control room noise, but also in combination with other signals that might plausibly occur at the same time. To avoid mutual masking, the frequencies of tonal signals associated with alarms that may be active at the same time should be separated by at least $20 \%$ of the center frequency. Interference among alarm signals is less of a concern if the signals consist of a number of widely separated frequency components or of brief groups of pulses presented at intervals (e.g., Patterson, 1982). 
Discussion: This guideline is consistent with the high-level design review principle of Physiological Compatibility (see Appendix A).

SOURCE: NUREG-0700, Authors.

\subsubsection{3-8 Readily Identifiable Source}

The operator should be able to quickly determine where to direct attention (e.g., which functional area of the plant, or which station) from the characteristics of the auditory alert and/or the source from which the auditory alert originated.

ADDITIONAL INFORMATION: This guideline pertains to the use of auditory tones to direct the operator to the location of a spatially-fixed alarm display device in order to expedite the operator's response to the alarm condition. The use of sound to indicate the location of the alarm display may be of less value if the advanced alarm systems allows the same alarm message to be retrieved from multiple locations (e.g., from redundant VDUs) in the control room. It should also be noted that in advanced control rooms that feature compact control consoles the alarm display devices may not be physically separated enough to use sound localization as a cue. In this case, coded audio signals (possibly from a single source) would be used to direct the operators' attention. Thus, this guidance is most appropriate for advanced alarm systems that feature spatially-fixed alarm display devices. NUREG-0700 states that coded signals from a single audio source should not be used to identify individual workstations within the primary operating area. Similarly, EPRI NP-3659 recommends that each major console should be equipped with a separate sound generator capable of producing a distinctive sound. If the direction of a source sound is to be used as a cue, the signal should not be a high-frequency tone, since such signals can be difficult to localize.

SOURCE: EPRI ALWR, NUREG-0700, Authors.

\subsubsection{3-9 Signal Level}

The signal intensity should be such that operators can reliably discern the signal above the ambient control room noise.

ADDITIONAL INFORMATION: The intensity of an audio signal should be such that operators are alerted aurally to an alarm occurrence under the most adverse anticipated background noise conditions. NUREG-0700 states that a signal level $10 \mathrm{~dB}(\mathrm{~A})$ above average ambient noise is generally adequate. In EPRI NP-3659 it is recommended that sound intensity should be limited to a maximum of $95 \mathrm{~dB}(\mathrm{~A})$, but that signal levels of $115 \mathrm{~dB}(\mathrm{~A})$ may be used if considered absolutely necessary to achieve required attention-getting reliability for alarms indicating extreme danger. The tendency for designers to err on the side of conservatism results in many audio signals being more intense than is necessary to ensure reliable detection (see Guideline 4.5.6.310, Avoid Startle).

Discussion: Only that portion of a background sound within a narrow frequency range of the signal affects its detection. Accordingly, the levels of tonal signals should be specified relative to the masked threshold of the signals in the presence of the ambient noise, i.e., relative to the level at which the signal is just audible. A signal presented $15 \mathrm{~dB}$ above its masked threshold will be clearly audible; signals $25 \mathrm{~dB}$ or 
more above threshold are likely to be aversive. Masked thresholds can be determined by experiment in the control room, or estimated using the methods described by Patterson (1982). Assuming the frequency spectrum of background noise is fairly uniform, the threshold for a signal with frequency $f$ is equal to the spectrum level of the background noise at $f$ plus $10 \log (0.15 f)$. Note that the spectrum level is the noise power per cycle at the signal frequency, not the overall noise level. If the frequency spectrum of background noise varies more than $6 \mathrm{~dB}$ in the vicinity of the signal (.i.e., within $0.15 f$ ), a more complex estimation procedure can be used (Patterson, 1982).

SOURCE: NUREG-0700, EPRI NP-3448, EPRI NP-3659, Authors.

\subsubsection{3-10 Avoid Startle}

The signal should capture the operator's attention but should not cause irritation or a startle reaction.

ADDITIONAL INFORMATION: Irritation and startle resulting from the audible alarm signals should be minimized through the design of audio signals, the selection of signal intensity, and the overall design of the audible alarm scheme.

Discussion: When a high-intensity sound is switched on instantaneously (i.e., when the level of the sound rises more than $10 \mathrm{~dB} / \mathrm{msec}$ ) it is likely to produce a startle reaction. The onsets of audio signals should be shaped so that the signals reach maximum level over a period of 20 to $30 \mathrm{msec}$. This "rise time" is long enough to avoid startle, but not so long that the onset of the signal becomes less attention-getting. Signal shaping is easily done with digital sound generation equipment. Patterson (1982) recommends increasing intensity from zero to maximum using the first quarter cycle of a sine function with a frequency of about $10 \mathrm{~Hz}$. This results in a steep initial rise (typically masked by ambient noise) followed by a more gradual increase at higher levels.

SOURCE: NUREG-0700, EPRI ALWR, EPRI NP-3448, Authors.

\subsubsection{3-11 Manual Disable/Adjustment of Signal Intensity}

Manual disable or adjustment of auditory signal intensity (loudness) should be avoided.

ADDITIONAL INFORMATION: The need to adjust auditory signal level can be alleviated by improved signal design and level selection. If signal level is adjustable, it should be controlled by administrative procedure. Under no circumstances should operators be able to disable audio alarm signals or reduce their level so as to render them inaudible.

Discussion: Kragt and Bonton (1983) conducted an observational assessment of operator use of the alarm system at a chemical plant. During a process upset, the operators found the auditory alarm characteristics irritating and would typically silence the alarms as soon as possible without necessarily identifying the alarms that came in. This indicates that the audio characteristics of the alarms were poorly designed, e.g., causing distraction as a result of being unnecessarily loud or preventing communication by sounding continuously once activated. There are numerous reports in the human factors literature of operators defeating auditory alerts and silencing alarm systems (see Sorkin, 1989). In addition, this guideline is consistent with the high-level design review principle of Error Tolerance and Control (see Appendix A).

SOURCE: NUREG-0700, Authors. 


\subsubsection{3-12 Sound Sources}

The number and placement of loudspeakers should be such that auditory signals are free of distortion and are equally audible at any operator work station in the primary operating area.

ADDITIONAL INFORMATION: Speakers should be oriented away from surfaces that could scatter or diffuse the acoustic wave. Speakers should not be located behind structures that could cause distortion, echoes, or sound shadows. When sound localization is used to direct the operator to particular alarm display devices the loudspeakers should be oriented such that their location can be quickly discerned and their location corresponds to the location of the intended alarm display device. Loudspeakers for adjacent alarm display devices should have adequate separation to allow their individual locations to be discerned.

SOURCE: NUREG-0700, EPRI NP-3659.

\subsubsection{3-13 Auditory Signal Discriminability}

Each audio signal should be unambiguous and easily distinguishable from every other tone in the control room.

ADDITIONAL INFORMATION: Current sound generation technology allows the design of alarm signals that make better use of the operator's ability to process audio information. It is possible to design signals (e.g., Patterson, 1982) that are not only more discriminable from one another than are conventional signals, but have the potential to carry more information. Signals should be composed of unique combinations of tone pattern, and frequency. In addition, the location of the sound source should be unique if sound localization is to be used to direct the operator to a particular alarm display device. If the direction of a source sound is to be used as a cue, the signal should not be a high-frequency tone, since such signals can be difficult to localize.

Discussion: This guideline is consistent with the high-level design review principle of Physiological Compatibility (see Appendix A).

SOURCE: EPRI NP-3448, NUREG-0700, Authors.

\subsubsection{3-14 Number of Tonal Signals}

When information is coded by the pitch of narrow-band signals (i.e., tones), no more than three frequencies should be used.

ADDITIONAL INFORMATION: The frequencies should not be in a ratio of 2:1 with one another, since it can be difficult to identify pitches an octave apart. NUREG-0700 and NUREG/CR-3217 recommend that no more than 5 separate frequencies should be used. Some operators may not reliably distinguish among more than three pitch codes. For critical alarms with differing response requirements, the more conservative guidance should be followed. If 
more than three critical alarms are to be coded, it is preferable to combine pitch with another dimension to create more distinctive signals.

SOURCE: EPRI NP-3659, Authors.

\subsubsection{3-15 Frequency of Tonal Signals}

Center frequencies should be widely spaced within a range of from 500 to $3,000 \mathrm{~Hz}$, although a wider range of from 200 to $5,000 \mathrm{~Hz}$ may be acceptable.

ADDITIONAL INFORMATION: NUREG-0700 recommends that tonal signals be broad band $(+/-100 \mathrm{~Hz})$ and widely spaced within the $200-5000 \mathrm{~Hz}$ range.

SOURCE: EPRI NP-3659, Authors.

\subsubsection{3-16 Pulse Codes}

No more than three pulse repetition rates should be used for coding purposes.

ADDITIONAL INFORMATION: Repetition rates should be between 1 and 8 pulses per second, since faster rates may not be perceived as pulses. Repetition rates should be sufficiently separated (e.g., differ by a factor of 2 ) to ensure operator discrimination.

SOURCE: EPRI NP-3659, NUREG-0700.

\subsubsection{3-17 Number of Frequency Modulated Signals}

No more than three modulated frequency codes for audible alarms should be used.

ADDITIONAL INFORMATION: Warbling sounds, with frequencies modulating from 1 to 3 times per second, are attention-getting as well as easily recognized, whereas slower modulation rates do not develop distinguishable characteristics rapidly enough to be appropriate for alerting applications.

SOURCE: EPRI NP-3659.

\subsubsection{3-18 Center Frequency of Frequency Modulated Signals}

If modulation of frequency $(\mathrm{Hz})$ of a signal is used to denote information, the center frequencies should be between 500 and $1000 \mathrm{~Hz}$.

SOURCE: NUREG-0700.

\subsubsection{3-19 Audio Pattern Codes}

If sequences of tones are used to represent information, the patterns should be easily recognizable. 


\begin{abstract}
ADDITIONAL INFORMATION: Patterson (1982) recommends warning sounds consisting of "bursts" composed of five or more brief pulses (about .1 sec in duration) with inter-pulse intervals of .15 to .3 seconds. The pulses may be designed to be distinctive with respect to their onset and offset shaping, fundamental frequency, and harmonic structure. The bursts may vary as to the number of pulses, the tempo at which they are presented, and the rhythmic and pitch contours.

Discussion: The resulting signals might be described as brief syncopated melodies. These bursts are not presented continuously, but are repeated at appropriate intervals. For example, an incoming alarm might be accompanied by a burst, repeated 1-2 seconds later to give a busy operator, alerted by the first presentation, an opportunity to grasp the message. The signal might then remain off for several seconds, allowing operators to communicate if necessary. If the alarm were urgent and remained unacknowledged, the burst might then be repeated at greater volume and/or at a faster tempo. A less critical alarm might repeat less frequently at a slower tempo.
\end{abstract}

SOURCE: EPRI NP-3448, Authors.

\title{
4.5.6.3-20 Compound Codes
}

A maximum of nine auditory signals should be used when coded in two or more dimensions.

ADDITIONAL INFORMATION: When signals differ in two or more dimensions (e.g., pitch and temporal pattern) a greater number of signals can be reliably distinguished. This maximum includes auditory signals used outside of the control room (e.g., fire alarm or site emergency alarm). The number of conditions for which reliably recognizable audio codes can be used can be maximized by taking advantage of differences in the perceived urgency of warning sounds (Edworthy, Loxley, and Dennis, 1991).

SOURCE: NUREG/CR-3217.

\subsubsection{3-21 Intensity Coding}

Coding by intensity should not be used.

ADDITIONAL INFORMATION: The range of intensities between the level required to ensure audibility and the level at which signals become aversive can be relatively narrow; the usefulness of this dimension for coding is therefore limited. EPRI NP-3659 recommends that only two levels of audio intensity be used for coding. The signals should differ from each other by a minimum of $6 \mathrm{~dB}(\mathrm{~A})$. The lower intensity should be about $10 \mathrm{~dB}(\mathrm{~A})$ above the ambient noise level, and the maximum signal-to-noise ratio should be $10 \mathrm{~dB}(\mathrm{~A})$ for most applications of sound intensity coding. In EPRI NP-3659 it is recommended that sound intensity should be limited to a maximum of $95 \mathrm{~dB}(\mathrm{~A})$, but that signal levels of $115 \mathrm{~dB}(\mathrm{~A})$ may be used if considered absolutely necessary to achieve required attention-getting reliability for alarms indicating extreme danger. Whether this coding would be effective would depend on the frequency spectrum of the ambient control room noise and the frequency of the signal.

SOURCE: NUREG-0700, EPRI NP-3448, EPRI NP-3659, Authors. 


\subsubsection{Organization of Alarms}

\subsubsection{Spatially Dedicated, Continuously Visible Alarm Displays}

\subsubsection{1-1 Functional Grouping of Alarms}

Alarms within a display should be grouped by function, system, or other logical organization.

ADDITIONAL INFORMATION: Alarm elements should be grouped so that system functional relationships are readily apparent. For example, area radiation alarms should be grouped on one display, not spread throughout the control room. As much as possible, the alarms should be grouped with controls and displays of the same system.

SOURCE: NUREG-0700, EPRI ALWR, EPRI NP-3659.

\subsubsection{1-2 Separation of Functional Groups}

Alarm functional groups should be visually distinct from one another.

SOURCE: EPRI NP-3659.

\subsubsection{1-3 Group Labels}

System/functional groups should be clearly delineated and labeled such that the operating crew can easily determine which systems have alarms that have not yet cleared and which system is affected by a particular incoming alarm.

SOURCE: EPRI ALWR.

\subsubsection{1-4 Coordinate Designation Identifiers}

If alarm displays are organized in matrices, the vertical and horizontal axes of the displays should be labeled with alphanumerics for ready coordinate designation of a particular visual element.

ADDITIONAL INFORMATION: Coordinate designation is preferred on the left and top sides of the display.

SOURCE: NUREG-0700.

\subsubsection{1-5 Density of Alarm Elements}

An alarm tile display matrix should contain a maximum of 50 alarms per matrix.

ADDITIONAL INFORMATION: Matrices smaller than 50 alarms are preferred.

SOURCE: NUREG-0700. 


\subsubsection{1-6 Ordering of Parameters}

Alarms should be ordered to depict naturally occurring relationships.

ADDITIONAL INFORMATION: Naturally occurring relationships (e.g., those derived from the physical process) include the following:

- $\quad$ pressure, flow, level, and temperature alarms in fluid systems;

- $\quad$ alarms for a given thermodynamic parameter at different points within the system which indicate a progression (e.g., within a fluid system, a series of pressure alarms starting with the source tank and ending with the system discharge);

- $\quad$ several alarms for the same variable indicating levels of severity (e.g., tank level low and tank level low-low);

- alarms related by cause and effect.

For example, pressure, flow, level, and temperature could be arranged left-to-right.

SOURCE: EPRI NP-3448, EPRI NP-3659.

\subsubsection{1-7 Consistent Ordering}

Alarm parameters (e.g., level, flow, pressure and temperature) arranged in one order on one panel should be arranged in the same order on other panels.

ADDITIONAL INFORMATION: Once an arrangement has been chosen, the arrangement should be used consistently within similar systems or alarm groups. Redundant components identified as $\mathrm{A}, \mathrm{B}$, and $\mathrm{C}$ that are placed left-to-right for one alarm display should be placed consistently for all displays; and elements arranged in left-to-right order to represent how fluid flows through one system should be in the same order for other systems.

SOURCE: EPRI NP-3659.

\subsubsection{1-8 Alarm Display Identification Label}

Each group of alarm displays should be identified by a label above the display.

ADDITIONAL INFORMATION: A group of displays could be a panel of tiles or a group of VDU-type alarm displays.

SOURCE: NUREG-0700, Authors. 


\subsubsection{Alarm Message Lists}

\subsubsection{2-1 Listing by Priority}

Lists of alarm messages should be segregated by alarm priority with highest priority alarms being listed first.

\section{SOURCE: NUREG/CR-3987.}

\subsubsection{2-2 Message Listing Options}

In addition to priority grouping, operators should have the capability to group alarm messages according to operationally relevant categories, such as function, chronological order, and status (unacknowledged, acknowledged/active, cleared).

ADDITIONAL INFORMATION: For example, the alarm messages should be capable of being listed in chronological order with the most recent messages placed at the top of the stack (i.e., alarm messages entered in a pushdown stack mode). Grouping alternatives should not interfere with the operator's detection of high priority alarms.

SOURCE: NUREG/CR-3987.

\subsubsection{2-3 Blank Lines}

Alphanumeric alarm lists should have a separation (blank row) every four or five alphanumeric messages.

SOURCE: NUREG/CR-3987.

\subsubsection{2-4 Scrolling of Message List}

The method of adding alarm messages to the list should preclude message scrolling.

ADDITIONAL INFORMATION: Scrolling makes it difficult to read alarm messages, especially when many alarms are coming in. An alternative method of viewing alarm lists, such as paging, is preferred.

\section{SOURCE: NUREG/CR-3987.}

\subsubsection{2-5 Message Overflow}

Alphanumeric alarm messages that overflow the first page of alarm messages should be kept on subsequent alarm pages.

ADDITIONAL INFORMATION: Important alarm information should not be truncated solely because the immediate display space is exceeded.

SOURCE: NUREG/CR-3987. 


\subsection{Control}

\subsubsection{General Alarm Control Guidelines}

\subsection{1-1 Provisions for Control Functions}

Separate controls should be provided for silence, acknowledgment, reset (acknowledging an alarm that has cleared and returning it to normal) and testing.

ADDITIONAL INFORMATION: A variety of controls is possible, such as push buttons, function keys, and on-screen controls.

SOURCE: NUREG-0700, NUREG/CR-3987, EPRI NP-3448.

\subsection{1-2 Distinct Coding of Control Functions}

Alarm system controls should be distinctively coded for easy recognition.

ADDITIONAL INFORMATION: The controls should be distinguishable from each other, by touch and sight, to prevent accidental operation of the wrong control. Such techniques as color coding, color shading the group of alarm controls, demarcating the group of alarm controls, or shape coding should be used.

SOURCE: NUREG-0700, EPRI NP-3659, EPRI NP-3448.

\subsection{1-3 Consistent Layout of Control Group}

Each set of alarm system controls should have the functions in the same relative locations.

ADDITIONAL INFORMATION: Consistent locations should be established for silence, acknowledge, reset, and test operating sequence controls.

SOURCE: EPRI NP-2411, EPRI NP-3659, NUREG-0700.

\subsection{1-4 Separate Controls for Tile and VDU Alarms}

If the alarm system contains both alarm tiles and VDU alarm displays, each should have its own set of operator controls.

ADDITIONAL INFORMATION: If alarm information is presented redundantly on tile and VDU displays, then alarm acknowledgement via one device should cause the redundant alarm to be automatically acknowledged on the other device.

SOURCE: NUREG/CR-3987.

\subsection{1-5 Defeating Controls}

Alarm system control designs should not allow the operator to defeat the control. 
ADDITIONAL INFORMATION: For example, some pushbuttons used for alarm silencing and acknowledgement can be held down by inserting an object in the ring around the pushbutton. Some soft controls may be easily defeated in software. The alarm system should be designed to prevent the controls from being defeated.

Discussion: This guideline is consistent with the high-level design review principle of Error Tolerance and Control (see Appendix A).

SOURCE: NUREG-0700, Authors.

\subsection{1-6 Access to New Undisplayed Alarms}

A VDU-based alarm system should provide rapid access to any new alarm messages that are not shown on the current display.

ADDITIONAL INFORMATION: When a new alarm has been indicated, e.g., by an auditory indication, plant personnel should have rapid access to the alarm information that describes the nature of the alarm condition.

SOURCE: NUREG/CR-3987.

\subsubsection{Silence Controls}

\subsection{2-1 Effect of Silence Control}

It should be possible to silence an auditory alert signal from any set of alarm system controls in the primary operating area.

ADDITIONAL INFORMATION: It is not necessary that silence capability be provided only where the specific alarm can be read. The primary purpose of the auditory signal is to alert the operator to a new alarm. Once alerted the visual signal alerts the operator to the specific alarm and its message. The auditory signal can rapidly become distracting and irritating to the operators.

SOURCE: NUREG-0700, NUREG/CR-3987.

\subsection{2-2 Manual Silencing}

Auditory signals should be silenced manually by the operators unless this interferes with other more critical operator actions.

ADDITIONAL INFORMATION: While manual silence is a generally desirable feature to get the operator's attention, it may become distracting to manually silence all alarms under high alarm conditions. Guidelines 4.7-1 and 4.7-2 address alarm system configuration changes made either automatically or by operator-selection, such as automatic silence of auditory alerts for lower priority alarms under high alarm conditions.

SOURCE: NUREG/CR-3217. 


\subsubsection{Acknowledge Controls}

\subsection{3-1 Effect of Acknowledge Control}

An alarm acknowledgement control should terminate the flashing of an alarm and have it continue at steady illumination until the alarm is cleared.

SOURCE: NUREG-0700.

\subsection{3-2 Acknowledgement Locations}

Acknowledgement should be possible only from locations where the alarm message can be read.

ADDITIONAL INFORMATION: If alarm information is available at multiple VDUs, then operators should be capable of acknowledging the alarm from the VDU at which they are working. If alarm information is presented on a large control room overview display, operators should be able to acknowledge it from alarm control locations where it can be seen. This flexibility will minimize disruption caused by the alarm system interactions. It should not be possible to acknowledge alarms from locations where they cannot be read.

Discussion: This guideline is consistent with the high-level design review principle of Error Tolerance and Control (see Appendix A).

SOURCE: Authors.

\subsection{3-3 Acknowledgement of Alarm Messages}

Non-SDCV alarms should only be acknowledged when the alarm message is on the screen.

ADDITIONAL INFORMATION: Alternatively, the acknowledgement action may display the alarm message.

Discussion: This guideline is consistent with the high-level design review principle of Error Tolerance and Control (see Appendix A).

SOURCE: NUREG/CR-3987, Authors.

\subsubsection{Reset Controls}

\subsection{4-1 Effect of Reset Control}

The reset control should place the alarm system in an unalarmed state after an alarm has cleared.

ADDITIONAL INFORMATION: The reset control should silence any audible signal indicating clearance and should extinguish the light and return the alarm to an inactive state. Note that 
some alarms may have automatic reset, when it is not necessary that the operators specifically know the reset condition.

SOURCE: NUREG-0700.

\subsection{4-2 Appropriate Use of Manual Reset}

A manual reset sequence should be used where it is important to explicitly inform operators of a cleared condition that had once been deviant.

ADDITIONAL INFORMATION: An automatic reset sequence should not be used in this situation.

SOURCE: EPRI NP-3659.

\subsection{4-3 Appropriate Use of Automatic Reset}

An automatic reset sequence should be available where operators have to respond to numerous alarms or where it is essential to quickly reset the system.

ADDITIONAL INFORMATION: A manual reset sequence should not be used in these situations.

SOURCE: EPRI NP-3659.

\subsection{4-4 Reset Control Location}

The reset control should be effective only from locations at which plant personnel know which alarm they are resetting.

Discussion: This guideline is consistent with the high-level design review principle of Error Tolerance and Control (see Appendix A).

SOURCE: NUREG-0700, Authors.

\subsection{Automated, Dynamic, and Modifiable Characteristics}

\section{7-1 Automated Alarm System Configuration}

If the alarm system automatically changes operational configurations under some alarm situations, then these configuration changes should be coupled with an alert to the operator and an indication that the configuration has changed.

ADDITIONAL INFORMATION: Alarm systems may provide automated functions under some alarm situations, such as automatic silence of auditory alerts for lower priority alarms under high alarm conditions. It is important that operators be notified of the change in system functioning. In addition, a prominent display of the present configuration should be available to remind operators of the current configuration of the system. 
Discussion: The configurable aspects of the alarm system can give rise to operator error due to confusion over changing modes of operation. A common human error, called "mode error," in digital, reconfigurable systems is failure to recognize the current operating mode of the system in use and, as a result, improperly interpret and use the information provided (Cook, Woods, and Howie, 1990; Sarter and Woods, 1992). In addition, this guideline is consistent with the high-level design review principles of Situation Awareness, Feedback, and Error Tolerance and Control (see Appendix A).

SOURCE: Authors.

\section{7-2 Operator-Selectable Alarm System Configuration}

If the alarm system provides operator-selectable operational configurations, then these configuration changes should be coupled with an indication of the present configuration.

ADDITIONAL INFORMATION: Alarm systems may provide the capability for operators to select alternative functional configurations of the alarm system under some alarm situations, such as automatic silence of auditory alerts for lower priority alarms under high alarm conditions. Another example may be operator selection of an alarm message suppression mode in which low priority messages are not presented via the alarm displays but may be accessed through operator action. It is important that the alarm system informs the operators that a requested change in system configuration has been successfully achieved. In addition, a prominent display of the present configuration should be available.

Discussion: See discussion of mode error in Guideline 4.7-1.

\section{SOURCE: Authors.}

\section{7-3 Acknowledgement of Alarm System Configuration Changes}

If a significant alarm system configuration change is to be made either automatically or by operator-selection, operator acknowledgement (or confirmation) of the change should be required.

ADDITIONAL INFORMATION: Alarm systems may provide the capability for operators to select alternative functional configurations of the alarm system under some alarm situations, such as automatic silence of auditory alerts for lower priority alarms under high alarm conditions. Another example may be operator selection of an alarm message suppression mode in which low priority messages are not presented via the alarm displays but may be accessed through operator action. It is important that the alarm system informs the operators that a requested change in system configuration has been successfully achieved. In addition, a prominent display of the present configuration should be available.

Discussion: See discussion of mode error in Guideline 4.7-1.

SOURCE: Authors. 


\section{7-4 Operator-Defined Alarms/Setpoints}

The alarm system may provide temporary, operator-defined alarms and operator-defined set points for specific conditions where such alarms are determined to be of assistance to the operators in selected evolutions (e.g., temporary alarms to support increased monitoring of a problem component, or at other times when the operator wants to know of a parameter trend that is approaching a limit).

ADDITIONAL INFORMATION: In addition, administrative controls should control the definition and removal of operator-defined alarm system characteristics.

Discussion: See discussion of mode error in Guideline 4.7-1.

SOURCE: EPRI ALWR, Authors.

\section{7-5 Interference of Operator-Defined Alarms/Setpoints with Existing Alarms}

Operator-defined alarms and setpoints should not override or interfere with the existing alarms and setpoints.

ADDITIONAL INFORMATION: In addition, administrative controls should control the definition and removal of operator-defined alarm system characteristics.

Discussion: This guideline is consistent with the high-level design review principle of Error Tolerance and Control (see Appendix A).

SOURCE: Authors.

\section{7-6 Control of Operator-Defined Alarms/Setpoints}

The alarm system should provide clear indication of operator defined alarms and setpoints as distinct from the alarm/setpoints designed into the system.

ADDITIONAL INFORMATION: In addition, administrative controls should control the definition and removal of operator-defined alarm system characteristics.

Discussion: See discussion of mode error in Guideline 4.7-1.

SOURCE: Authors.

\section{7-7 Automatic Mode-Defined Setpoints}

If an alarm system provides automatic adjustment of setpoints for different plant modes or conditions, the need for operator acknowledgement/confirmation of the significant changes should be evaluated.

ADDITIONAL INFORMATION: Alarm systems may alter setpoints in a effort to minimize nuisance alarms. While, such changes may be associated with well-understood, easily recogniz- 
able plant conditions, others may be less familiar and not readily understood by plant personnel. In the latter situation, plant personnel may misunderstand the alarm information because they do not realize the setpoints have changed. When this situation is of concern, operator confirmation of the change should be considered.

Discussion: See discussion of mode error in Guideline 4.7-1.

SOURCE: Authors.

\subsection{Reliability, Test, Maintenance, and Failure Indication}

\subsubsection{Reliability}

\subsection{1-1 Design for Reliability}

The alarm system should be designed so that no single failure will result in the loss of a large number of alarms.

Discussion: This guideline is consistent with the high-level design review principle of Error Tolerance and Control (see Appendix A).

SOURCE: Authors.

\subsection{1-2 VDU Reliability}

Where alarms are presented on a VDU as the primary display, operators should be able to access the alarms from more than one VDU.

ADDITIONAL INFORMATION: Failure of a single VDU should not remove the operator's access to VDU-based alarm presentations at their primary workstation. Alarm printer displays should not be the only back-up to a VDU display.

Discussion: This guideline is consistent with the high-level design review principle of Error Tolerance and Control (see Appendix A).

SOURCE: Authors.

\subsection{1-3 Dual Light Bulbs}

Annunciator tile-type displays should be designed with dual light bulbs so that a single bulb failure will not interfere with the operator's detection of the alarm condition.

ADDITIONAL INFORMATION: Alarm system displays should be designed with a high level of reliability. In the case of annunciator tile displays, each tile should be lit by two or morc light bulbs to protect against loss of indication due to failure of a light bulb.

SOURCE: EPRI NP-3448. 


\subsection{1-4 Flasher Failure Mode}

In case of flasher failure of an active alarm element, the element should assume a highly salient state such as a high flash rate or a steady on (e.g., illuminated) state rather than a less salient state such as off.

ADDITIONAL INFORMATION: NUREG-0700 states that in the case of a flasher failure the active alarm element should remain on (e.g., illuminated). However, a unique and highly salient code is preferred. The code should be unique to prevent confusion between new and acknowledged alarms. It should be salient to alert the operator to the malfunction of the alarm display system. In addition, other alerting mechanisms such as warning messages may be used to inform the operator of a malfunction in the alarm display system.

Discussion: This guideline is consistent with the high-level design review principles of Situation Awareness and Error Tolerance and Control (see Appendix A).

SOURCE: NUREG-0700, Authors.

\subsubsection{Test}

\subsection{2-1 Test Availability}

Test controls should be available to initiate operational test conditions for all essential aspects of the alarm system (including processing logic, audible alarms, and visual alarm indications).

SOURCE: NUREG-0700, EPRI NP-3659, EPRI NP-3448.

\subsection{2-2 Testing Requirement}

Periodic testing of the alarm system should be required and controlled by administrative procedure.

ADDITIONAL INFORMATION: Simple functional tests are normally required once per operating shift. Reliability analyses of the alarm system may be used to determine appropriate intervals and degree of testing to be performed on the alarm system.

SOURCE: NUREG-0700.

\subsubsection{Maintenance}

\subsection{3-1 Design for Maintainability}

The alarm system should be designed so that maintenance activities can be performed with minimal interference with the activities of the operators. 
ADDITIONAL INFORMATION: Desirable design features may include built-in test capabilities, modular components that can be rapidly removed and replaced, and rear access panels which prevent maintenance activities for obstructing the operator's view of controls and displays.

SOURCE: Authors, EPRI NP-3448.

\subsection{3-2 Tagged-Out Alarms}

Tagging out an alarm (taking it out of service) should require disabling of the associated visual and audio signals.

ADDITIONAL INFORMATION: A tagged-out alarm should never be lighted or flashing, and should never cause any audible device to sound.

SOURCE: EPRI NP-3448.

\subsection{3-3 Maintenance Alarm Indication}

Cues for prompt recognition of an out-of-service alarm should be designed into the system.

ADDITIONAL INFORMATION: Tagging out an alarm should not prevent the identification of the alarm which is tagged; and not obscure any other alarm or interfere with operations.

SOURCE: NUREG-0700, EPRI NP-3448.

\subsection{3-4 Distinctive Coding of Long Alarm Maintenance}

If an alarm tile must be "ON" for an extended period during normal operations because of equipment repair or replacement, it should be (1) distinctively coded for positive recognition during this period, and (2) controlled by administrative procedures.

SOURCE: NUREG-0700.

\subsection{3-5 Tile Cover Replacement}

If a lamp replacement requires legend tile removal, there should be a way to ensure that the tile is replaced in the correct location.

ADDITIONAL INFORMATION: The alarm element and/or the replacement task should be designed to prevent incorrect positioning of the cover, legend, or tile. For example, annunciator tiles might be permanently marked with a unique identifier specifying their position in the alarm window matrix.

SOURCE: NUREG-0700, EPRI NP-3448. 


\subsection{3-6 Hazard Avoidance}

Lamp replacement should not pose an electrical shock hazard.

SOURCE: NUREG-0700.

\subsection{3-7 Operator Aids for Lamp Replacement}

Operator aids should be provided if needed for lamp replacement.

ADDITIONAL INFORMATION: Operator aids include instructions and specialized tools.

SOURCE: NUREG-0700.

\subsubsection{Failure Indication}

\subsection{4-1 Alarm System Failure Indication}

Operators should be given prompt indication of a failure of the alarm system or its major subcomponents.

Discussion: NRC Information Notice 93-47 describes incidents where the operators were unaware of alarms that were inoperable for long periods of time. Since operators rely on the alarm system as the first indication of a process disturbance, it is important that the alarm system notify the operator of any loss of functioning when it occurs. In general, the alarm system should have a fail-safe design in which the alarm system assumes a configuration that is more consistent (rather than less consistent) with safety when a malfunction occurs (e.g., loss of the flash capability results in salient indication rather than a steady off state). Alarm system functional criteria including failure indication are addressed in NUREG/CR-3217. In addition, this guidelines is consistent with the high-level design review principles of Situation Awareness, Feedback, and Error Tolerance and Control (see Appendix A).

SOURCE: Authors.

\subsection{Alarm Response Procedures (ARPs)}

\section{9-1 Alarm Response Procedure Scope}

ARPs should be available for every alarm condition.

SOURCE: EPRI NP-3659, IEC 964, EPRI NP-3448.

\section{9-2 Alarm Response Procedure Access}

Operators should have immediate access to ARPs from the location at which the alarm messages are read.

ADDITIONAL INFORMATION: An operator should not be required to leave the location at which the alarm message is displayed in order to access ARP information. In a tile system, the 
identification and indexing of alarm response procedures should be consistent with the method of identifying the alarm. The means used for identifying row and column locations of alarms should be distinct so that possible confusion of these identifiers is avoided. A computerized system may display the appropriate procedure for a given alarm on a VDU when the operator "selects" the alarm message.

Discussion: This guideline is consistent with the high-level design review principles of Task Compatibility and Response Workload (see Appendix A).

SOURCE: Authors, NUREG/CR-3987, EPRI NP-3448.

\section{9-2 Alarm Response Procedure Content}

ARPs should contain the following information:

- The system/functional group to which the alarm belongs,

- The exact alarm tile or legend,

- The alarm source (sensor or sensors sending the signal, including processing or signal validation logic) and the actuating device or devices for the alarm (with a reference to a schematic diagram on which such devices can be found),

- Alarm setpoints,

- Priority,

- Potential underlying causes for the alarm (e.g., low water level -- feed flow deficient in the long term),

- Required immediate operator actions, including actions the operator can take to confirm the existence of the alarm condition,

- Actions which are automatically taken when the alarm occurs (and which the operator should verify as having taken take place),

- Followup actions, and

- $\quad$ Pertinent references.

SOURCE: Authors, Regulatory Guide 1.33, EPRI NP-3448, IEC 964.

\section{9-3 Consistency}

Information in ARPs should be consistent with information on control boards, in alarm system, in I\&C procedures used to calibrate alarm setpoints, in controlling documents that determine setpoints (e.g., Technical Specifications, and accident analyses), in P\&IDs, and in other plant procedures.

Discussion: This guideline is consistent with the high-level design review principles of Consistency and Error Tolerance and Control (see Appendix A).

SOURCE: Authors.

\section{9-4 Alarm Response Procedure Format}

The ARP format should: 
- $\quad$ Highlight the ARP identifier on each page of the procedure,

- Highlight important items,

- Locate information categories in the same position on each page,

- Consistently present information throughout the ARP, and

- Minimize the need for operators to page back and forth to obtain the information.

SOURCE: EPRI NP-3448.

\subsection{Control-Display Integration and Layout}

\subsection{0-1 Display and Line of Sight}

Visible alarm indications should be located within about 60 degrees on either side of the direct line of sight of the operator's normal work position.

SOURCE: EPRI NP-3659.

\subsection{0-2 Interference from Nearby Indicators}

When unilluminated display elements are used to represent acceptable plant conditions, indicator lights used to present information about the state of equipment should not be located near these elements.

SOURCE: EPRI NP-3659.

\subsection{0-3 Location of Displays and Alarms}

Alarm displays and controls should be located in close relative proximity so that alarm controls can be used while the displays can be read.

ADDITIONAL INFORMATION: The design should not require an operator to leave the workstation to acknowledge or reset an alarm.

SOURCE: EPRI ALWR, EPRI NP-3448, EPRI NP-2411.

\subsection{0-4 Location of First-Out Alarms}

First-out displays should be located at the main workstation for the system and/or at a plant overview display visible to the crew.

SOURCE: NUREG-0700.

\subsection{0-5 Consistent Ordering}

The ordering (e.g., left-to-right positioning) of displayed alarm groups should be consistent with the ordering of displays and controls of related plant systems and components.

SOURCE: EPRI NP-3659. 


\subsection{0-6 Location for Prompt Response}

Alarm displays and controls should be arranged and located such that the operating crew member(s) who must respond to an alarm can access the alarm information in sufficient time to respond adequately.

ADDITIONAL INFORMATION: The design should never require one operator to read an alarm message only to recite it to another person. Consideration should be given to the need for the senior reactor operator to hear the control room alarms from all parts of the control room vital area.

SOURCE: Regulatory Guide 1.114, EPRI ALWR.

\subsection{0-7 Location for Access to Process Controls and Displays}

Visual alarm panels should be located near the related controls and displays which are required for corrective or diagnostic action in response to the alarm.

ADDITIONAL INFORMATION: If displays and controls associated with an alarm are on different panel segments, ensure that the alarm displays are located near the process display segment.

SOURCE: NUREG-0700, EPRI NP-3659, EPRI NP-2411, IEC 964. 


\section{REFERENCES}

Baker, S., Hollnagel, E., Marshall, E., and Owre, F., "An Experimental Comparison of Three Computer-Based Alarm Systems: Design, Procedure and Execution," HWR-134, Halden Reactor Project, Norway, 1985 .

Baker, S., Gertman, D., Hollnagel, E., Holmstrom, C., Marshall, E., and Owre, F., "An Experimental Comparison of Three Computer-Based Alarm Systems: Results and Conclusions," HWR-142, Halden Reactor Project, Norway, 1985 b.

Banks, W.W., and Boone, M.P., "Nuclear Control Room Annunciators: Problems and Recommendations," NUREG/CR-2147, Nuclear Regulatory Commission, Washington, D.C., 1981.

Beltracchi, L., "Alarm Coding of a Model-Based Display," in 1988 IEEE Fourth Conference on Human Factors and Power Plants, Institute of Electrical and Electronics Engineers, New York, 1988.

Bennett, K., and Flach, J., "Graphical Displays: Implications for Divided Attention, Focused Attention, and Problem Solving," Human Factors, 34, 513-533, 1992.

Beranek, L.L., Acoustical Measurements, American Institute of Physics, Cambridge, Massachusetts, 1988.

Cook, R., Woods, D., and Howie, M., "The Natural History of Introducing New Information Technology into a High-Risk Environment," in Proceedings of the Human Factors Society 34th Annual Meeting, Human Factors Society, Santa Monica, California, 1990.

Cory, F., Ettinger, B., Fink, R., Zarechnak, A., and Ketchel, J., "Control Room Annunciator System Replacement Specification and Evaluation of Alarm Suppression and Diagnostic Schemes," in Proceedings of the Topical Meeting on Nuclear Plant Instrumentation, Control, and Man-Machine Interface Technologies, American Nuclear Society, Inc., La Grange Park, Illinois, 1993.

Corsberg, D., "Effectively Processing and Displaying Alarm Information," in Fourth IEEE Conference on Human Factors and Power Plants, Institute of Electrical and Electronics Engineers, New York, 1988.

Crouch, D., Higgins, J., Luckas, W., MacDougall, E., and Ruger, C., "An Assessment of Potential Upgrades to Control Room Annunciators, " BNL A-3967-89-2, Brookhaven National Laboratory, Upton, New York, 1989.

Edworthy, J., Loxley, S., and Dennis, I., "Improving Auditory Warning Design: Relationship Between Warning Sound Parameters and Perceived Urgency," Human Factors, 33, 205-231, 1991.

Electric Power Research Institute, "Advanced Light Water Reactor Utility Requirements Document (URD) - Volume II ALWR Evolutionary Plant," Revision 4, 12/92, Electric Power Research Institute, 1992.

Fink, R., "A Procedure for Reviewing and Improving Power Plant Alarm Systems," EPRI NP-3448, Electric Power Research Institute, Palo Alto, California, 1984. 
Fink, R., Williges, R., and O'Brien, J., "Appropriate Choice of Alarm System Technologies: EPRI Research," in 1992 IEEE Fifth Conference on Human Factors and Power Plants, Institute of Electrical and Electronics Engineers, New York, 1992.

Fujita, Y., "Improved Annunciator System for Japanese Pressurized-Water Reactors," Nuclear Safety, 30, 209-221, 1989.

Fujita, Y., and Kawanago, S., "An Improved Annunciator System for Japanese PWRs," in Transactions of the American Nuclear Society, 54, 191-192, 1987.

Fujita, Y. et al., "Improved Annunciator System for Japanese PWRs: Functions and Evaluation," in Man-Machine Interface in the Nuclear Industry, International Atomic Energy Agency, Vienna, 1988.

Fujita, Y., and Sanquist, T., "Operator Cognitive Processes Under Abnormal Plant Conditions With Conventional and Advanced Control Room Designs," in 1988 IEEE Fourth Conference on Human Factors, Institute of Electronics and Electrical Engineers, New York, 1988.

Gertman, D., Owre, F., Marshall, E., and Verle, A., "Survey on Computerized Alarm and Annunciator Systems," HWR-176, Halden Reactor Project, Norway, 1986.

Hollywell, P., and Marshall, E., "An Experiment to Support the Design of VDU-Based Alarm Lists for Power Plant Operators," in N. Stanton (ed.) Human Factors in Alarm Design, Taylor and Francis, Ltd., London, 1994.

International Electrotechnical Commission, "International Standard: Design for Control Rooms of Nuclear Power Plants," IEC 964, Bureau Central de la Commission Electrotechnique Internationale, Geneva, Switzerland, 1989.

Kahneman, D., and Triesman, A., "Changing Views of Attention and Automaticity," in R. Parasuraman and R. Davies (eds.) Varieties of Attention, Academic Press, New York, 1984.

Kennedy, W., "Lessons Learned in Process Control From the Halden Reactor Project," NUREG-1361, U.S. Nuclear Regulatory Commission, Washington, D.C., 1989.

Kinkade, R.G., and Anderson, J., "Human Factors Guide for Nuclear Power Plant Control Room Development," EPRI NP-3659, Electric Power Research Institute, Palo Alto, California, 1984.

Kragt, H., "A Comparative Simulation Study of Annunciator Systems," Ergonomics, 27, 927-945, 1984.

Kragt, H., and Bonton, J., "Evaluation of a Conventional Process-Alarm System in a Fertilizer Plant," in IEEE Transactions on Systems, Man, and Cybernetics, 13, 586-600, 1983.

Madni, A., "The Role of Human Factors in Expert System Design and Acceptance," Human Factors, $\underline{30}, 395-414,1988$.

Malin, J., Schreckenghost, D., Woods, D., Potter, S., Johannesen, L., Holloway, M., and Forbus, K., "Making Intelligent Systems Team Players: Case Studies and Design Issues," NASA Technical 
Rankin, W.L., Rideout, T.B., Triggs, T.J., and Ames, K.R., "Computerized Annunciator Systems," NUREG/CR-3987, U.S. Nuclear Regulatory Commission, Washington, D.C., 1985.

Reason, J., "Generic Error-Modelling Systems (GEMS): A Cognitive Framework for Locating Common Human Error Forms," in J. Rasmussen, K. Duncan, and J. Leplat (eds.) New Technology and Human Error, J. Wiley and Sons, New York, 1987.

Reason, J., "Cognitive Aids in Process Environments: Prostheses or Tools?," in E. Hollnagel, G. Mancini, and D.D. Woods (eds.), Cognitive Engineering in Complex Dynamic Worlds, Academic Press, New York, 1988.

Reason, J., "Modelling the Basic Error Tendencies of Human Operators," Reliability Engineering and System Safety, 22, 137-153, 1988.

Reason, J., "Human Error," Cambridge University Press, New York, 1990.

Reiersen, C.S., Marshall, E., and Baker, S., "A Comparison of Operator Performance When Using Either an Advanced Computer-Based Alarm System or a Conventional Annunciator Panel," HPR-331, Halden Reactor Project, Norway, 1987.

Sarter, N., and Woods, D., "Mode Error in Supervisory Control of Automated Systems," in Proceedings of the Human Factors Society 36th Annual Meeting, Human Factors Society, Santa Monica, California, 1992.

Seminara, J., "Control-Room Deficiencies, Remedial Options, and Human Factors Research Needs," NP5795, Electric Power Research Institute, Palo Alto, California, 1988.

Seminara, J.L., Seidenstein, S., Eckert, S.K., and Smith, D.L., "Human Factors Methods for Nuclear Control Room Design: Volume 1, Human Factors Enhancement of Existing Control Rooms," EPRI NP1118, Electric Power Research Institute, Palo Alto, California, 1979.

Sheehy, E., Davey, E., Fiegel, T., and Guo, K., "Usability Benchmark for CANDU Annunciation Lessons Learned," in Proceedings of the Topical Meeting on Nuclear Plant Instrumentation, Control, and Man-Machine Interface Technologies, American Nuclear Society, La Grange Park, Illinois, 1993.

Sorkin, R., "Why are People Turning Off Our Alarms?," Human Factors Society Bulletin, 32 [4], 3-4, 1989.

Sorkin, R., "Design of Auditory and Tactile Displays," in G. Salvendy (ed.) Handbook of Human Factors, J. Wiley and Sons, New York, 1987.

Sorkin, R., Kantowitz, B., and Kantowitz, S., "Likelihood Alarm Displays," Human Factors, $\underline{\text { 30, }}$ 445$459,1988$.

Sorkin, R., and Woods, D., "Systems with Human Monitors: A Signal Detection Analysis," Human Computer Interaction, 1, 49-75, 1985. 
Memorandum 104738, National Aeronautics and Space Administration, Lyndon B. Johnson Space Center, Houston, Texas, 1991.

Malone, T. et al., "Human Factors Evaluation of Control Room Design and Operator Performance at Three Mile Island-2," NUREG/CR-1270, U.S. Nuclear Regulatory Commission, Washington, D.C., 1980.

Marshall, E., "A Preliminary Evaluation of the HALO System for Handling Alarms," HWR-83, Halden Reactor Project, Norway, 1982.

Marshall, E., and Owre, F., "The Experimental Evaluation of an Advanced Alarm System," in Advances in Human Factors in Nuclear Power Systems, American Nuclear Society, La Grange Park, Illinois, 1986.

Matsushita, K. et al., "Improvement of PWR Control Room Design," in Man-Machine Interface in the Nuclear Industry (Tokyo Conference Proceedings), International Atomic Energy Agency, Vienna, Austria, 1988.

Moore, R., Popovic, J., Pauksens, J., "Alarm Annunciation in CANDU 3 Control Room Design," in Proceedings of the Topical Meeting on Nuclear Plant Instrumentation, Control, and Man-Machine Interface Technologies, American Nuclear Society, La Grange Park, Illinois, 1993.

Norman, D., "The Psychology of Everyday Things," Basic Books, New York, 1988.

MPR Associates, "Power Plant Alarm Systems: A Survey and Recommended Approach for Evaluating Improvements," EPRI NP-4361, Electric Power Research Institute, Palo Alto, California, 1985.

O'Hara, J., "Advanced Human-System Interface Design Review Guideline, Volume 1: General Evaluation Model, Technical Development, and Guideline Description, "NUREG/CR-5908, Brookhaven National Laboratory, Upton, New York, 1994.

O'Hara, J., Brown, W., Baker, C., Welch, D., Granda, T., and Vingelis, P., "Advanced Human-System Interface Design Review Guideline, Volume 2: Evaluation Procedures and Guidelines for Human Factors Engineering Reviews," NUREG/CR-5908, Brookhaven National Laboratory, Upton, New York, 1994.

O'Hara, J., and Brown, W., "Compilation of Alarm System Guidelines and Evaluation of Their Applicability to Hybrid and Advanced Control Rooms," BNL Technical Report No. A3957-2-10/91, Brookhaven National Laboratory, Upton, New York, 1991.

Patterson, R.D., "Guidelines for Auditory Warning Systems on Civil Aircraft," CAA 82017, Civil Aviation Authority, London, 1982.

Pine, S.M., Schulz, K.A., Edman, T.R., Hanson, T.G., Evans, T.G., Gonzalez, W., Smith, D., and Seminara, J., "Human Engineering Guide for Enhancing Nuclear Control Rooms," NP-2411, Electric Power Research Institute, Palo Alto, California, 1982.

Rankin, W.L., Duvernoy, E.G., Ames, K.R., Morgenstern, M.H., and Eckenrode, R.J., "Near-Term Improvements for Nuclear Power Plant Control Room Annunciator Systems," NUREG/CR-3217, U.S. Nuclear Regulatory Commission, Washington, D.C., 1983. 
U.S. Department of Defense, "Human Factors Engineering Design for Army Material," MIL-HDBK759A, Department of the Army, Washington, D.C., 1981.

U.S. Nuclear Regulatory Commission, "Guidelines for Control Room Design Reviews," NUREG-0700, Washington, D.C., 1981.

U.S. Nuclear Regulatory Commission, "Unrecognized Loss of Control Room Annunciators," NRC Information Notice 93-47, Washington, D.C., 1993.

U.S. Nuclear Regulatory Commission, "Quality Assurance Program Requirements (Operation)," Regulatory Guide 1.33, Revision 2, Washington, D.C., 1978.

U.S. Nuclear Regulatory Commission, "Instrumentation for Light-Water-Cooled Nuclear Power Plants to Assess Plant and Environmental Conditions During and Following an Accident," Regulatory Guide 1.97, Washington, D.C., 1983.

U.S. Nuclear Regulatory Commission, "Guidance on Being Operator at the Controls of a Nuclear Power Plant," Regulatory Guide 1.114, Revision 2, Washington, D.C., 1989.

Wickens, C., "Attention," in P. Hancock (ed.) Human Factors Psychology, Elsevier Science Publishers, New York, 1987.

Woods, D., "The Cognitive Engineering of Problem Representations," in G. Weir and J. Alty (eds.) Human-Computer Interaction and Complex Systems, Academic Press, London, 1991.

Woods, D., O'Brien, J., and Hanes, L., "Human Factors Challenges in Process Control: The Case of Nuclear Power Plants," in G. Salvendy (ed.) Handbook of Human Factors, J. Wiley and Sons, New York, 1987. 


\section{APPENDIX A \\ HIGH-LEVEL DESIGN REVIEW PRINCIPLES}

\section{General Principles}

Personnel Safety - The design should reflect applicable system and personnel safety factors, including minimizing the potential for injury and exposure to harmful materials.

Cognitive Compatibility - The operator's role should have a level of workload that is not so high as to negatively affect performance, but sufficient to maintain vigilance and familiarity by carrying out purposeful and meaningful activities.

Physiological Compatibility - The design of the interface should reflect consideration of human physiological characteristics including visual/auditory perception, biomechanics (reach and motion), characteristics of motor control, and anthropometry.

Simplicity of Design - The HSI should represent the simplest design consistent with functional and task requirements.

Consistency - There should be a high degree of consistency between the HSI, the procedures, the training systems, and the overall Final Safety Analysis Report descriptions and assumptions. The way the system functions and appears to the operating crew always should be consistent and reflect a high degree of standardization and be fully consistent with procedures and training.

\section{Primary Task Design Principles}

Situation Awareness - The information presented to the users by the HSI should be correct, rapidly recognized, and easily understood (e.g., "direct perception" or "status at a glance" displays) and support higher-level goals of user awareness of the status of the system.

Task Compatibility - The system should meet the requirements of users to perform their tasks (including operation, safe shutdown, inspection, maintenance, and repair). Data should be presented in forms and formats appropriate to the task (including the need to access confirmatory data or raw data in the case of higher-level displays) and control options should encompass the range of potential actions; there should be no unnecessary information or control options.

User Model Compatibility - All aspects of the system should be consistent with the users' mental models (understanding and expectations about how the system behaves developed through training, use of procedures, and experience) and consistent with established conventions (i.e., expressed in customary, commonplace, useful and functional terms, rather than abstract, unusual or arbitrary forms, or in forms requiring interpretation).

Organization of HSI Elements - The organization of all aspects of the HSI (from the elements in individual displays, to individual workstations, to the entire control room) should be based on Safety Analysis Reports of the facility and user requirements and should reflect the general principles of organization by importance, frequency, and order of use. Critical safety-function information should be 
available to the entire operating crew in dedicated locations to ensure its recognition, and to minimize data search and response time.

Logical/Explicit Structure - All aspects of the system (formats, terminology, sequencing, grouping, and operator decision support aids) should reflect an obvious logic based on task requirements or some other non-arbitrary rationale. The relationship of each display, control, and data processing aid to the overall task/function should be clear. The structure of the interface and its associated navigation aids should make it easy for users to recognize where they are in the data space and should enable users to rapidly access data not currently visible (e.g., on other display pages). The way the system works and is structured should be clear to the user.

Timeliness - The system design should take into account users' cognitive processing capabilities as well as process-related time constraints to ensure that user tasks can be performed within the time required. Information flow rates and control performance requirements that are too fast or too slow may diminish performance.

Controls/Displays Compatibility - The data entry and control requirements should be compatible with the displays.

Feedback - The system should provide useful information on system status, permissible operations, errors and error recovery, dangerous operations, and validity of data.

\section{Secondary Task Control Principles}

Cognitive Workload - The information presented by the system should be rapidly recognized and understood; therefore, the system should minimize the cognitive capacities that the user must allocate to making mental calculations or transformations and use of recall memory (recalling lengthy lists of codes, complex command strings, information from one display to another, or lengthy action sequences). "Raw" data should be processed and presented in directly usable form (although raw data should be accessible to the user for confirmation).

Response Workload - The system should require the minimum number of necessary actions to accomplish a task; e.g., single vs. command keying, menu selection vs. multiple command entry, single input mode (keyboard, mouse) vs. mixed mode. In addition, the system should not require the entry of redundant data, nor the re-entry of information already in the system, nor the entry of data that the system can derive from data that is already resident.

\section{Task Support Principles}

Flexibility - The system should give the user multiple means to carry out actions (and verify automatic actions) and permit display/control to be formatted in a configuration most convenient for the task. Flexibility should be limited to situations where it offers advantages in task performance (such as to accommodate different levels of experience of the users); it should not be provided for its own sake because there is a trade-off with consistency and the imposition of interface management workload (which detracts from monitoring and operations tasks). 
User Guidance and Support - The system should provide an effective "help" function. Informative, easyto-use, and relevant guidance should be provided on-line and off-line to help the user understand and operate the system.

Error Tolerance and Control - A fail safe design should be provided wherever failure can cause damage to equipment, injury to personnel or inadvertent operation of critical equipment. Therefore, the system should generally be designed such that a user error will not have serious consequences. If an error is made, its negative effects should be controlled and minimized. The system should offer simple, comprehensible notification of the error, and provide simple, effective methods for recovery. 


\section{APPENDIX B \\ ALARM SYSTEM CHARACTERIZATION CHECKLIST}

1. General Alarm System Characteristics (Guidelines Section 4.1)

1.1 Functional characteristics (e.g., alert, inform, guide, feedback) of the alarm system

1.2 The methods by which consistency was established between the alarm system and (1) non-alarm HSI standards and conventions, and (2) general HFE principles, standards, and guidelines A design guideline or system specification may be available from the designer/utility to support this information requirement

1.3 Development tests, evaluations, and validation tests performed on the system

2. Alarm Definition (Guidelines Section 4.2)

2.1 Alarm categories (the events, states, etc from which alarms are selected)

2.2 The criteria used to select alarm parameters to represent the categories

2.3 The criteria for determination of setpoints

2.4 The verification process (for task appropriateness)

- $\quad$ Process by which alarm inclusion was checked

- Process for assuring that non-alarms are not presented in the alarm system

2.5 Alarm states (new, acknowledged, cleared, and reset)

3. Alarm Signal and Condition Processing (Guidelines Section 4.3)

3.1 Alarm signal validation

3.2 Processing of nuisance alarms

3.3 Processing of alarm redundancy

3.4 Processing to determine relative alarm importance

3.5 Processing to identify patterns/events/states

3.6 Processing to generate alarms

- Expected alarms that are not in

- Alarms that are in but are not expected based upon plant condition 
4. Alarm Condition Priority and Message Availability (Guidelines Section 4.4)

4.1 Dimensions used to prioritize alarms, e.g.,

- Need for operator action

- $\quad$ Safety system challenge

- Threat to critical safety function

- Other

4.2 Alarm priority dimensions

- Number of levels for each dimension

- Method for assigning priority (for static prioritization) or computing priority (for dynamic prioritization)

4.3 The treatment of alarms that have been removed through filtering (complete removal) or suppression (available to operators upon request)

4.4 For selected scenarios, listings of the following should be obtained to support the review:

- $\quad$ Priorities assigned to alarms

- Alarms suppressed

- Alarms filtered

5. Alarm Display (Guidelines Section 4.5)

Information to be collected for spatially-dedicated continuously-visible (SDCV) alarm displays, alarm message lists, and alarms integrated into process displays:

\subsection{General characteristics}

- Display functions (e.g., operator monitoring and decision-making capabilities to be supported)

- Degree of independence of alerting and informing functions

- Degree of independence of priority and detailed information

- Principles and criteria for allocation of alarms to major display types

- Alarm graphics

- Consistency of alarm coding

\subsection{Display of high-priority alarms}

5.3 Display of alarm status

5.4 Display of shared alarm

5.5 Alarm messages

5.6 Coding methods 
5.7 Detailed arrangement of alarm information

- SDCV alarm displays

- Alarm message lists

5.8 An inventory of alarm display elements (symbols, acronyms, labels, measurement units, coding) should be developed so it can be compared with the same display elements in the rest of the HSI and procedures (as per Guideline 4.1-3, Consistency with the Main HSI)

6. Alarm Controls (Guidelines Section 4.6)

Information to be collected for silence, acknowledge, reset, test, and other alarm system control functions:

\subsection{Modes of User Interaction}

- Dialog types (e.g., menus, command language)

- Verification indications

- Navigation and access of additional information

- $\quad$ Additional parameter information and process displays

6.2 Devices (design implementation)

- $\quad$ Types (push buttons, switches, touch screen)

- Coding

- Dialog/protocol

- Organization/layout (of control devices)

- Location (with respect to alarm displays and panels)

7. Automated, Dynamic, and Modifiable Characteristics (Guidelines Section 4.7)

7.1 An inventory of system features and characteristics which automatically change in response to plant conditions

7.2 An inventory of operator-definable features and characteristics, eg, alarms and setpoints

7.3 HSI characteristics of automatic and operator-defined dynamic features and characteristics

- $\quad$ Methods of input/control

- Methods of verifying modifications/feedback

- $\quad$ Methods of display

7.4 Administrative controls for operator-defined dynamic features

8. Reliability, Test, Maintenance, and Failure Indication (Guidelines Section 4.8)

8.1 Design features addressing alarm system reliability 
8.2 Design features addressing alarm system test by operators

8.3 Design features addressing alarm system maintenance

8.4 Method of indicating loss of entire alarm system or its components such as sensors, processors, displays, and controls

9. Alarm Response Procedures (ARPs) (Guidelines Section 4.9)

9.1 ARP information content

9.2 ARP format

9.3 APR location

9.4 Methods of user access to, and interaction with ARPs (especially computer-based ARPs)

10. Control-Display Integration and Layout (Guidelines Section 4.10)

10.1 Control console layout of alarm display devices and controls

10.2 Alarm display layouts for VDUs

10.3 Relationship between alarm controls and displays and the associated process indicators and controls

10.4 Physical relationship between the operators and the alarm controls and displays and associated process indicators and controls 


\section{APPENDIX C \\ INDEX OF ALARM SYSTEM DESIGN REVIEW GUIDELINES}

Guideline

Page

4.1 General Guidelines $\ldots \ldots \ldots \ldots \ldots \ldots \ldots \ldots \ldots \ldots \ldots$. . . . . . . . . . . .

4.1-1 Alarm System Functional Criteria . . . . . . . . . . . . . . . . . . . . . 4-1

4.1-2 Alarm System Upgrade Functionality . . . . . . . . . . . . . . . . . . . . . . . 4-1

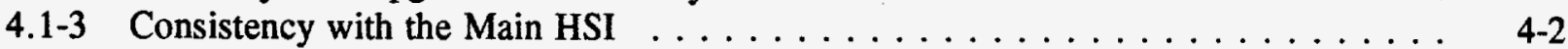

4.1-4 Conformance to HSI Design Review Guidelines . . . . . . . . . . . . . . . 4-2

4.1-5 Alarm System Validation ....................... 4-3

$4.2 \quad$ Alarm Definition $\ldots \ldots \ldots \ldots \ldots \ldots \ldots \ldots \ldots \ldots \ldots \ldots$

$4.2-1$ Alarm Selection $\ldots \ldots \ldots \ldots \ldots \ldots \ldots \ldots \ldots \ldots \ldots \ldots \ldots \ldots$

$4.2-2$ Setpoint Determination . . . . . . . . . . . . . . . . . . 4 4-3

4.2-3 Setpoint Determination and Nuisance Alarm Avoidance . . . . . . . . . . 4-4

4.2-4 Darkboard Configuration $\ldots \ldots \ldots \ldots \ldots \ldots \ldots \ldots \ldots \ldots . \ldots \ldots$

4.3 Alarm Processing and Reduction $\ldots \ldots \ldots \ldots \ldots \ldots \ldots$

4.3-1 Assured Functionality Under High Alarm Conditions . . . . . . . . . . . . . . . 4-5

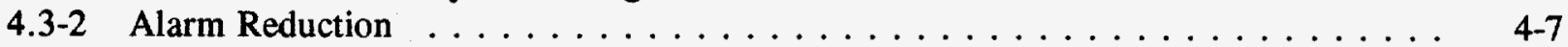

4.3-3 Alarm Signal Validation $\ldots \ldots \ldots \ldots \ldots \ldots \ldots \ldots \ldots \ldots \ldots \ldots$

4.3-4 Time Delay Processing . . . . . . . . . . . . . . . . . . . . . . 4-8

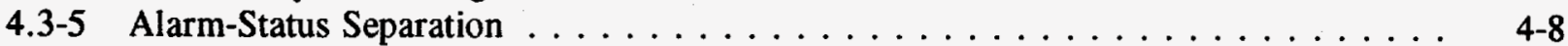

4.3-6 First-Out Processing . . . . . . . . . . . . . . . . . . . . . 4-9

4.3-7 Mode Dependence Processing . . . . . . . . . . . . . . . . . . . . . 4-9

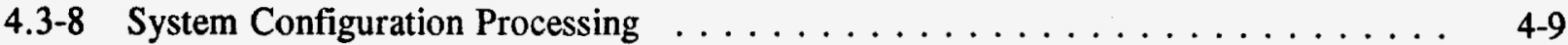

4.3-9 Logical Consequences Processing . . . . . . . . . . . . . . . . . 4-10

4.3-10 Exceptions to Known Alarm Patterns . . . . . . . . . . . . . . . . . . . . . . 4-10

4.3-11 Exceptions to Expected Alarm Patterns . . . . . . . . . . . . . . . . . . 4-10

4.3-12 Processing Complexity $\ldots \ldots \ldots \ldots \ldots \ldots \ldots \ldots \ldots \ldots \ldots \ldots \ldots$ 4.11

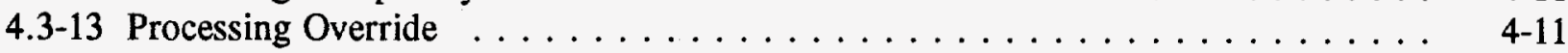

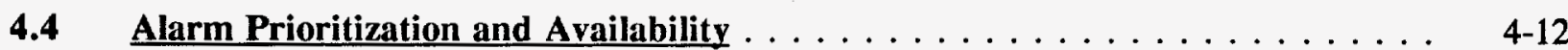

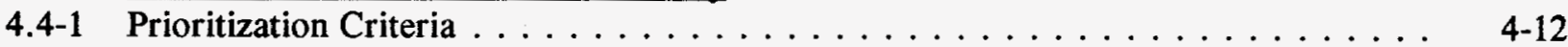

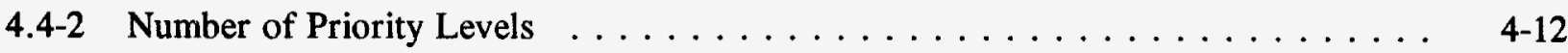

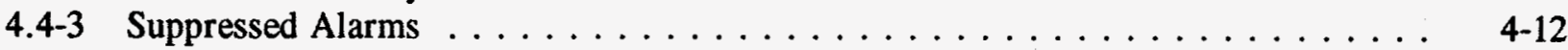

4.4-4 Filtered Alarms $\ldots \ldots \ldots \ldots \ldots \ldots \ldots \ldots \ldots \ldots \ldots$. . . . . . . . . . . .

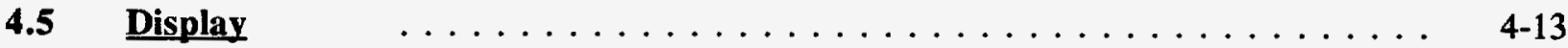

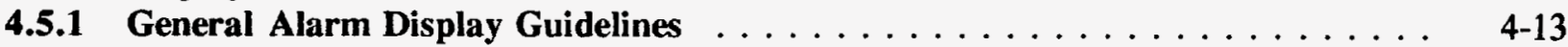

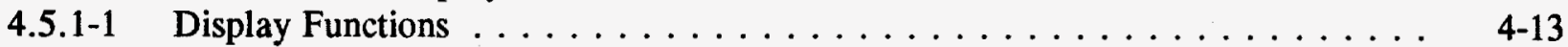

4.5.1-2 Independence of Alarm Alerting and Informing Functions . . . . . . . . . 4-13

4.5.1-3 Presentation of Alarm Priority with Detailed Alarm Information . . . . . . . . . . 4-14

4.5.1-4 Use of Spatially-Dedicated, Continuously-Visible Displays . . . . . . . . . . 4 4-14

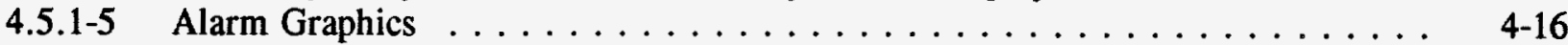

4.5.1-6 Alarm Coding Consistency $\ldots \ldots \ldots \ldots \ldots \ldots \ldots \ldots \ldots \ldots$ 4-16 
Guideline

Page

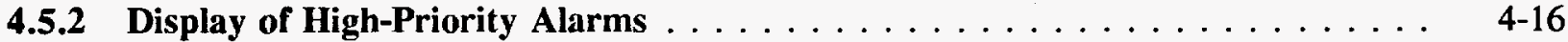

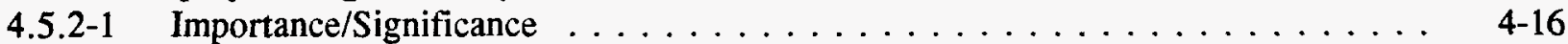

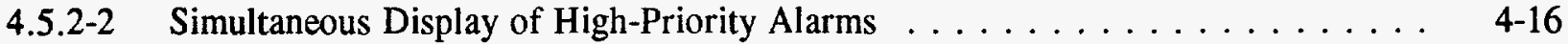

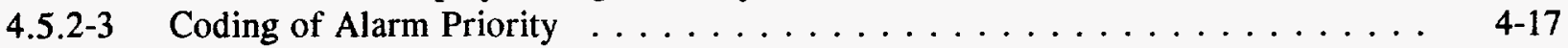

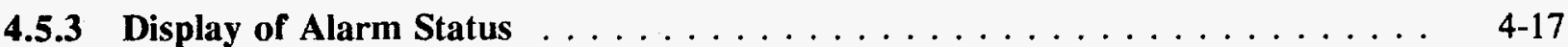

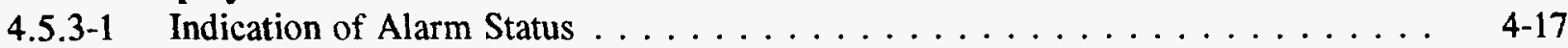

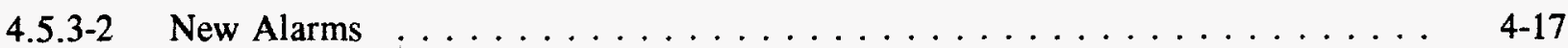

4.5.3-3 Notice of Undisplayed New Alarms . . . . . . . . . . . . . . . . . . . . . . . . . . . . .

4.5.3-4 Acknowledged Alarms . . . . . . . . . . . . . . . . . . . . 4-18

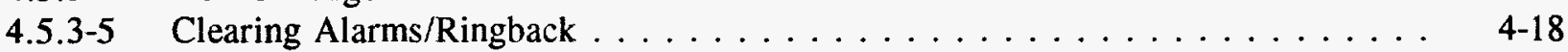

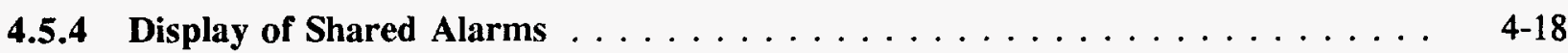

4.5.4-1 Minimize Shared Alarms . . . . . . . . . . . . . . . . . . . . 4-18

4.5.4-2 Shared Alarm Identification . . . . . . . . . . . . . . . . . . 4 4-19

4.5.4-3 Shared Alarm Reflash . . . . . . . . . . . . . . . . . . . . 4-19

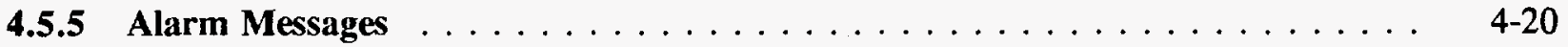

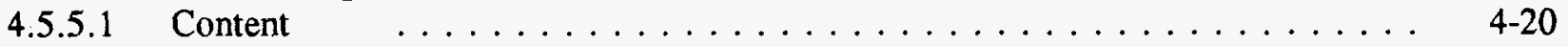

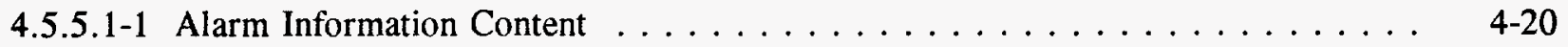

4.5.5.1-2 Alarm Tile/Legend . . . . . . . . . . . . . . . . . . . . . . 4-20

4.5.5.1-3 Alarm Source . . . . . . . . . . . . . . . . . . . . . . . 4-21

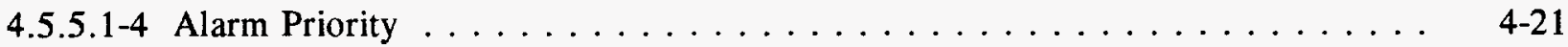

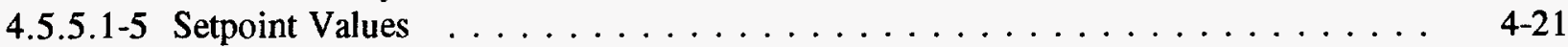

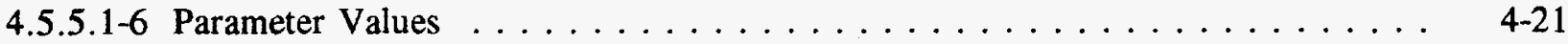

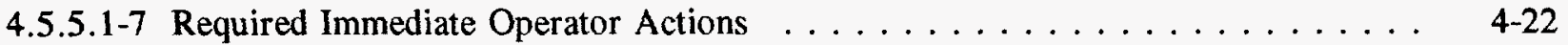

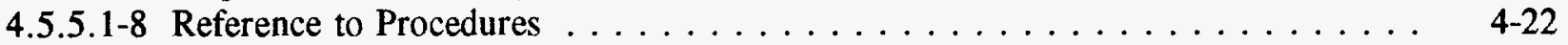

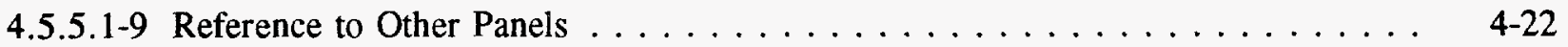

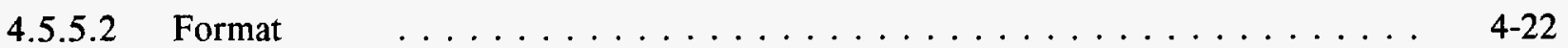

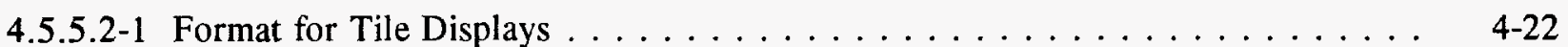

4.5.5.2-2 Format of VDU and Printer Messages $\ldots \ldots \ldots \ldots \ldots \ldots$. . . . . . . . .

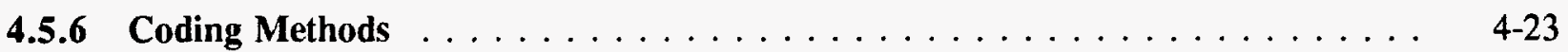

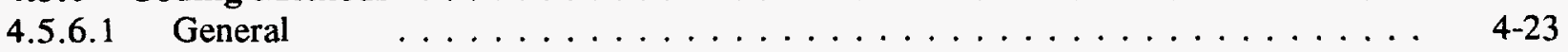

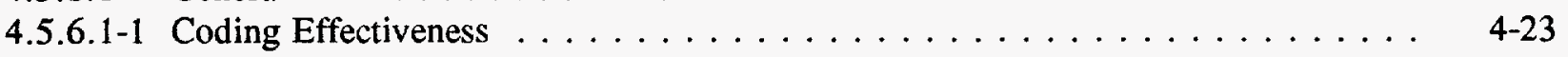

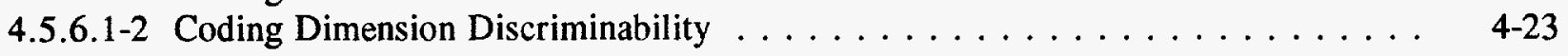

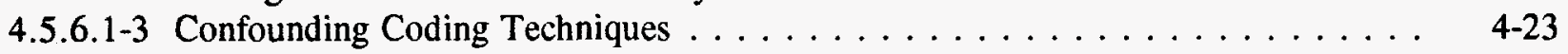

4.5.6.1-4 Coding Complexity . . . . . . . . . . . . . . . . . . 4-24

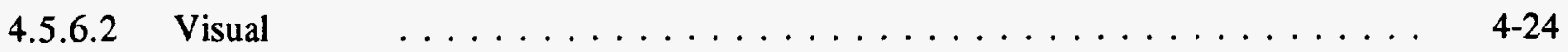

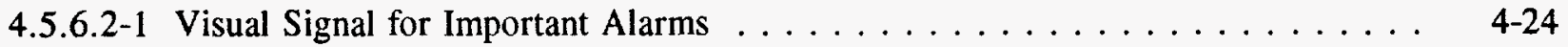

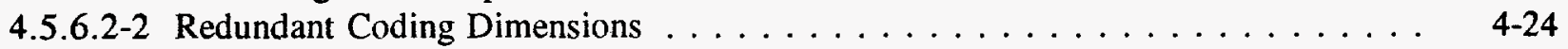

4.5.6.2-3 Flash Rate . . . . . . . . . . . . . . . . . . . . . . 4-24

4.5.6.2-4 Brightness Levels for Transilluminated Displays . . . . . . . . . . . . . 4 4-25

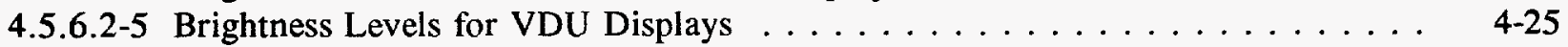




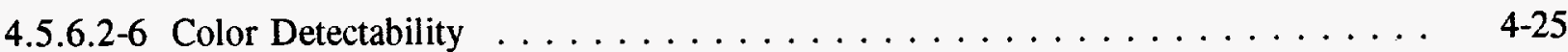

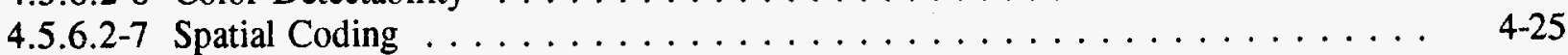

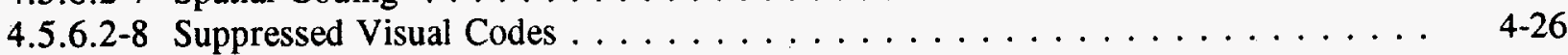

4.5.6.3 Audible Codes ... . . . . . . . . . . . . . . . . . . . . 4 4-26

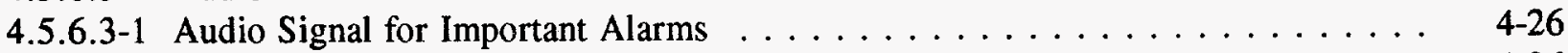

4.5.6.3-2 Auditory Coding of Remote Alarms . . . . . . . . . . . . . . . . . 4 4-26

4.5.6.3-3 Distinguishable Auditory Signals . . . . . . . . . . . . . . . . . . . 4 4-27

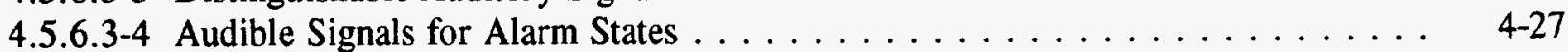

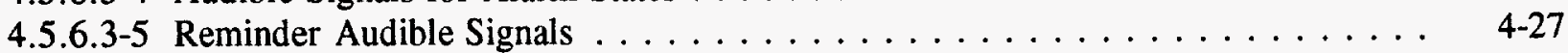

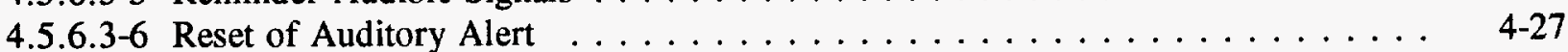

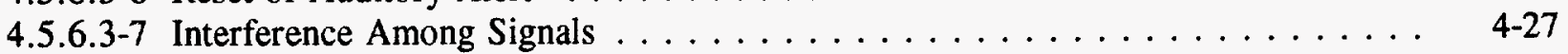

4.5.6.3-8 Readily Identifiable Signal . . . . . . . . . . . . . . . . . . . . . . . . . . . . . . . . . . . . . . . . . . . . . . .

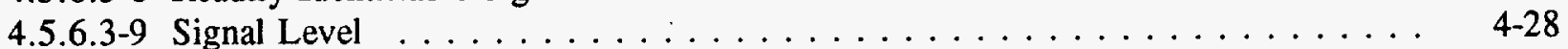

4.5.6.3-10 Avoid Startle . . . . . . . . . . . . . . . . . . . . . . . . . . 4 4-29

4.5.6.3-11 Manual Disable/Adjustment of Signal Intensity . . . . . . . . . . . . . . . . . . . . . . . . . . . . . . . . .

4.5.6.3-12 Sound Sources . . . . . . . . . . . . . . . . . . . . . . . 4-30

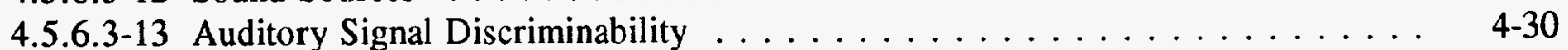

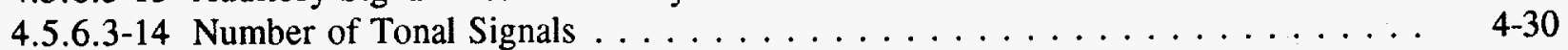

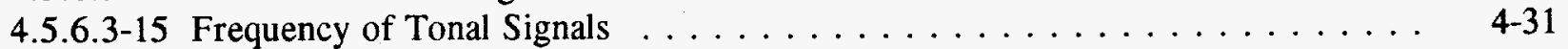

4.5.6.3-16 Pulse Codes . . . . . . . . . . . . . . . . . . . . . 4 4-31

4.5.6.3-17 Number of Frequency Modulated Signals . . . . . . . . . . . . . . . . . . . . . . . . . .

4.5.6.3-18 Center Frequency of Frequency Modulated Signals . . . . . . . . . . . . 4 4-31

4.5.6.3-19 Audio Pattern Codes . . . . . . . . . . . . . . . . . . . . . . 4-31

4.5.6.3-20 Compound Codes $\ldots \ldots \ldots \ldots \ldots \ldots \ldots \ldots \ldots \ldots \ldots \ldots$ 4.32

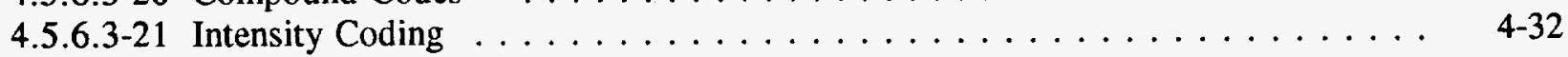

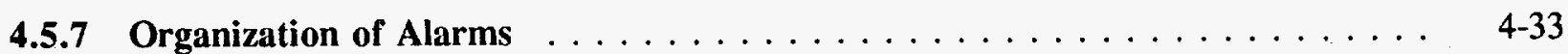

4.5.7.1 Spatially Dedicated Continuously Visible Alarm Displays . . . . . . . . . . . 4-33

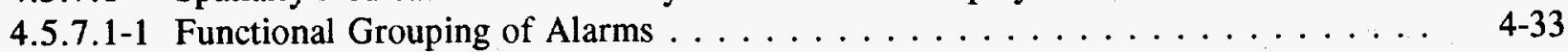

4.5.7.1-2 Separation of Functional Groups $\ldots \ldots \ldots \ldots \ldots \ldots \ldots \ldots$ 4.33 $\ldots \ldots \ldots$

4.5.7.1-3 Group Labels . . . . . . . . . . . . . . . . . . . . . . 4-33

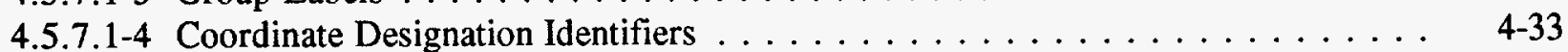

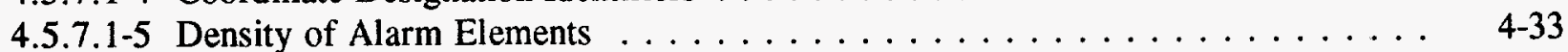

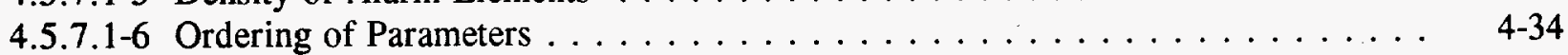

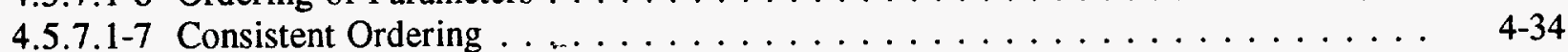

4.5.7.1-8 Alarm Display Identification Label $\ldots \ldots \ldots \ldots \ldots \ldots \ldots \ldots$. . . . . . . . . . . . . . . . .

4.5.7.2 Alarm Message Lists $\ldots \ldots \ldots \ldots \ldots \ldots \ldots \ldots \ldots \ldots \ldots \ldots$

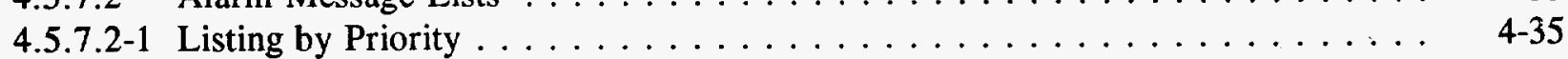

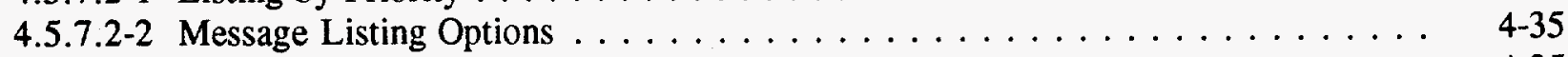

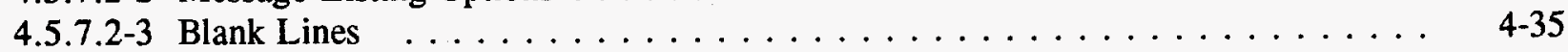

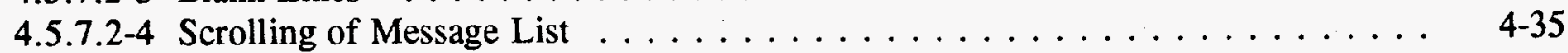

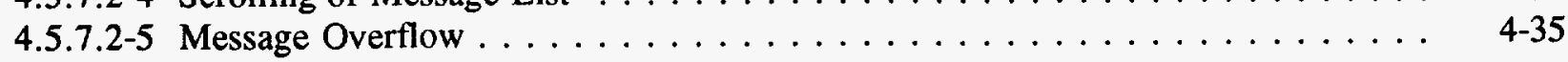


Guideline $\quad$ Page

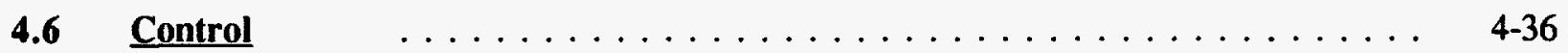

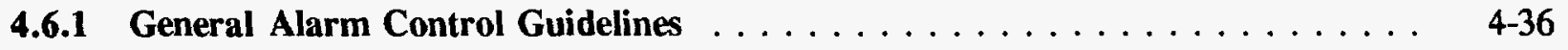

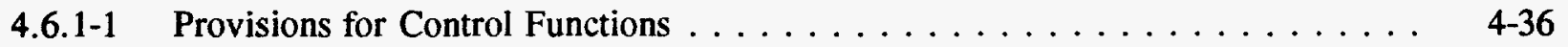

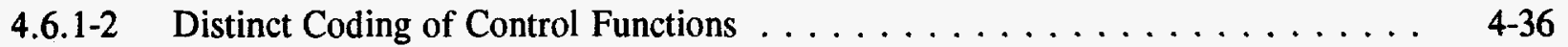

4.6.1-3 Consistent Layout of Control Group . . . . . . . . . . . . . . . . . . 4-36

4.6.1-4 Separate Controls for Tile and VDU Alarms . . . . . . . . . . . . . . . 4-36

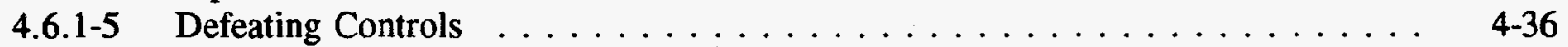

4.6.1-6 Access to New Undisplayed Alarms . . . . . . . . . . . . . . . . 4-37

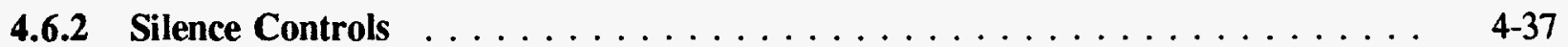

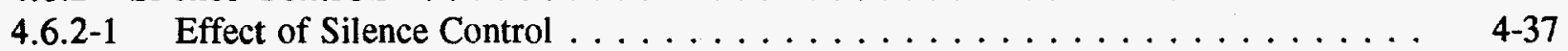

4.6.2-2 Manual Silencing $\ldots \ldots \ldots \ldots \ldots \ldots \ldots \ldots \ldots \ldots \ldots \ldots \ldots$

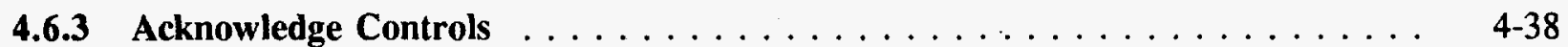

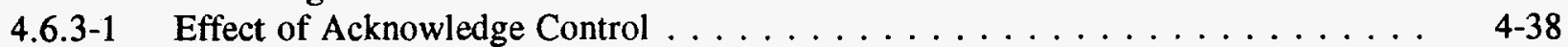

4.6.3-2 Acknowledgement Locations . . . . . . . . . . . . . . . . . . . . 4-38

4.6.3-3 Acknowledgement of Alarm Messages . . . . . . . . . . . . . . . 4-38

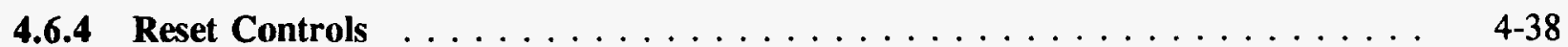

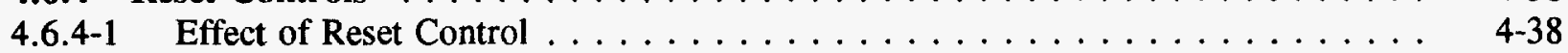

4.6.4-2 Appropriate Use of Manual Reset . . . . . . . . . . . . . . . . . . 4-39

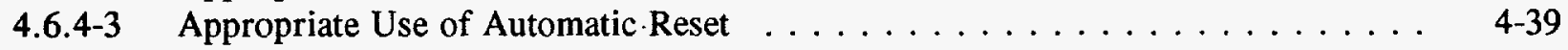

4.6.4-4 Reset Control Location . . . . . . . . . . . . . . . . . . 4-39

4.7 Automated, Dynamic, and Modifiable Characteristics . . . . . . . . . . . 4-39

4.7-1 Automated Alarm System Configuration . . . . . . . . . . . . . . . . . . . . . . . . . . . . .

4.7-2 Operator-Selectable Alarm System Configuration . . . . . . . . . . . . . . . 4 4-40

4.7-3 Acknowledgement of Alarm System Configuration Changes . . . . . . . . . . . 4 4-40

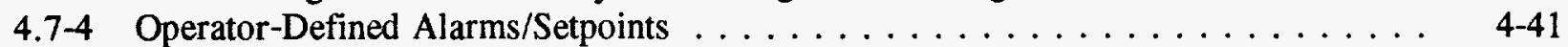

4.7-5 Interference of Operator-Defined Alarms/Setpoints with Existing Alarms . . . . . 4 4-41

4.7-6 Control of Operator-Defined Alarms/Setpoints ................. . 4-41

4.7-7 Automatic Mode-Defined Setpoints . . . . . . . . . . . . . . . . . 4-41

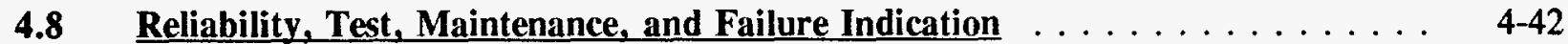

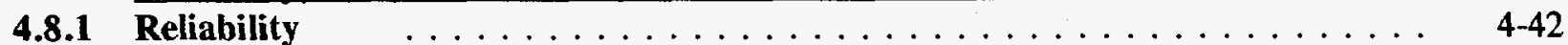

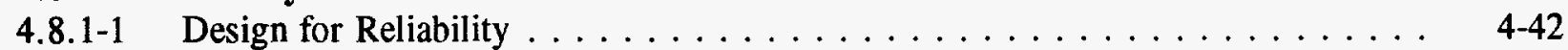

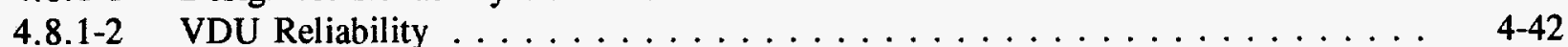

4.8.1-3 Dual Light Bulbs $\ldots \ldots \ldots \ldots \ldots \ldots \ldots \ldots \ldots \ldots \ldots \ldots \ldots \ldots \ldots$

4.8.1-4 Flasher Failure Mode $\ldots \ldots \ldots \ldots \ldots \ldots \ldots \ldots \ldots \ldots$

4.8.2 Test $\ldots \ldots \ldots \ldots \ldots \ldots \ldots \ldots \ldots \ldots \ldots \ldots \ldots \ldots$

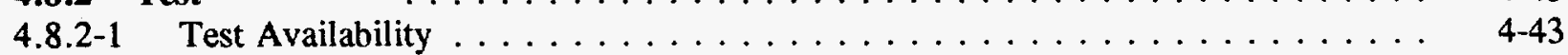

4.8.2-2 Testing Requirement $\ldots \ldots \ldots \ldots \ldots \ldots \ldots \ldots \ldots \ldots \ldots$ 


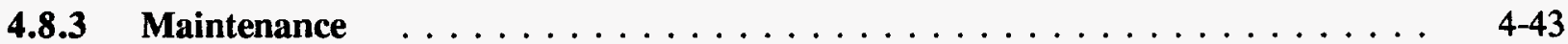

4.8.3-1 Design for Maintainability . . . . . . . . . . . . . . . . . . . . . $4-43$

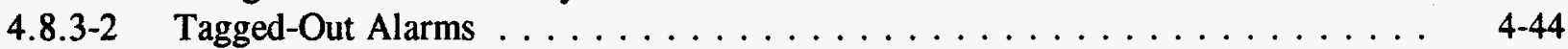

4.8.3-3 Maintenance Alarm Indication . . . . . . . . . . . . . . . . . . . . 4-44

4.8.3-4 Distinctive Coding of Long Alarm Maintenance . . . . . . . . . . . . . . . . . 4-44

4.8.3-5 Tile Cover Replacement . . . . . . . . . . . . . . . . . . . . . . . $4-44$

4.8.3-6 Hazard Avoidance . . . . . . . . . . . . . . . . . . . . . 4-45

4.8.3-7 Operator Aids for Lamp Replacement . . . . . . . . . . . . . . . . . . . . 4-45

4.8.4 Failure Indication $\ldots \ldots \ldots \ldots \ldots \ldots \ldots \ldots \ldots \ldots \ldots \ldots$

4.8.4-1 Alarm System Failure Indication . . . . . . . . . . . . . . . . 4-45

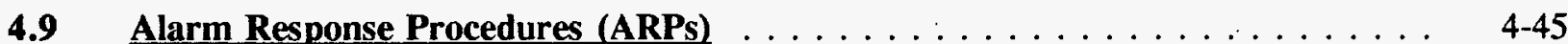

4.9-1 Alarm Response Procedure Scope . . . . . . . . . . . . . . . . . . . . . . 4-45

4.9-2 Alarm Response Procedure Access . . . . . . . . . . . . . . . . . . . . . . 4-46 . . . . . . . . . . . . . .

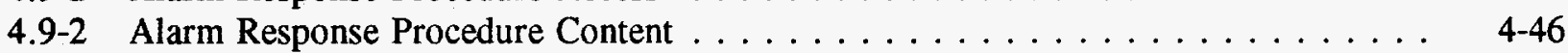

4.9-3 Consistency $\ldots \ldots \ldots \ldots \ldots \ldots \ldots \ldots \ldots \ldots \ldots \ldots \ldots \ldots \ldots \ldots$

4.9-4 Alarm Response Procedure Format . . . . . . . . . . . . . . . . . . . 4-46

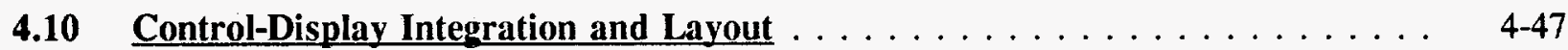

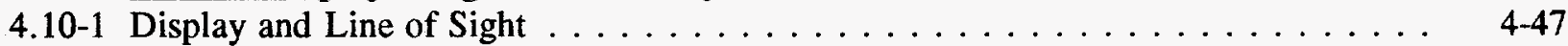

4.10-2 Interference from Nearby Indicators $\ldots \ldots \ldots \ldots \ldots \ldots \ldots$. . . . . . . . . . . . . . . .

4.10-3 Location of Displays and Alarms . . . . . . . . . . . . . . . . . . 4-47

4.10-4 Location of First-Out Alarms . . . . . . . . . . . . . . . . . . . . . . . 4 4-47

4.10-5 Consistent Ordering . . . . . . . . . . . . . . . . . . . . . . . . 4 47

4.10-6 Location for Prompt Response . . . . . . . . . . . . . . . . . . . . . . 4-48

4.10-7 Location for Access to Process Controls and Displays . . . . . . . . . . . . . 4-48 


\begin{tabular}{|c|c|}
\hline $\begin{array}{l}\text { NRC FORM } 335 \\
\text { (2-89) } \\
\text { NRCM 1102, } \\
\text { 3201,3202 } \\
\text { BIBLIOGRAPHEAR REGULATORY COMMISSION } \\
\text { (See instructions on the reverse) }\end{array}$ & $\begin{array}{l}\text { 1. REPORT NUMBER } \\
\text { (Assignod by NRC. Add Vol., Supp., Rev., } \\
\text { and Addendum Numbers, if any.) } \\
\text { NUTREG/CR-6105 } \\
\text { BNL-NUREG-52391 }\end{array}$ \\
\hline \multirow{4}{*}{$\begin{array}{l}\text { 2. TITLE AND SUBTITLE } \\
\text { Human Factors Engineering Guidance for the Review of } \\
\text { Advanced Alarm Systems }\end{array}$} & \\
\hline & 3. DATE REPORT PUBLISHED \\
\hline & \begin{tabular}{|c|r|} 
MONTH & YEAR \\
September & 1994 \\
\end{tabular} \\
\hline & $\begin{array}{l}\text { 4. FIN OR GRANT NUMBER } \\
\text { A3967 }\end{array}$ \\
\hline \multirow[t]{2}{*}{$\begin{array}{l}\text { 5. AUTHOR(S) } \\
\text { J. M. O'Hara, W. S. Brown, J. C. Higgins, W. F. Stubler }\end{array}$} & $\begin{array}{l}\text { 6. TYPE OF REPORT } \\
\text { Technical }\end{array}$ \\
\hline & 7. PERIOD COVERED (inclusive Dates) \\
\hline \multirow{2}{*}{\multicolumn{2}{|c|}{$\begin{array}{l}\text { 8. PERFORMING ORGANIZATION - NAME AND ADDRESS (If NRC, provide Division, Otfice or Region, U.S. Nuclear Regulatory Commission, and mailing address; if cantractor, provide } \\
\text { name and mailing address.) }\end{array}$}} \\
\hline & \\
\hline \multirow{2}{*}{\multicolumn{2}{|c|}{$\begin{array}{l}\text { 9. SPONSORING ORGANIZATION - NAME AND ADDRESS (If NRC, type "Same as above"; if contractor, provide NRC Division, Office or Region, U.S. Nuclear Regulatory Commission, } \\
\text { and mailing address.) }\end{array}$}} \\
\hline & \\
\hline \multicolumn{2}{|l|}{ 10. SUPPLEMENTARY NOTES } \\
\hline 11. ABSTRACT (200 words or less) & \\
\hline
\end{tabular}

This report provides guidance to support the review of the human factors aspects of advanced alarm system designs in nuclear power plants. The report is organized into three major sections. The first section describes the methodology and criteria that were used to develop the design review guidelines. Also included is a description of the scope, organization, and format of the guidelines. The second section provides a systematic review procedure in which important characteristics of the alarm system are identified, described, and evaluated. The third section provides the detailed review guidelines. The review guidelines are organized according to important characteristics of the alarm system including: alarm definition; alarm processing and reduction; alarm prioritization and availability; display; control; automated, dynamic, and modifiable characteristics; reliability, test, maintenance, and failure indication; alarm response rocedures; and control-display integration and layout.

K: Y WORDS/DESCR!PTORS (List words or phrases that will assist researchers in locating the report.

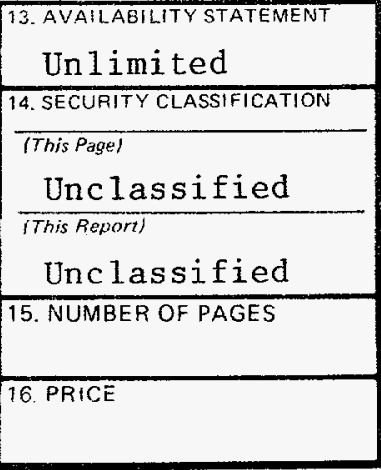

